\title{
Catalytic asymmetric transfer hydrogenation of ketones: Recent advances
}

\author{
Francisco Foubelo, Carmen Nájera and Miguel Yus* \\ Departamento de Química Orgánica, Facultad de Ciencias, and Centro de Innovación en Química \\ Avanzada (ORFEO-CINQA), Universidad de Alicante, Apdo. 99, E-03080 Alicante, Spain
}

\begin{abstract}
In this review article we will consider the main processes on asymmetric transfer hydrogenation (ATH) of ketones from 2008 up today. The most effective organometallic compounds (derived from $\mathrm{Ru}, \mathrm{Rh}, \mathrm{Ir}, \mathrm{Fe}, \mathrm{Os}, \mathrm{Ni}, \mathrm{Co}$, and $\mathrm{Re}$ ) and chiral ligands (derived from amino alcohols, diamines, sulphur- and phosphorous-containing compounds, as well as heterocyclic systems) will be shown paying special attention to functionalized substrates, tandem reactions, processes under nonconventional conditions, supported catalysts, dynamic kinetic resolutions (DKR), the use of water as a green solvent, theoretical and experimental studies on reaction mechanisms, enzymatic processes and finally applications to the total synthesis of biologically active organic molecules.
\end{abstract}

Keywords: transfer hydrogenation, chiral secondary, alcohols, metal catalysis, chiral ligands, ketones

\section{Introduction}

The reduction of carbon-oxygen double bonds (carbonyl compounds) is an important transformation in synthetic organic chemistry because it is a general entry to alcohols. ${ }^{1}$ Apart of some procedures not generally applied (electrochemical, photochemical or biochemical reactions), normally this methodology involves the use of molecular hydrogen under catalytic conditions, the use of a metal hydride, and transfer hydrogenation (TH). The last method, also called hydrogen transfer, ${ }^{2}$ has several advantages compared to the use of hydrogen or hydrides such as (a) simple equipment, (b) low catalyst loading, (c) safe manipulation, (d) environmentally friendly solvents, (e) volatile byproducts easily removed, and (f) it can be applied to industrial processes. ${ }^{3}$ Particularly significant is the asymmetric version of this reaction, namely the asymmetric transfer hydrogenation (ATH), ${ }^{4}$ for which an asymmetric information in form of a chiral ligand is needed, together with a transition metal catalyst, such as those derived from ruthenium, rhodium, iridium, iron, and in less extension osmium, cobalt, nickel and rhenium. Concerning the general mechanism accepted for the $\mathrm{TH}$, exemplified on Scheme 1 by using a secondary alcohol as the hydrogen source, it can involve a dihydride intermediate (eq a) or a monohydride one, in this second case with two possible variants: the inner sphere without ligand assistance (eq b) or the outer sphere with participation of the ligand (eq c) (Scheme 1). ${ }^{5}$ More details on mechanistic aspects will be given later on in the corresponding section.

\footnotetext{
* Corresponding author. Tel.: +34 965 903548; fax: +34 965903549.

E-mail address: yus@ua.es (M. Yus).
} 

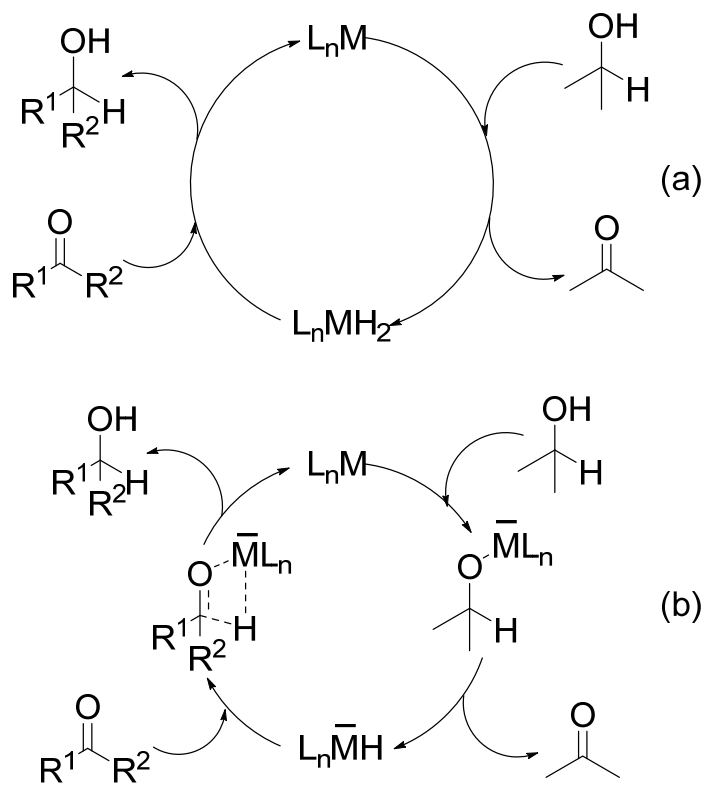

(a)

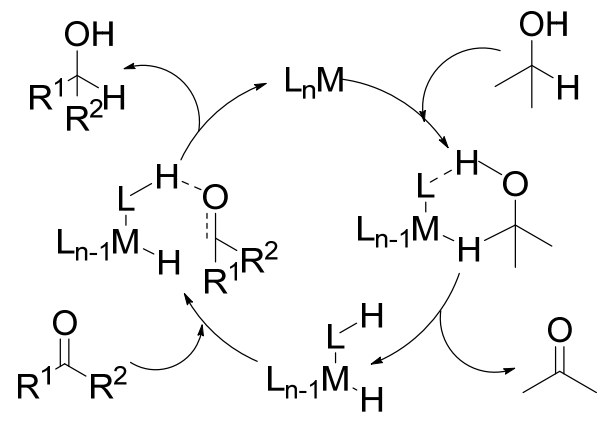

Scheme 1. Mechanism for TH: (a) dihydride route; (b) monohydride inner sphere mechanism; (c) monohydride outer sphere mechanism. ${ }^{5}$

In the next part of the article, the most significant information about the ATH of ketones from 2008 up today will be given, considering different metal catalysts, ligands and reaction conditions, paying special attention to the best enantioselective methodologies and their application to synthetic organic chemistry.

\section{Reaction scope: Catalysts and chiral ligands}

The ATH of alkyl aryl ketones has been performed using different transition metals $(\mathrm{Ru}, \mathrm{Rh}, \mathrm{Ir}, \mathrm{Fe}, \mathrm{Os}, \mathrm{Ni}, \mathrm{Co}, \mathrm{Re})$ in combination with chiral ligands containing coordinating atoms (oxygen, nitrogen, sulphur and phosphorous).

\subsection{Ruthenium catalysts}

\subsubsection{Aminoalcohols as ligands}

Different chiral 1,2-amino alcohols have been used in combination with a $\mathrm{Ru}$ catalyst for the ATH of prochiral ketones (Table 1). For instance, the ligand 1 was used for the enantioselective reduction of several phenones with the $p$-cymene derived complex $\left[\mathrm{RuCl}_{2}(p \text {-cymene })\right]_{2}(\mathrm{CRu})$ in $\mathrm{KOH}$ as base with good results (Table 1 , entry 1$){ }^{6}$ The isosorbide derivative 2 gave variable data in combination with the benzene complex 
$\left[\mathrm{RuCl}_{2} \text { (benzene) }\right]_{2}(\mathrm{BRu})$ and $t$-BuOK as base (Table 1 , entry 2$){ }^{7}$ Another isosorbide derivative 3 was studied only for acetophenone and pCRu with $t$-BuOK (Table 1, entry 3). ${ }^{8}$ The aminoalcohol 4 was active in the same process with $\mathrm{CRu}$ and $\mathrm{KOH}$ giving variable results (Table 1, entry 4). ${ }^{9}$ Ethanol was the hydrogen source used in combination with the ligand 5 and $\mathrm{CRu}$ to get variable results in terms of conversions but excellent enantioselectivities (Table 1 , entry 5). ${ }^{10}$ Several ketones were satisfactorily reduced with $\mathrm{CRu}$ and the aminoalcohol 6, the obtained enantioselectivities being explained by calculations (Table 1, entry 6). ${ }^{11}$ From a series of 1,2-aminoalcohols the ligand 7 showed to be the most active in collaboration with $\mathrm{CRu}$ working in aqueous sodium formate, although variable results were achieved (Table 1, entry 7). ${ }^{12}$ Based on the $\alpha$-pinene skeleton, several ligands mainly of type 8 (but also their corresponding dimers) were prepared and used in the ATH with $\mathrm{CRu}$ and $\mathrm{KOH}$ as base showed in (Table 1, entry 8). ${ }^{13}$ Finally, Cinchona derivatives were also used as ligands for the ATH of aromatic ketones reaching up to $90 \%$ ee. ${ }^{14}$ One special case, that really did not use an aminoalcohol, was reported by employing amino acids as ligands and $\mathrm{BRu}$ or its hexametyl derivative $\left[\mathrm{RuCl}_{2}\left(\mathrm{Me}_{6} \mathrm{C}_{6}\right)\right]_{2}(\mathrm{HRu})$ for the ATH of acetophenone, with good conversions (up to $95 \%$ ) but modest enantioselectivities (24-68\% ee). ${ }^{15}$

Table 1. ATH of phenones with ruthenium complexes in the presence of chiral aminoalcohols. 


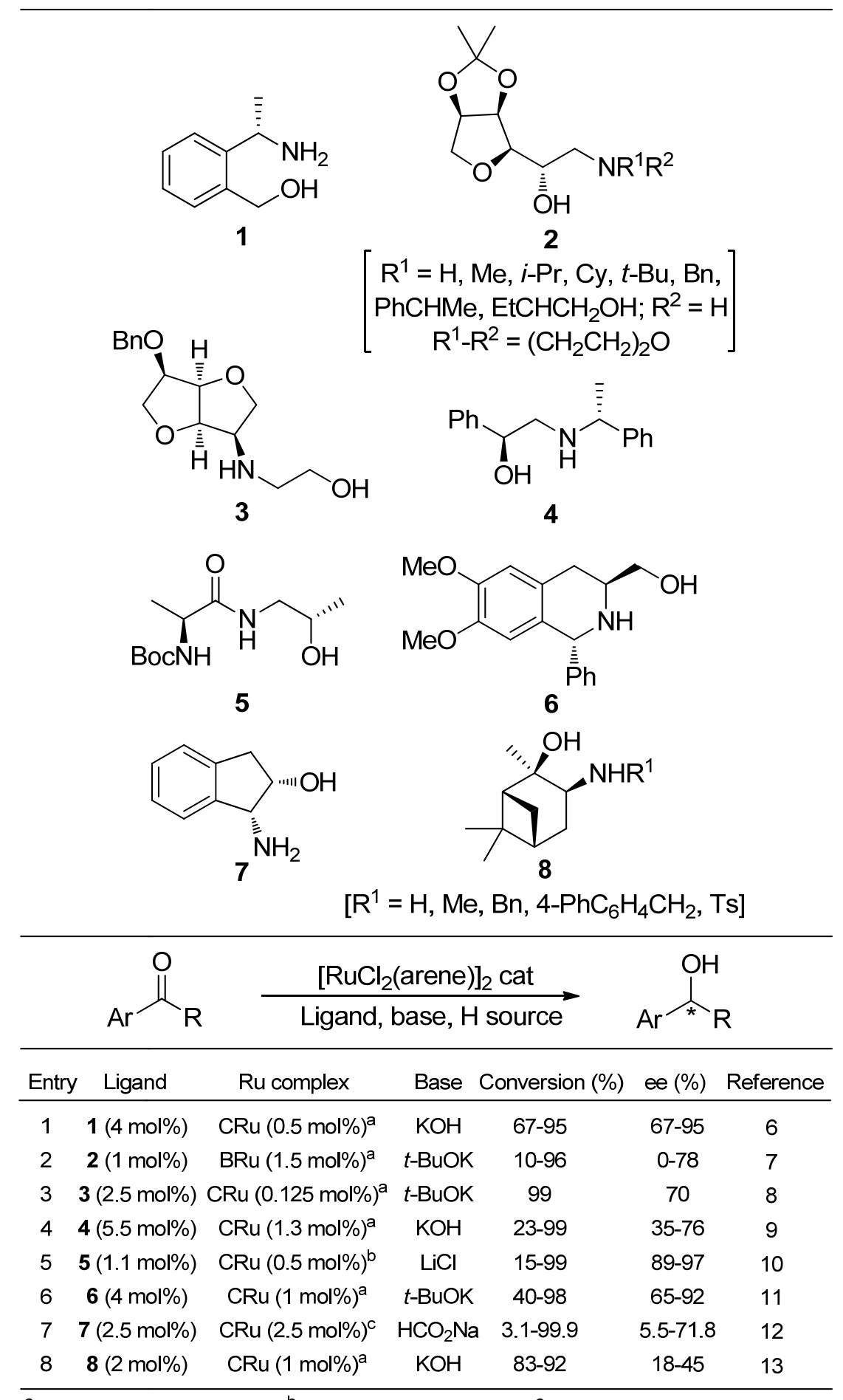

${ }^{\mathrm{a}}$ Hydrogen source: $i-\mathrm{PrOH} .{ }^{\mathrm{b}}$ Hydrogen source: $\mathrm{EtOH} .{ }^{c} \mathrm{Hydrogen}$ source: $\mathrm{HCO}_{2} \mathrm{Na}$.

\subsubsection{Diamines as ligands}

Since the pivotal introduction of $N$-(p-toluenesulfonyl)-1,2diphenylethylenediamine (TsDPEN, 9) as chiral ligand for the Ru(II)-catalyzed asymmetric transfer hydrogenation of ketones, ${ }^{16}$ several ligands of this type have been reported for that process. In general, two different processes have been implemented: either the ligand is used mixed with the $\mathrm{Ru}$ catalyst or, in most of the cases, the ligand is previously attached to the metal to afford a structurally well-defined complex, which is used as the catalyst. For the first approach, the 
ATH of phenones has been carried out using ligands $\mathbf{1 0}^{17}$ and $\mathbf{1 1}^{18}$ and CRu as the metal complex together with formic acid/triethylamine (TEA) or sodium formate/water, respectively, as reduction agents (Table 2, entries 1 and 2, respectively). In addition, monotosylated diamine 12 was very effective in terms of conversion and enantioselectivity for the ATH of phenones using CRu as metallic component (Table 2, entry 3). ${ }^{19}$

Table 2. ATH of phenones with ruthenium complexes in the presence of chiral diamines.<smiles>NC(c1ccccc1)[C@H]([NH3+])c1ccccc1</smiles>

9<smiles>O=C(NC(c1ccccc1)c1ccccc1)C1CCCN1</smiles>

11<smiles>CC(C)C(N)C([NH3+])c1ccccc1</smiles>

10

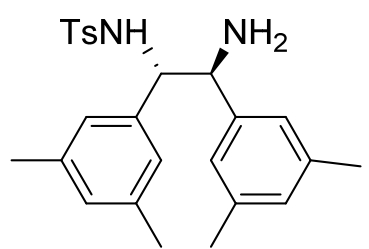

12

\begin{tabular}{|c|c|c|c|c|c|c|}
\hline \multirow[b]{2}{*}{ Entry } & \multirow[b]{2}{*}{ Ligand } & \multicolumn{3}{|c|}{$\underset{\text { Ligand, base, } \mathrm{H} \text { source }}{\left[\mathrm{RuCl}_{2}(p \text {-cymene })\right]_{2}(0.5 \mathrm{~mol} \%)}$} & \multicolumn{2}{|c|}{$\mathrm{Ar}_{\mathrm{*}}^{\mathrm{OH}}$} \\
\hline & & $H$ source & Base & Conversion (\%) & ee $(\%)$ & Reference \\
\hline 1 & 10 (1.2 mol\%) & $\mathrm{HCO}_{2} \mathrm{H}$ & $\mathrm{Et}_{3} \mathrm{~N}$ & $42-99$ & $85-98$ & 17 \\
\hline 2 & 11 (1 mol\%) & $\mathrm{HCO}_{2} \mathrm{Na}$ & $\mathrm{HCO}_{2} \mathrm{Na}$ & $6-100$ & $32-90$ & 18 \\
\hline 3 & 12 (1.2 mol\%) & $\mathrm{HCO}_{2} \mathrm{Na}$ & $\mathrm{HCO}_{2} \mathrm{Na}$ & $95-99$ & $83-94$ & 19 \\
\hline
\end{tabular}

Concerning well defined chiral tosyl diamine Ru complexes, used in ATH of ketones, ${ }^{20}$ the complex 13 was the best within a series of different $N, N$ - and arene

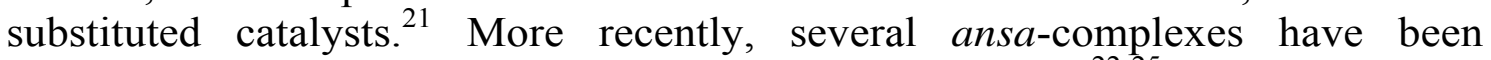
developed for the same process, such as compounds 14-18, ${ }^{22-25}$ which have been shown to be active in the ATH of ketones, mainly aromatic derivatives, using the formic acid/triethylamine combination as the hydrogen source giving variable yields and enantioselectivities. 


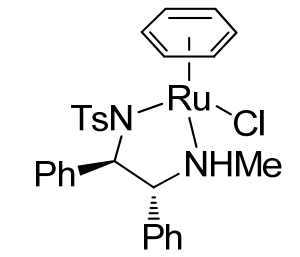

$13^{21}$ (1 mol\%)

$\mathrm{HCO}_{2} \mathrm{H}, \mathrm{Et}_{3} \mathrm{~N}$

96- $100 \%$ conv, $64-96 \%$ ee

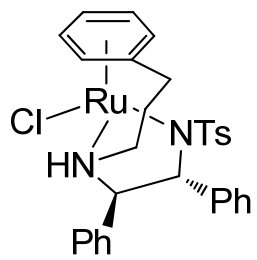

$14^{22}$ (1 mol\%)

$\mathrm{R}=\mathrm{H}, \mathrm{Me}, \mathrm{Ph}\left(\mathrm{CH}_{2}\right)_{3}$

$\mathrm{HCO}_{2} \mathrm{H}, \mathrm{Et}_{3} \mathrm{~N}$

$1.7-100 \%$ conv, $36-96.5 \%$ ee

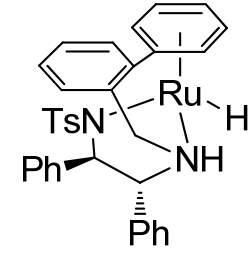

$15^{23}(0.5 \mathrm{~mol} \%)$

$\mathrm{HCO}_{2} \mathrm{H}, \mathrm{Et}_{3} \mathrm{~N}$

43-100\% conv, 33-97\% ee

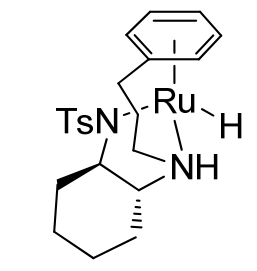

$16^{23}$ (0.5 mol\%)

$\mathrm{HCO}_{2} \mathrm{H}, \mathrm{Et}_{3} \mathrm{~N}$

$25-100 \%$ conv, $26-92 \%$ ee

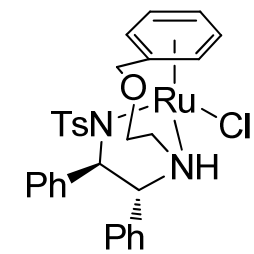

$17^{24}$ (0.5 mol\%)

$\mathrm{HCO}_{2} \mathrm{H}, \mathrm{Et}_{3} \mathrm{~N}$

$22-100 \%$ conv, $14-99 \%$ ee

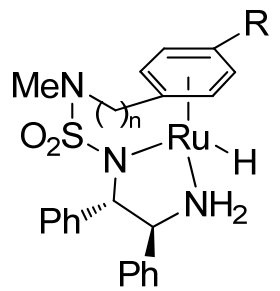

$18^{25}$ (0.1-0.5 mol\%)

$\mathrm{R}=\mathrm{H}, \mathrm{Me} ; \mathrm{n}=2,3$

$\mathrm{HCO}_{2} \mathrm{H}, \mathrm{Et}_{3} \mathrm{~N}$

$22-100 \%$ conv, $70-100 \%$ yield

$51-99.9 \%$ ee

The complex between $\mathrm{CRu}$ and TsDPEN (9) was used in the mono reduction of the meso epoxydiene 19 to give the alcohol 20 yielding opposite enantiomeric ratio, depending on the hydrogen source, a phenomenon never observed before for a similar transformation (Scheme 2). ${ }^{26}$<smiles>O=C1[C@H]2C(=O)[C@@H]3C(C4CO4)C=CC2[C@H]13</smiles>

19

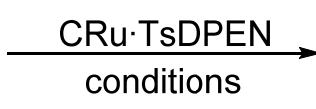

i-PrOH:

$\mathrm{HCO}_{2} \mathrm{H} \mathrm{Et}_{3} \mathrm{~N}:$ ent-20 $(64 \%$ ee)

Scheme 2. ATH of compound 19 under different reaction conditions.

The diastereomeric ligands $\mathbf{1 1}$ and $\mathbf{2 1}$ have been used in the CRu-catalyzed ATH of phenones using sodium formate in water with variable results. It is remarkable that the configuration of the obtained $R$ or $S$ alcohol is independent of the stereochemistry of the diamine moiety of the ligand used. ${ }^{27}$ Other prolinamide ligands $22^{28}$ and $23^{29}$ were the best ones form a series of analogues able to act in combination with $\mathrm{CRu}$ to perform the $\mathrm{ATH}$ of phenones in aqueous sodium formate. $C_{2}$-Symmetric disulfonamide 24 was introduced for the ATH of different phenones using isopropanol as the reducing agent, potassium hydroxide as the base, and both complexes BRu and $\mathrm{CRu}$ as catalysts, in general yields and enantioselectivities being excellent. ${ }^{30}$ Another disulfonamide chiral ligand 25, and aryl substituted derivatives were reported to be efficient in the same process, but using aqueous sodium formate as reducing agent. ${ }^{31}$ 


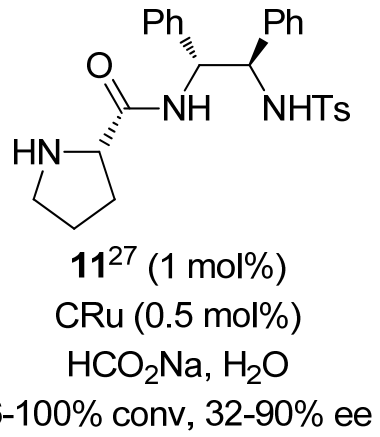

L

$\mathbf{2 2}^{28}(5 \mathrm{~mol} \%)$

$\mathrm{CRu}(2.5 \mathrm{~mol} \%)$

$\mathrm{HCO}_{2} \mathrm{Na}, \mathrm{H}_{2} \mathrm{O}$

$35-99 \%$ yield, $90-99 \%$ ee

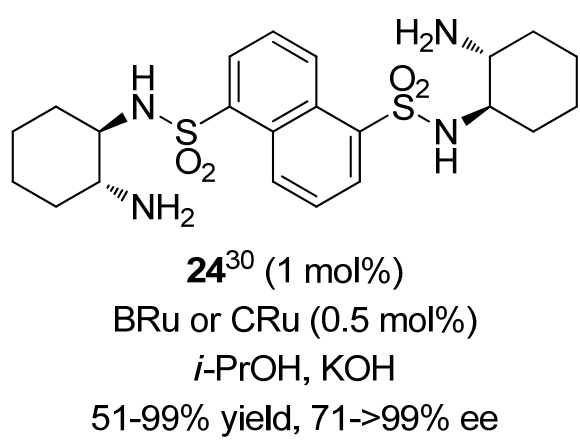

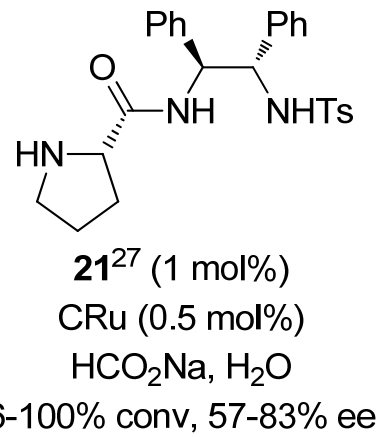<smiles>C[C@H](NC(=O)C1CCCN1)c1ccccc1</smiles>

$23^{29}(3 \mathrm{~mol} \%)$

$\mathrm{CRu}(1.25 \mathrm{~mol} \%)$

$\mathrm{HCO}_{2} \mathrm{Na}, \mathrm{H}_{2} \mathrm{O}$

$41-95 \%$ yield, $23-90 \%$ ee

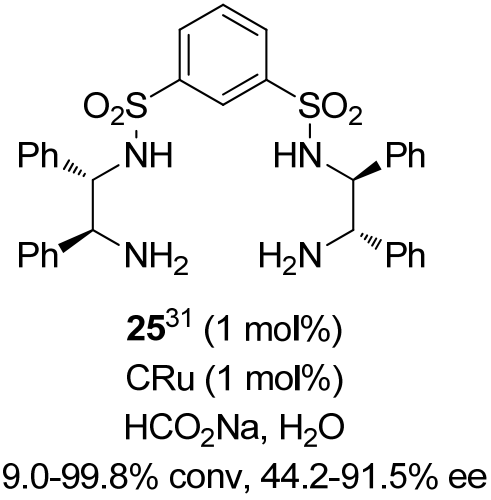

The chiral pool has also been used as a source of chiral ligands in the ATH of ketones. For instance, some $\alpha$-amidothioamide ligands derived from D-glucose of type $\mathbf{2 6}^{32 \mathrm{a}}$ or $27^{32 \mathrm{~b}}$ have been used with limited success concerning conversion for the ATH of acetophenone using sodium isopropanolate in THF as reducing media. However, the same process worked nicely when rhodium was used as the metallic component (see below). Also derived from (+)-limonene are the amino oximes 28, which have been used in combination with different $\mathrm{Ru}$ complexes $(\mathrm{CRu}, \mathrm{BRu}, \mathrm{HRu})$ for the ATH of phenones with variable results in terms of conversion and enantioselectivity. ${ }^{33}$ Another natural product that has been used to prepare the chiral ligand 29 is $(+)$-camphor. This ligand was employed with $\mathrm{CRu}$ and isopropanol and potassium hydroxide as reaction medium for the ATH of phenones with modest to poor results. ${ }^{34}$ 


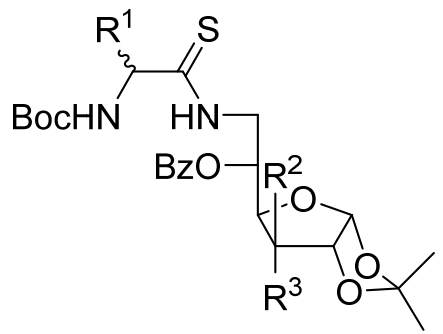

$26^{32 \mathrm{a}}(0.55 \mathrm{~mol} \%)$

$\mathrm{R}^{1}=\mathrm{H}, \mathrm{Me}, i-\mathrm{Pr}, \mathrm{Ph}, \mathrm{Bn}$

$\mathrm{R}^{2}, \mathrm{R}^{3}=\mathrm{H}, \mathrm{Me}, \mathrm{OBn}$

$\mathrm{CRu}(0.25 \mathrm{~mol} \%)$

i-PrONa, THF

$12-13 \%$ conv, $79-81 \%$ ee

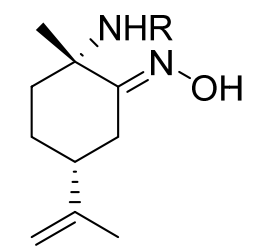

$$
\begin{gathered}
\mathbf{2 8}^{33}(2 \mathrm{~mol} \%) \\
\mathrm{R}=\mathrm{Ph}, \mathrm{Bn} \\
i-\mathrm{PrOH}, \mathrm{KOH}
\end{gathered}
$$

$27-99 \%$ conv, $6-78 \%$ ee

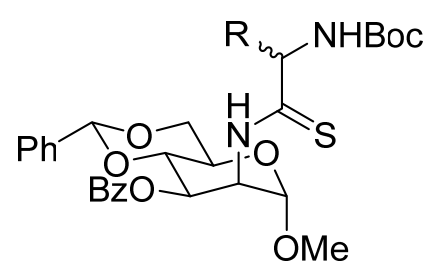

$27^{32 \mathrm{~b}}(0.55 \mathrm{~mol} \%)$

$\mathrm{R}^{1}=\mathrm{Me}, i-\mathrm{Pr}, i-\mathrm{Bu}, \mathrm{Ph}, \mathrm{Bn}$

$R^{2}, R^{3}=H, M e, O B n$

$\mathrm{CRu}(0.25 \mathrm{~mol} \%)$

i-PrONa, THF

0-39\% \% conv, $87-90 \%$ ee

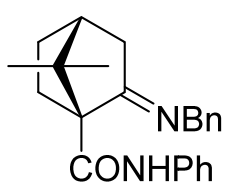

$$
\begin{gathered}
2^{34}(1 \mathrm{~mol} \%) \\
\text { CRu }(0.3-1 \mathrm{~mol} \%)
\end{gathered}
$$$$
i-\mathrm{PrOH}, \mathrm{KOH}
$$

2.9-96.5\% conv, $4.1-67.4 \%$ ee

Natural (+)-limonene was the starting material to prepare Ru complexes of the type $\mathbf{3 0}$, which were successfully used in the ATH of phenones with the formic acid/triethylamine combination. In general, results were better than using complexes derived from the same natural product but with different configuration at the sterocenters. ${ }^{35}$ Ruthenacycles of the type $\mathbf{3 1}$ have been shown to be effective in the ATH of aromatic and heterocyclic ketones using isopropanol and potassium tert-butoxide as reduction combination. ${ }^{36}$<smiles>C=C(C)[C@H]1CC[C@@]2(C)N[R](Cl)(c3ccccc3)N([As])[C@@H]2C1</smiles>

$$
30^{35}(1 \mathrm{~mol} \%)
$$$$
\mathrm{HCO}_{2} \mathrm{H}, \mathrm{Et}_{3} \mathrm{~N}
$$

$66-100 \%$ conv, $14-93 \%$ ee

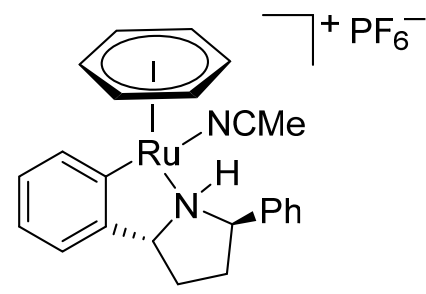

$31^{36}(1 \mathrm{~mol} \%)$

i-PrOH, $t$-BOOK

$44-96 \%$ yield, $35-94 \%$ ee

\subsubsection{Sulphur containing ligands}

Few chiral sulfur containing ligands have been involved in the ATH of ketones. Among them, the amino thiol 32 was very efficient as its hydrochloride in the HRu-catalyzed ATH of phenones using formic acid and triethylamine as the solvent combination. The in situ formed complex between the ligand and the Ru moiety was characterized by $\mathrm{X}$ - 
ray analysis. ${ }^{37}$ For the same process, thiourea-derived ligands of the type 33 were successfully used, the corresponding intermediate complexes also being characterized by the same technique. ${ }^{38}$

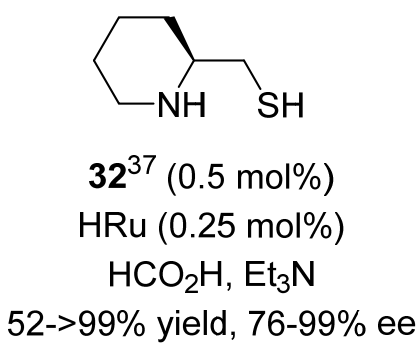

$52->99 \%$ yield, $76-99 \%$ ee

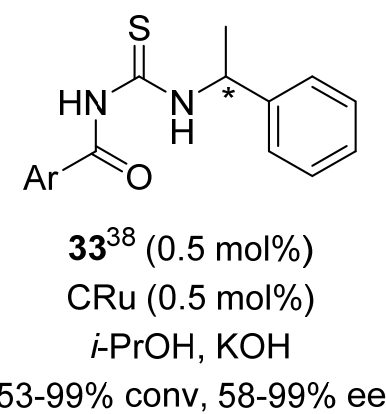

$53-99 \%$ conv, $58-99 \%$ ee

\subsubsection{Phosphorous containing ligands}

A series of amino phosphonite derivatives were prepared, generally from natural amino acids, and have been used in combination with BRu or mainly CRu for the ATH of phenones under isopropanol and basic conditions (sodium or potassium hydroxide). Thus, ligands $34,{ }^{39} 35^{40}$ and $36^{41}$ show a very variable efficiency in the mentioned reaction. Not having a diamine-derived structure are the ligands $37^{42}$ and 38 , ${ }^{43}$ which were reported to be in general efficient for the ATH of different phenones with BRu or $\mathrm{CRu}$, respectively, in the presence of isopropanol and sodium hydroxide as the base. 

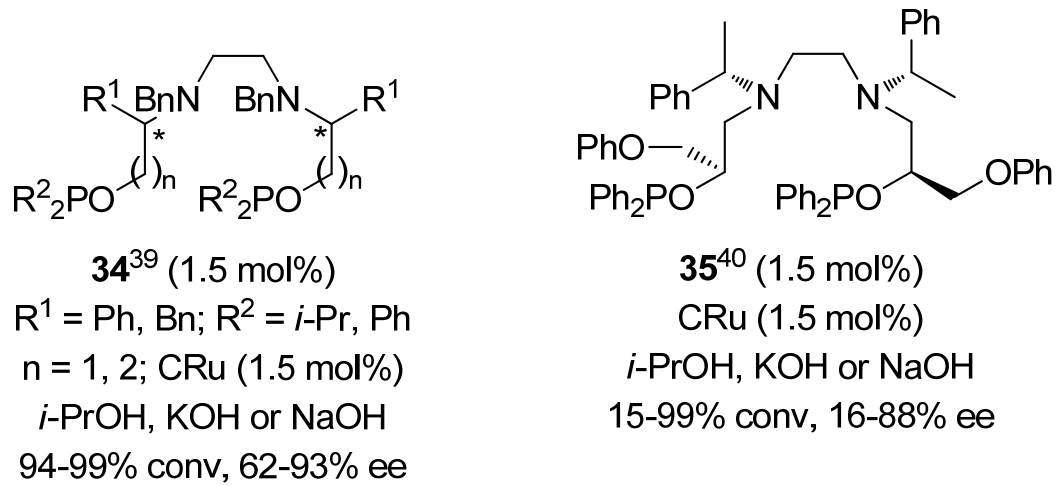

$35^{40}(1.5 \mathrm{~mol} \%)$

CRu (1.5 mol\%)

$i-\mathrm{PrOH}, \mathrm{KOH}$ or $\mathrm{NaOH}$

$15-99 \%$ conv, $16-88 \%$ ee

94-99\% conv, $62-93 \%$ ee<smiles>[R]C(COP)NC(=O)C(=O)NC([R])COP</smiles>

$36^{41}$ (0.1-0.5 mol\%)

$\mathrm{R}=i-\mathrm{Pr}, \mathrm{Ph}, \mathrm{Bn}$

$\mathrm{CRu}(0.1-0.5 \mathrm{~mol} \%)$

i- $\mathrm{PrOH}, \mathrm{KOH}$ or $\mathrm{NaOH}$

$90-99 \%$ conv, $<16-77 \%$ ee
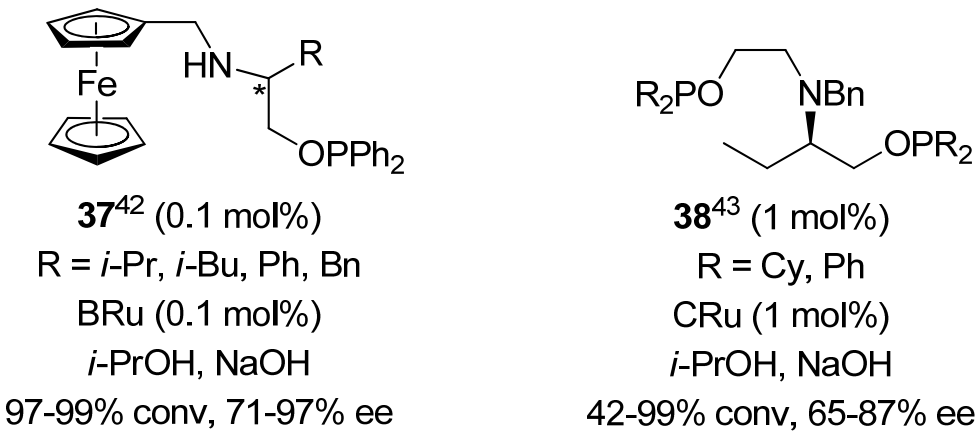

Phosphoramidite derivatives 39 and $\mathrm{CRu}$, either reacting in situ or previously prepared, catalyzed properly the ATH of acetophenones using isopropanol as a hydrogen source and potassium hydroxide as the base, so good conversions but poor enantioselectivities were obtained. ${ }^{44}$ Two phosphine derivatives, namely compounds $\mathbf{4 0}^{45}$ and $\mathbf{4 1}^{46}$ were reported to be active in combination with the ruthenium dichloride-triphenyl phosphine complex for the ATH of phenones in the presence of isopropanol and sodium hydroxide as base. Actually, the corresponding isolated complexes were directly used in the reaction. 

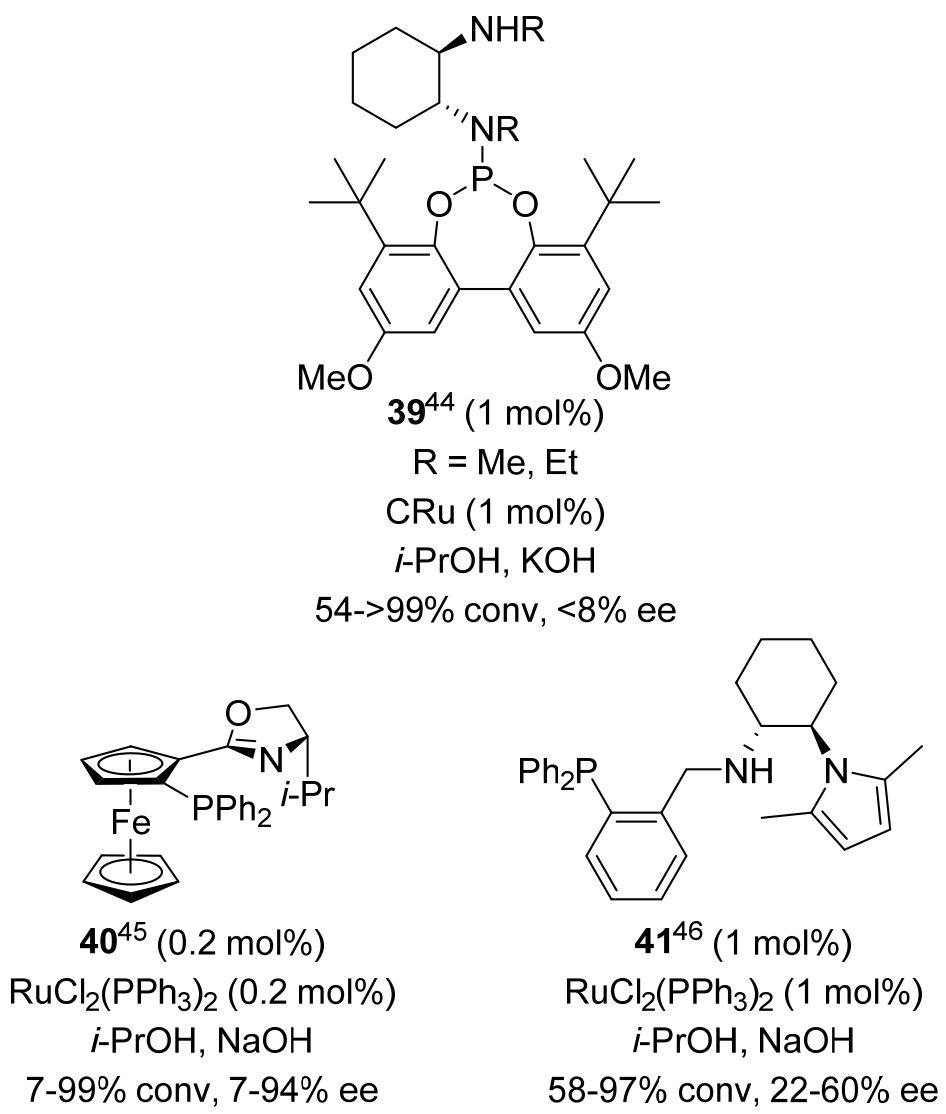

\subsubsection{Heterocyclic ligands}

Ruthenium(II) complexes $\mathbf{4 2}$ and $\mathbf{4 3}{ }^{48}$ containing a heterocyclic chiral ligand were proven to be excellent catalysts for the ATH of phenones, employing potassium isopropoxide in isopropanol as the reducing medium.

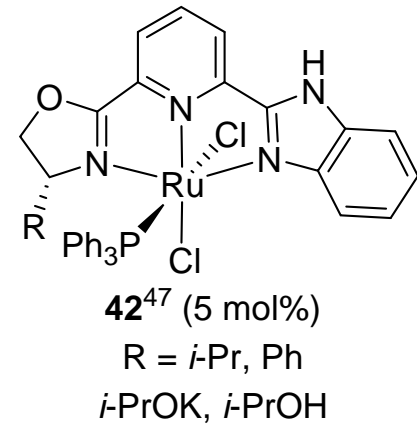

95-96\% yield, 56-79\% ee

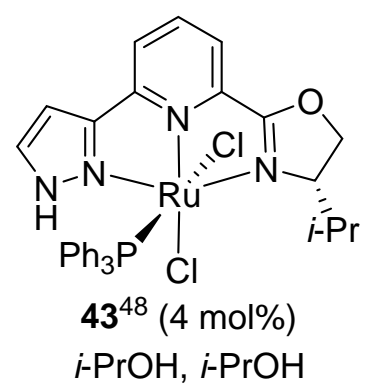

75-99\% conv, 67-99\% ee

From a series of proline derivatives, the ligand $\mathbf{4 4}$ was the most efficient in the ATH of several phenones using $\mathrm{CRu}$ as the metallic component and isopropanol/potassium hydroxide as the reaction medium. Results were in general very good and DFT calculations could explain the obtained stereochemistry. ${ }^{49}$ Another triazole-derived ligand 45 was the best one from a family of diamine derivatives able to act together with a Ru-carbonyl complex as catalyst for the ATH of phenones, isopropanol being the hydrogen source under basic conditions. When an aliphatic ketone was reduced, namely cyclohexyl methyl ketone, conversion was excellent (93\%) but, as expected, enantioselectivity was very poor $(13 \%$ ee $) .{ }^{50}$ 


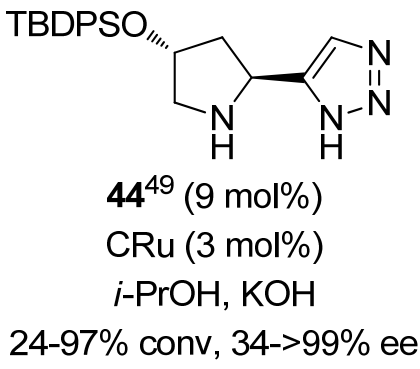

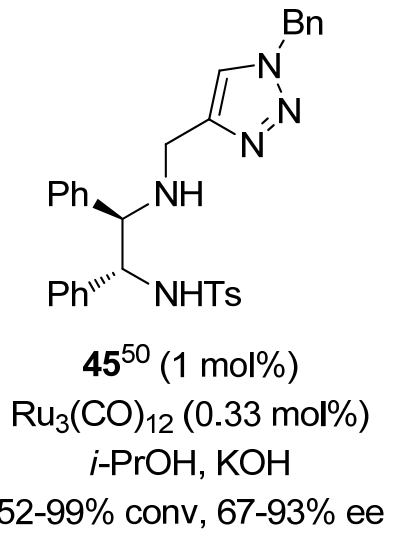

\subsection{Rhodium catalysts}

To the best of our knowledge, only one amino alcohol, the ligand 6 (Table 1), was used in the ATH of acetophenone under $\left[\mathrm{RhCl}_{2} \mathrm{Cp}^{*}\right]_{2}$ catalysis $(1 \mathrm{~mol} \%)$ in the presence of isopropanol and potassium tert-butoxide, conversion (up to $94 \%$ ) and enantioselectivity (up to $99 \%$ ) being excellent. ${ }^{11}$ However, the use of diamines and their derivatives have been extensively used in the ATH of phenones. Thus, ligands $\mathbf{9}^{27}$ (Table 2) and $21^{27}$ were employed in combination with the rhodium complex $\left[\mathrm{RhCl}_{2} \mathrm{Cp}^{*}\right]_{2}$ and sodium formate under aqueous conditions to perform the ATH of aromatic ketones with variable results (3-68\% conv, $22-85 \%$ ee). The same reaction conditions, but using the ligand $2 \mathbf{2 4}^{30}$ gave excellent results $(69-99 \%$ yield, $74-99 \%$ ee) for the same process. Other type of ligands described for this reaction were compounds $46,{ }^{51} \mathbf{4 7},{ }^{52} \mathbf{4 8},{ }^{52} \mathbf{4 9}$ and $\mathbf{5 0}^{54}$ with different activity for the ATH of phenones (Table 3).

Table 3. ATH of phenones with rhodium complexes in the presence of chiral diamines. 


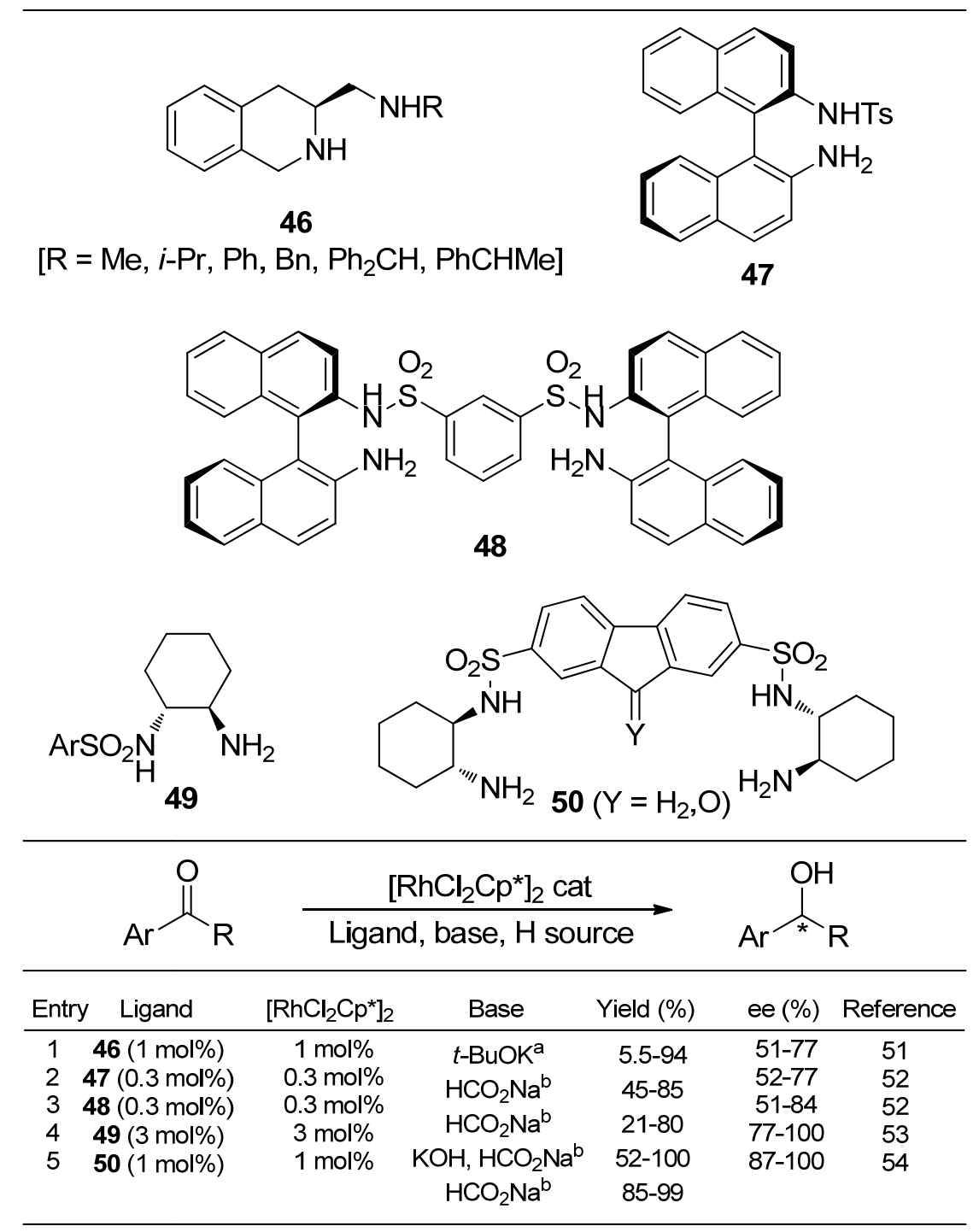

a Hydrogen source: $i$-PrOH. ${ }^{b}$ Hydrogen source: $\mathrm{HCO}_{2} \mathrm{Na}$.

Other ligands derived from natural products $\mathbf{2 6}^{32 \mathrm{a}}$ and $27^{32 \mathrm{~b}}$ already described for the ruthenium-catalyzed $\mathrm{ATH}$, were also used in connection with the complex $\left[\mathrm{RhCl}_{2} \mathrm{Cp}^{*}\right]_{2}$ for the ATH of phenones in general with variable conversions and enantioselectivities (12-100\% conv, $11-99 \%$ ee). Concerning the use of rhodium complexes derived from 1,2-diamines, compounds $\mathbf{5 1} 1^{55}$ and $\mathbf{5 2}{ }^{56}$ have shown to be in general excellent catalysts in the ATH of phenones. It is remarkable that in the first case the hydrogenation of an aliphatic ketone, namely cyclohexyl methyl ketone worked properly giving $87 \%$ conv and $87 \%$ ee. 


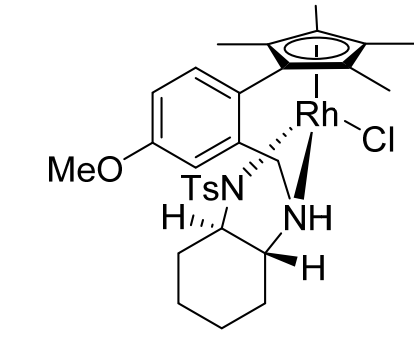

$51^{55}(0.5 \mathrm{~mol} \%)$

$\mathrm{HCO}_{2} \mathrm{H}, \mathrm{Et}_{3} \mathrm{~N}$

$37-100 \%$ conv, $60-98 \%$ ee

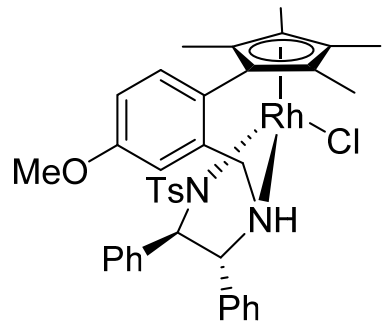

$52^{56}(0.5 \mathrm{~mol} \%)$

$\mathrm{HCO}_{2} \mathrm{H}, \mathrm{Et}_{3} \mathrm{~N}$

$68-99 \%$ yield, $70->99 \%$ ee

The complex RhClCp*TsDPEN was very active for the transformation of chromenones 53 into compounds 54 with formic acid and sodium formate in water. As it is shown, both the $\mathrm{C}=\mathrm{O}$ and the $\mathrm{C}=\mathrm{C}$ were simultaneously hydrogenated to give the final products (Scheme 3). ${ }^{57}$

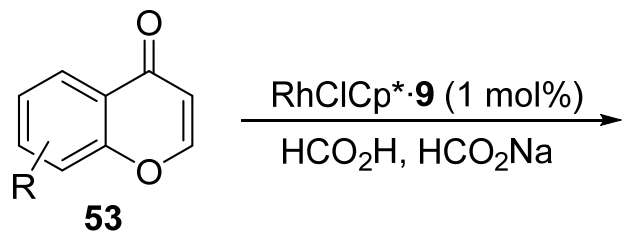<smiles>[R]c1ccc2c(c1)OCC[C@H]2O</smiles>

$23-99 \%$ yield, $98-99 \%$ ee

Scheme 3. Compounds 54 prepared by ATH. ${ }^{57}$

A complex between ligands $39^{44}$ and $\left[\mathrm{RhCl}_{2} \mathrm{Cp}^{*}\right]_{2}$ was also effective in the ATH of acetophenone using potassium hydroxide or triethylamine as bases giving modest results $(20-95 \%$ conv, $10-18 \%$ ee). The amide or hydroxamic acid derived proline 55 were used in collaboration with the rhodium complex $\left[\mathrm{RhCl}_{2} \mathrm{Cp}^{*}\right]_{2}$ to perform mainly the ATH of phenones using lithium formate in water as the reaction mixture. Conversions and enantioselectivities are generally good. ${ }^{58}$ The same ligand gave worst results when the iridium complex $\left[\mathrm{IrCl}_{2} \mathrm{Cp}^{*}\right]_{2}$ was used as the organometallic complex. Concerning the use of $\mathrm{N}$-heterocyclic carbenes as ligands and a rhodium catalyst, the precursor 56 was rather active in the ATH of different phenones under basic conditions and with the complex $[\mathrm{Rh}(\operatorname{cod}) \mathrm{Cl}]_{2}$ as the organometallic component. ${ }^{59}$ The triazole derivative 57 has been reported to be very efficient in the ATH of phenones with $\left[\mathrm{RhCl}_{2} \mathrm{Cp}^{*}\right]_{2}$ as the metallic complex and sodium isopropoxide as the hydrogen source. ${ }^{60}$

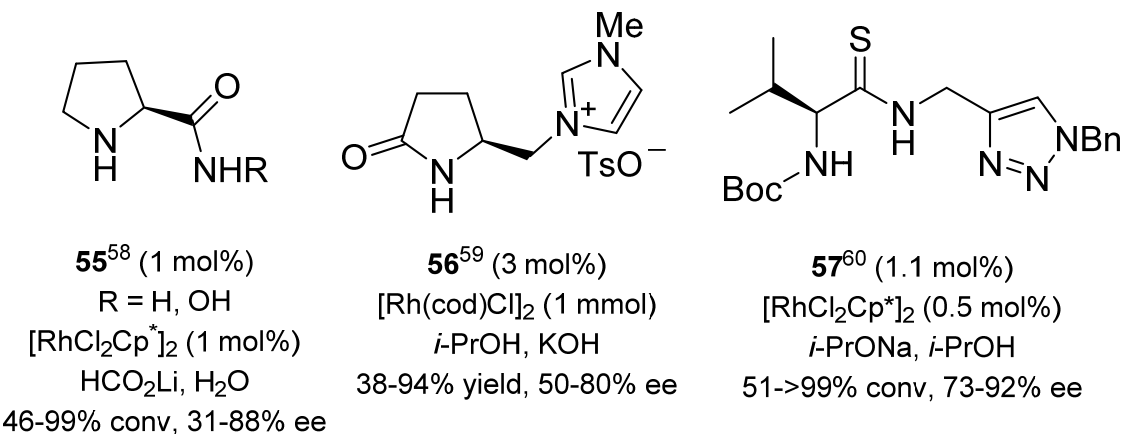


Rhodium preformed complexes have also been used in these type of reductions. Thus, the ATH of several phenones with isopropanol and potassium hydroxide as the hydrogen source, under the influence of complex 58, produced the corresponding alcohols in good yields and moderate enantioselectivities. ${ }^{61}$ However, neutral or cationic salen rhodium complexes 59 or $\mathbf{6 0}$, respectively, gave variable conversions and very poor enantioselectivities in the ATH of acetophenone with isopropanol and potassium hydroxide as the reaction medium. ${ }^{62}$

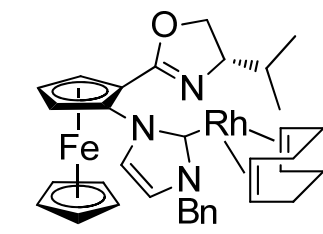

$$
\mathbf{5 8}^{61}(10 \mathrm{~mol} \%)
$$

i- $\mathrm{PrOH}, \mathrm{KOH}$

$72-93 \%$ yield, $39-67 \%$ ee

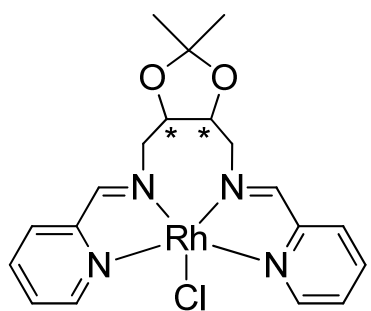

$59^{62}(0.5 \mathrm{~mol} \%)$

$i-\mathrm{PrOH}, \mathrm{KOH}$

$79.8 \%$ conv, $0.9 \%$ ee

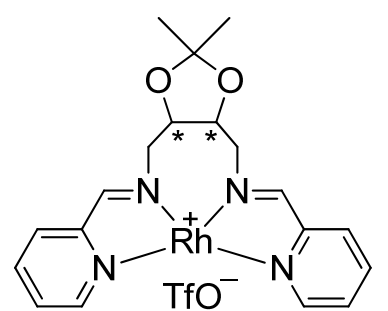

$\mathbf{6 0}^{62}(0.5 \mathrm{~mol} \%)$

$i-\mathrm{PrOH}, \mathrm{KOH}$

$23-68 \%$ conv, $2.5-6.7 \%$ ee

\subsection{Iridium catalysts}

From several iridium complexes derived from natural amino acids, the series containing a proline moiety $\mathbf{6 1}$ is an example of catalysts active in the ATH not only of phenones, but also of pinacolone with remarkable results (up to $60 \%$ conv, up to $80 \%$ ee), although with high catalyst loading. ${ }^{63}$ The tetrahydroisoquinoline derived alcohol $\mathbf{6}$, which worked nicely in these reduction processes with rodium and ruthenium catalysts, was also used in combination with the complex $\left[\mathrm{IrCl}_{2} \mathrm{Cp}^{*}\right]_{2}$ in the ATH of acetophenone under isopropanol and potassium tert-butoxide conditions with moderate results $\left(35 \%\right.$ conv, $75 \%$ ee). ${ }^{11}$ In addition, similar results were obtained when cationic or neutral iridium complexes $62^{64}$ and $\mathbf{6 3},{ }^{65}$ were used for the ATH of phenones, isopropanol and potassium hydroxide being the reaction medium.

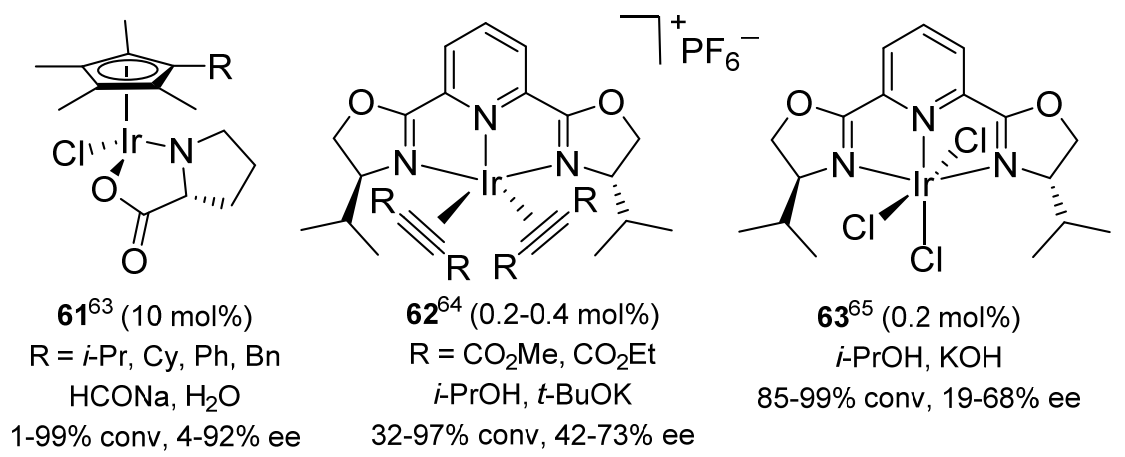

$\mathrm{N}$-Heterocyclic carbenes, either generated in situ from the ligand and the complex $\left[\mathrm{IrCl}_{2} \mathrm{Cp}^{*}\right]_{2}$ or already prepared, such in the case of complexes $64,{ }^{66} \mathbf{6 5}^{67}$ and $\mathbf{6 6},{ }^{68}$ were used in the ATH of phenones with variable results. Similarly, the two sulphurcontaining ligands $67^{69}$ and $\mathbf{6 8}^{70}$ were efficient in the ATH of aromatic and heterocyclic ketones using different iridium(I) complexes as metallic components and isopropanol as the hydrogen source. 


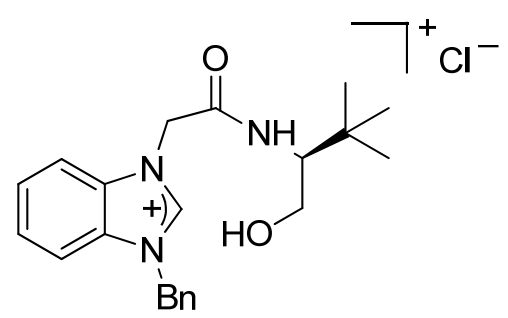

$64^{66}(4 \mathrm{~mol} \%)$

$\left[\mathrm{IrCl}_{2} \mathrm{Cp}^{*}\right]_{2}(4 \mathrm{~mol} \%)$

$i-\mathrm{PrOH}, \mathrm{KOH}, \mathrm{NaOH}$, or $t-\mathrm{BuOK}$

$27-58 \%$ yield, $49-60 \%$ ee

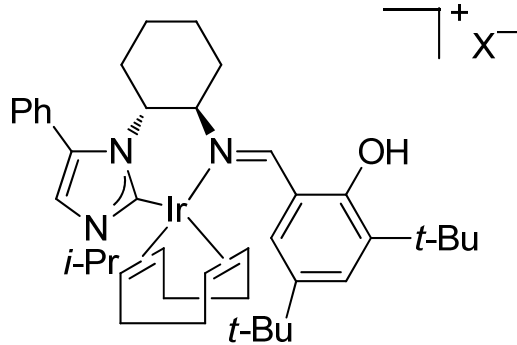

$6^{67}$ (4 mol\%)

$\mathrm{X}=\mathrm{B}\left[3,5-\left(\mathrm{F}_{3} \mathrm{C}\right)_{2} \mathrm{C}_{6} \mathrm{H}_{3}\right]_{4}$

$i$-PrOH, $t$-BuOK

$42-68 \%$ yield, $3-41 \%$ ee

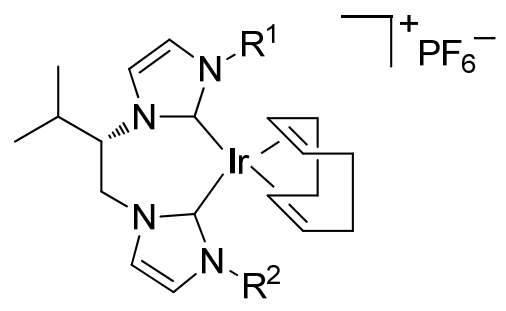

$6^{68}(4 \mathrm{~mol} \%)$

$\mathrm{R}^{1}, \mathrm{R}^{2}=\mathrm{Me}, n-\mathrm{Pr}, i-\mathrm{Pr}, \mathrm{Ph}, \mathrm{CHPh}_{2}$

$i$-PrOH, $t$-BuOK

78->99\% conv, 6-55\% ee<smiles>CC(C)(C)[S@](=O)c1ccccc1CNCc1ccccn1</smiles>

$67^{69}(1 \mathrm{~mol} \%)$

$\left[\mathrm{IrCl}(\mathrm{COE})_{2}\right]_{2}(1 \mathrm{~mol} \%)$

$i$-PrOH, $t$-BuOK

$10-98 \%$ conv, $10-79 \%$ ee

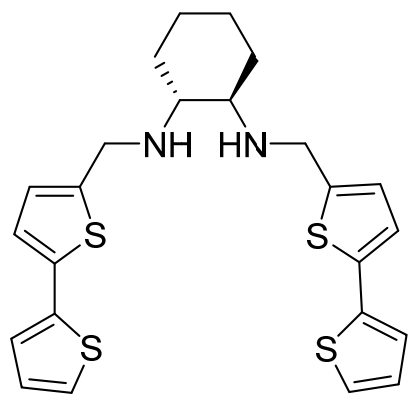

$6^{70}(1.1 \mathrm{~mol} \%)$

$\mathrm{IrCl}(\mathrm{CO})\left(\mathrm{PPh}_{3}\right)_{2}(1 \mathrm{~mol} \%)$

$i$-PrOH, $t$-BuOK

$90-97 \%$ yield, $34-90 \%$ ee

The so-called $\mathrm{PN}_{4}$-ligands 69 and $\mathbf{7 0}$ have also been explored in the iridium-catalyzed ATH of propiophenone with isopropanol under basic conditions, giving in this case the corresponding alcohol with variable results. ${ }^{71}$ 
<smiles>[R]C(N=Cc1ccccc1-c1ccccc1C=NC([R])C([R])N[SH]c1ccc(C)cc1)=C([R])NSc1ccc(C)cc1</smiles>

$$
69^{71}(0.1 \mathrm{~mol} \%)
$$

$\mathrm{R}=\mathrm{Ph} ; \mathrm{R}-\mathrm{R}=\left(\mathrm{CH}_{2}\right)_{4}$ $[\mathrm{IrCl}(\mathrm{COD})]_{2}$ or $\left[\mathrm{IrHCl}_{2}(\mathrm{COD})\right]_{2}$ or $\mathrm{IrCl}(\mathrm{COD}) \mathrm{PPh}_{3}$ (0.1 $\left.\mathrm{mol} \%\right)$

i- $\mathrm{PrOH}, \mathrm{KOH}$

$43-95 \%$ conv, $36-49 \%$ ee<smiles>[R]C(NCc1ccccc1-c1ccccc1CNC([R])C([R])N[SH](=O)([O-])c1ccc(C)cc1)=C([R])NSc1ccc(C)cc1</smiles>

$7^{71}(0.1 \mathrm{~mol} \%)$

$$
\mathrm{R}=\mathrm{Ph} ; \mathrm{R}-\mathrm{R}=\left(\mathrm{CH}_{2}\right)_{4}
$$

$[\mathrm{IrCl}(\mathrm{COD})]_{2}$ or $\left[\mathrm{IrHCl}_{2}(\mathrm{COD})\right]_{2}$ or $\mathrm{IrCl}(\mathrm{COD}) \mathrm{PPh}_{3}(0.1 \mathrm{~mol} \%)$

$i-\mathrm{PrOH}, \mathrm{KOH}$

$7-62 \%$ conv, $30-75 \%$ ee

\subsection{Iron catalysts}

Several iron complexes have been reported to be efficient in the ATH of ketones, mainly phenones. Thus, when complexes $71,{ }^{72} 72^{73}$ and $73^{74}$ were used in these processes, the corresponding chiral alcohols were produced with variable results. Similar results were also obtained with other type of iron derivatives, such as bisisonitrile iron complexes 74. The reductions of different cyclic and acyclic alkyl-aryl and -heteroaryl ketones were performed in isopropanol under basic conditions. ${ }^{75}$

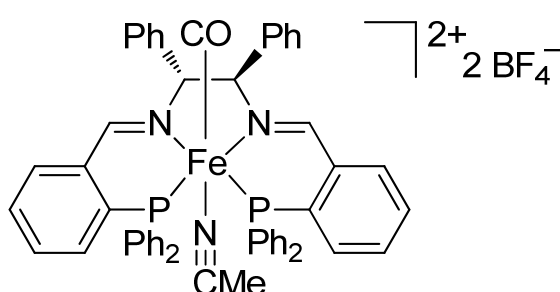

$$
71^{72}(0.95-0.17 \mathrm{~mol} \%)
$$

$i$-PrOH, $t$-BuOK

$48-91 \%$ yield, $12-96 \%$ ee

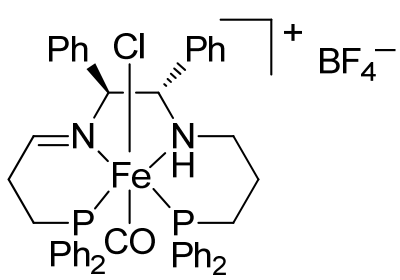

$7^{74}(0.016-0.05 \mathrm{~mol} \%)$

$i$-PrOH, $t$-BuOK

$55-99 \%$ yield, $25-92 \%$ ee

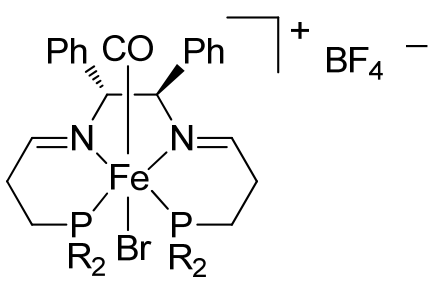

$7^{73}(0.1 \mathrm{~mol} \%)$

$\mathrm{R}=\mathrm{Et}, i-\mathrm{Pr}, \mathrm{Cy}, \mathrm{Ph}, 2-\mathrm{MeC}_{6} \mathrm{H}_{4}, 4-\mathrm{MeC}_{6} \mathrm{H}_{4}$,

$3,5-\mathrm{Me}_{2} \mathrm{C}_{6} \mathrm{H}_{3}, 4-\mathrm{F}_{3} \mathrm{CC}_{6} \mathrm{H}_{4}, 3,5-\left(\mathrm{F}_{3} \mathrm{C}\right)_{2} \mathrm{C}_{6} \mathrm{H}_{3}$

$i$-PrOH, $t$-BuOK

$<94 \%$ yield, $<90 \%$ ee

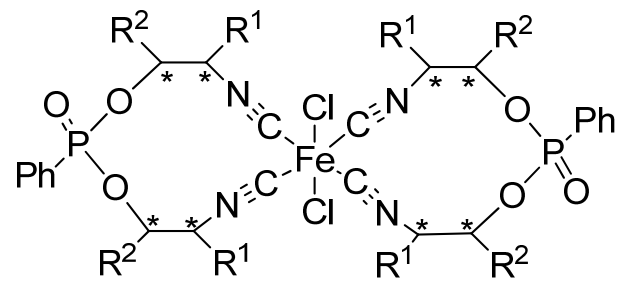

$\mathbf{7 4}^{75}$ (5 mol\%)

$\mathrm{R}^{1}, \mathrm{R}^{2}, \mathrm{H}, \mathrm{Me}, i-\mathrm{Pr}, t-\mathrm{Bu}, \mathrm{Bn}$

$i-\mathrm{PrOH}, t-\mathrm{BuOK}$

6->99\%, $17-67 \%$ ee 


\subsection{Osmium, nickel, cobalt and rhenium catalysts}

Other organometallic complexes different than those derived from ruthenium, rhodium, iridium and iron have also been used in ATH, although in a lesser extension. Thus, osmium complexes of the type $\mathbf{7 5}$ derived from a pyridine box ligand have been used in the ATH of different phenones in general with excellent conversions and good enantioselectivities. ${ }^{76}$ In the same manner, half-sandwich complexes of osmium(II) with natural amino acids $\mathbf{7 6}$ have been prepared and used as very efficient catalyst $(0.04$ $\mathrm{mol} \%$ ) in the ATH of acetophenone with variable results concerning conversion and enantioselectivity. ${ }^{77}$ In addition, osmium complexes containing the 2aminomethylpyridine unit $\mathbf{7 7}$ have been shown to be very active in the ATH of aromatic ketones with excellent results. ${ }^{78}$
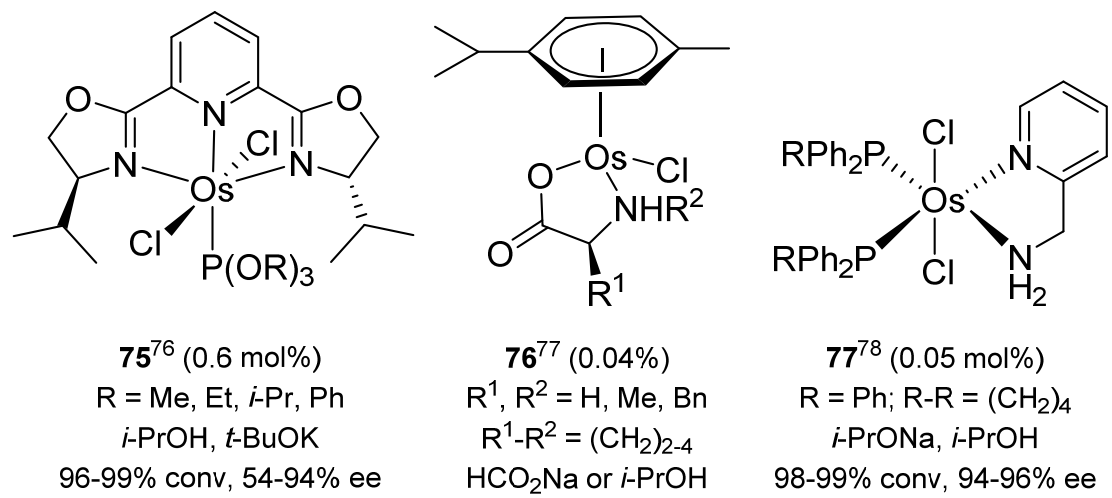

$$
\begin{gathered}
\mathbf{7 6}^{\mathbf{7 7}}(0.04 \%) \\
\mathrm{R}^{1}, \mathrm{R}^{2}=\mathrm{H}, \mathrm{Me}, \mathrm{Bn} \\
\mathrm{R}^{1}-\mathrm{R}^{2}=\left(\mathrm{CH}_{2}\right)_{2-4} \\
\mathrm{HCO}_{2} \mathrm{Na} \text { or } i-\mathrm{PrOH} \\
18-98 \% \text { conv, } 8-72 \% \text { ee }
\end{gathered}
$$

$$
\begin{gathered}
\mathbf{7 7}^{78}(0.05 \mathrm{~mol} \%) \\
\mathrm{R}=\mathrm{Ph} ; \mathrm{R}-\mathrm{R}=\left(\mathrm{CH}_{2}\right)_{4} \\
i-\mathrm{PrONa}, i-\mathrm{PrOH} \\
\text { 98-99\% conv, } 94-96 \% \text { ee }
\end{gathered}
$$

Regarding nickel catalysts, to our best knowledge there is only one report on the use of a nickel(II) compound in combination with the ligand $\mathbf{7 8}$ and employing isopropanol under basic conditions as the reducing medium, so different phenones were hydrogenated in good yields and enantioselectivities. ${ }^{79}$ Concerning rhenium, the chiral ligand 79 has been shown as the best one, in combination with a rhenium compound, from a family of systems of this type in the ATH of several phenones using isopropanol and triethylamine as the reaction medium. ${ }^{80}$ Cobalt has been also involved in these reductions. Thus, cobalt nanoparticles, prepared by thermal decomposition of dicobalt octacarbonyl, were stabilized by $\omega$-functionalized long-chain carboxylic acids as $\mathbf{8 0}$ and used as cocatalysts in the ruthenium-catalyzed ATH of phenones. ${ }^{81}$ 


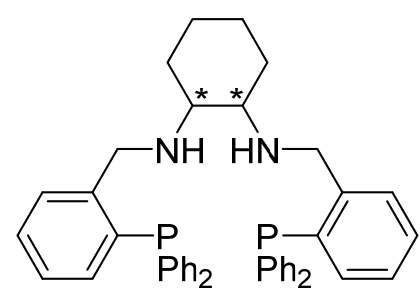

$7^{79}$ (1 $\left.\mathrm{mmol} \%\right)$

$\mathrm{Ni}\left(\mathrm{PPh}_{3}\right)_{2} \mathrm{Cl}_{2}(1 \mathrm{~mol} \%)$

$i-\mathrm{PrOH}, \mathrm{KOH}$

$51->99 \%$ yield, $60-84 \%$ ee

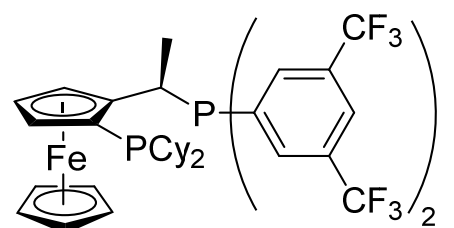

$79^{80}(1 \mathrm{~mol} \%)$

$\mathrm{ReOCl}_{3}\left(\mathrm{AsPh}_{3}\right)_{2}(1 \mathrm{~mol} \%)$

i- $\mathrm{PrOH}, \mathrm{Et}_{3} \mathrm{~N}$

$30->99 \%$ yield, $19-58 \%$ ee<smiles></smiles>

\section{Functionalized substrates}

Although several cases of functionalized substrates were treated in the Section 2, in this part specific functionalized carbonyl compounds, mainly derived from aromatic and heterocyclic ketones, will be considered. $\alpha$-Alkoxy- and $\alpha$-thioalkoxy phenones $\mathbf{8 1}$ were hydrogenated with CRu as catalyst and TsDPEN (9) as chiral ligand in the presence of formic acid and triethylamine as the hydrogen source in tetrahydrofuran. Yields and enantioselectivities for products $\mathbf{8 2}$ are excellent (Scheme 4). ${ }^{82}$

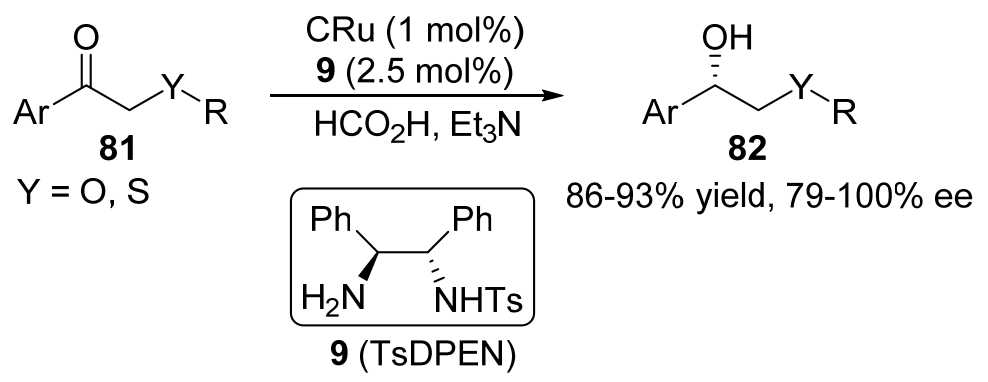

Scheme 4. Preparation of functionalized alcohols $82 .{ }^{82}$

The same catalytic combination was used for the ATH of $\alpha$-amino phenones $\mathbf{8 3}$ under similar reaction conditions but using acetonitrile as solvent, so the corresponding chiral amino alcohols 84 were obtained (Scheme 5). ${ }^{83}$

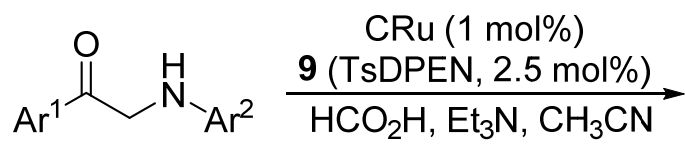

83<smiles>OC([Al])CN[Te]</smiles>

84

$67-93 \%$ yield, $57-95 \%$ ee 
Scheme 5. Preparation of amino alcohols $84 .^{83}$

The ATH of $\alpha$-fluoro phenones 85 using CRu or $\left[\mathrm{RuCl}_{2} \text { (mesitylene) }\right]_{2}(\mathrm{MRu})$ and chiral diamines $\mathbf{9}$ or $\mathbf{8 6}$ has been performed using sodium formate or the formic acid/triethylamine combination giving the expected fluorinated alcohols $\mathbf{8 7}$ with up to $97.5 \%$ ee (Scheme 6). ${ }^{84}$

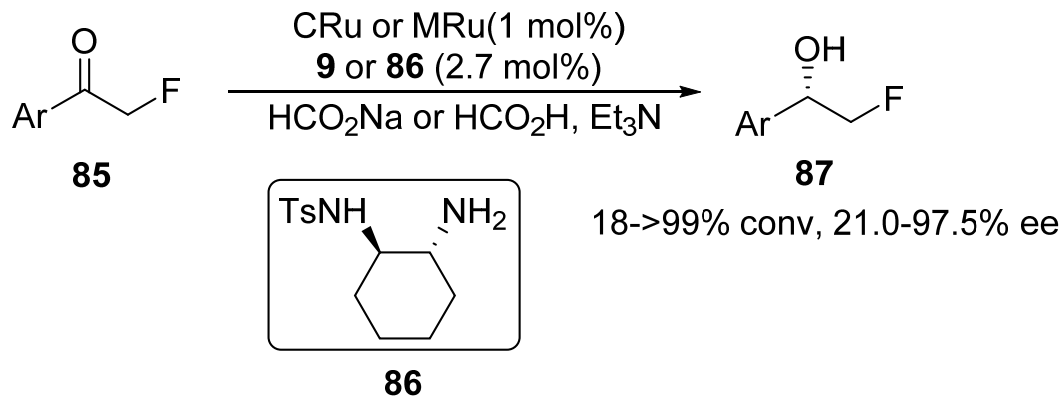

Scheme 6. Preparation of $\beta$-fluoro alcohols $87 .{ }^{84}$

Iridium complexes 89 were efficient in the ATH of $\alpha$-cyano phenones $\mathbf{8 8}$ using either formic acid (with or without triethylamine) or sodium formate in aqueous methanol as the hydrogen source, so the corresponding chiral $\beta$-hydroxy nitriles $\mathbf{9 0}$ were obtained with variable yields and enantioselectivities (Scheme 7). ${ }^{85}$

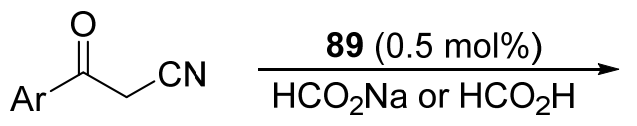

88

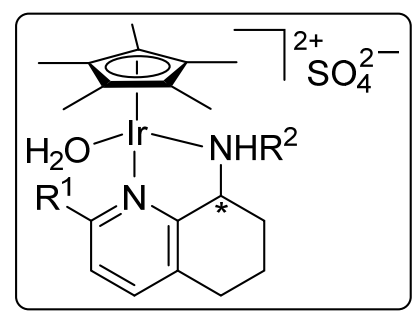

89

$\mathrm{R}^{1}, \mathrm{R}^{2}=\mathrm{H}, \mathrm{Me}$<smiles>N#CC[C@@H](O)[Al]</smiles>

90

Scheme 7. Preparation of $\beta$-hydroxy nitriles $90 .{ }^{85}$

Several diamines forming in situ iridium complexes were previously tested for the transformation of $\mathbf{8 8}$ to $\mathbf{9 0}$, among them the complex $\mathbf{9 1}$ being the most active with formic acid in aqueous methanol as reaction medium, to give the expected alcohols in $45-96 \%$ yields and $73-99 \%$ ee. The same reaction conditions were applied to the ATH of $\alpha$-nitro phenones 92 to yield the corresponding $\beta$-nitro alcohols 93 (Scheme 8). ${ }^{86}$ 


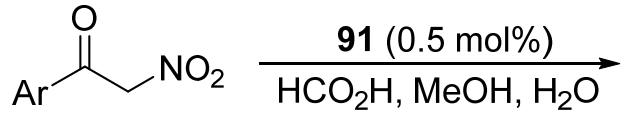

92

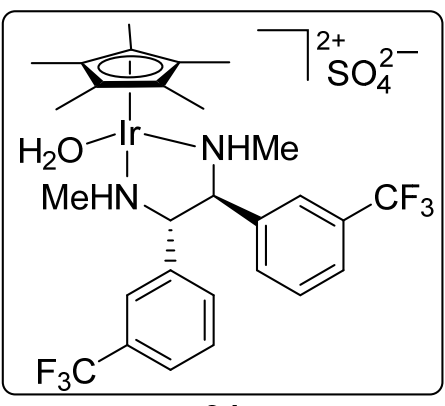

91<smiles>O=[N+]([O-])CC(O)[Te]</smiles>

93

$35-85 \%$ yield, $76-99 \%$ ee

Scheme 8. Preparation of $\beta$-nitro alcohols $93 .^{86}$

Another type of functionalized ketones are the trichloromethyl derivatives. These compounds 94 were submitted to ATH under the ruthenium catalysts 95 with the mixture formic acid/triethylamine to yield the corresponding trichloromethyl alcohols 96 with excellent results. It is remarkable that the reaction worked for both aromatic and aliphatic substrates with comparable yields and enantioselectivities (Scheme 9). ${ }^{87}$<smiles>[R]C(=O)Cl</smiles>

94
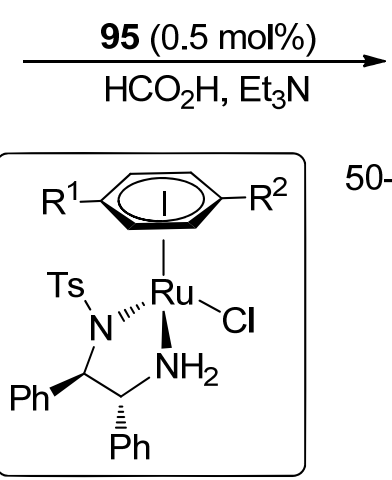

95

a: $R^{1}=R^{2}=H$

b: $\mathrm{R}^{1}=\mathrm{Me} ; \mathrm{R}^{2}=i-\mathrm{Pr}$

Scheme 9. Preparation of alcohols $96 .{ }^{87}$

Unsymmetrical benzyls $\mathbf{9 7}$ were hydrogenated with the formic acid/triethylamine combination under the catalytic action of complex 95b giving mainly the corresponding syn-diols 98 with variable yields but excellent enantio- and diastereoselectivities (Scheme 10). ${ }^{88}$<smiles>O=C(Br)C(=O)Br</smiles>

97<smiles>CCOC(C)C</smiles>

$20.4-97.6 \%$ yield, $87.3-98.9 \%$ ee $1.8-29.7 \mathrm{dr}$

Scheme 10. Preparation of diols $98{ }^{88}$ 
Functionalized acetylenic ketones bearing an ester group at the $\omega$-position 99 reacted with a mixture of formic acid and triethylamine in a process promoted by the catalyst $\mathbf{1 0 0}$ to yield the corresponding hydroxy esters $\mathbf{1 0 1}$ in good yields and ee (Scheme 11). The same process was also applied to acetylenic diketones, the corresponding anti-diols being the reaction products obtained. ${ }^{89}$

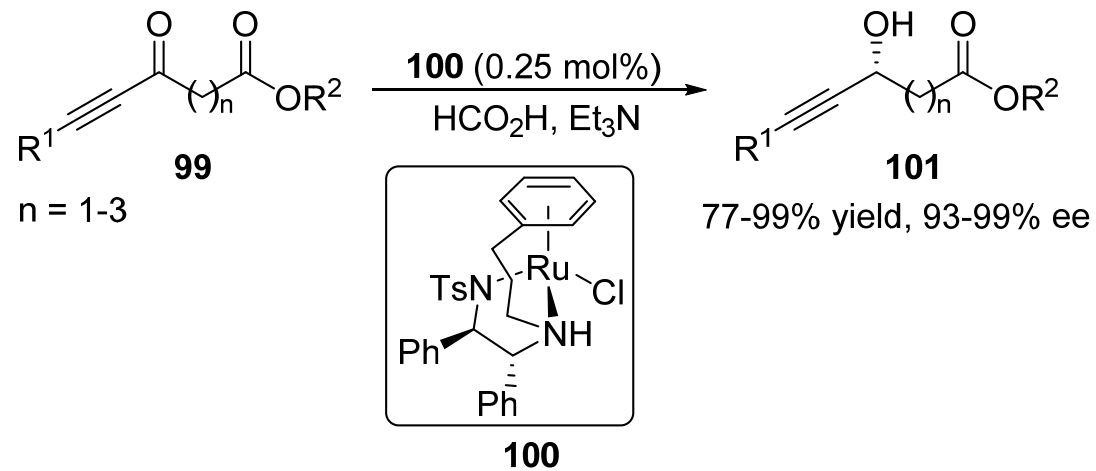

Scheme 11. Preparation of hydroxy esters $101 .{ }^{89}$

The complex resulting from the reaction of CRu and TsDPEN (9), generated in situ, catalyzed effectively the ATH of the cyclic $\alpha$-keto amide $\mathbf{1 0 2}$ with formic acid and triethylamine yielding the heterocyclic moiety of pantolactam 103 (Scheme 12). ${ }^{90}$

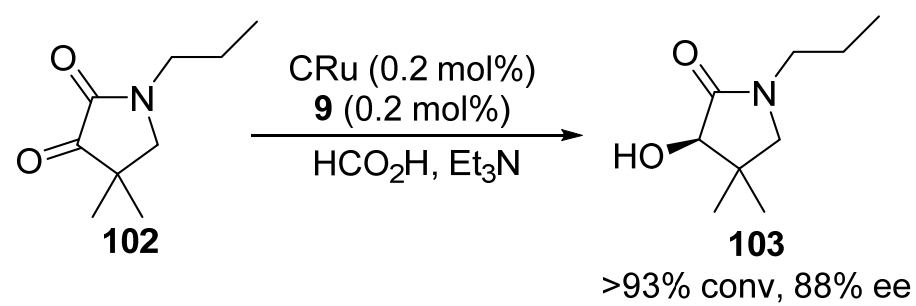

Scheme 12. Preparation of lactam 103. ${ }^{90}$

Aromatic ketones bearing a sulfonamide functionality 104 were the starting materials for the complex 95b-catalyzed ATH with formic acid and triethylamine, so the corresponding chiral hydroxyl sulfonamides 105 were isolated with excellent levels of yields and enantioselectivities (Scheme 13). ${ }^{91}$

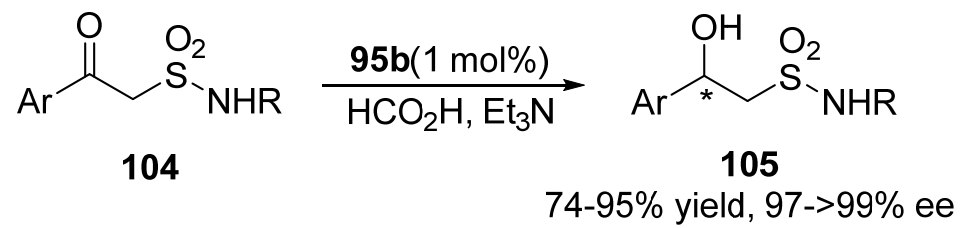

Scheme 13. Preparation of $\beta$-hydroxy sulfonamides $105 .{ }^{91}$

Finally, the in situ generated $\alpha$-sulfonyl ketones, starting from $\alpha$-bromo ketones 106 and a sulfinate, were submitted to an ATH with the catalyst 95b and aqueous sodium formate yielding the corresponding $\beta$-hydroxy sulfones 107 with excellent results (Scheme 14). ${ }^{92}$ 


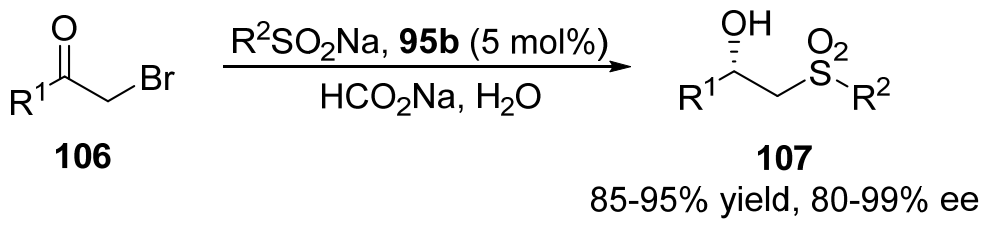

Scheme 14. Preparation of $\beta$-hydroxy sulfones $107 .^{92}$

\section{Tandem reactions}

Tandem reactions are of interest in synthetic organic chemistry because complex structures can be prepared from more simple precursors, eliminating the need of purification steps of the synthetic intermediates, saving on amounts of reagents, labor and waste. There are examples in literature of tandem or "multistep one-pot" reactions involving an ATH in one of the steps. Thus, reaction of substituted salicylaldehydes $\mathbf{1 0 8}$ with $\alpha$-bromo acetophenones 109 under basic conditions gave an acyl benzofuran derivative 110, by alkylation followed by Intramolecular aldol condensation, which was in situ submitted to an ATH with formic acid and triethylamine catalyzed by the rhodium complex 111 to give the corresponding alcohols 112 with excellent results (Scheme 15). ${ }^{93}$

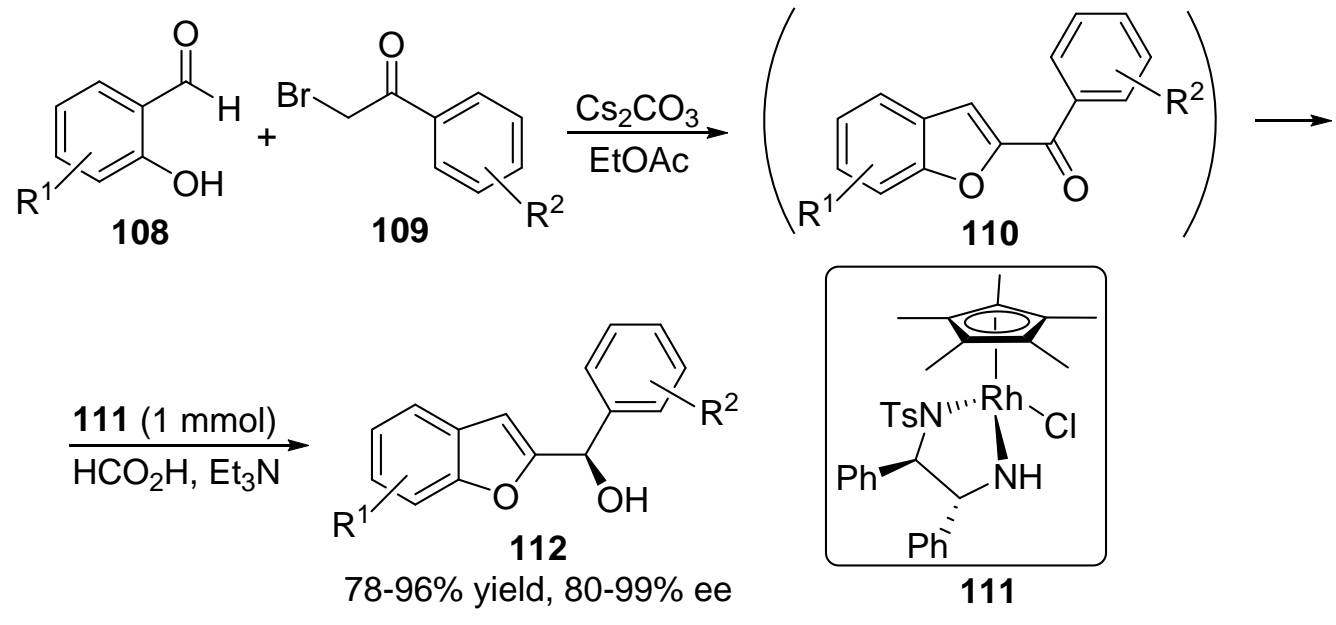

Scheme 15. Preparation of benzofuranyl alcohols $112 .{ }^{93}$

Another tandem reaction involving an ATH process is the alkylation of acetophenones 113 with a primary alcohols $\mathbf{1 1 4}^{94}$ in the presence of the complex $\mathrm{CRu}$ and the ligand 5 under basic conditions, in which the alkylated ketone intermediate 115, formed by aldol condensation and hydrogenation, suffered ATH giving the corresponding alcohol 116 with modest yields but good enantioselectivities (Scheme 16). ${ }^{95}$ 


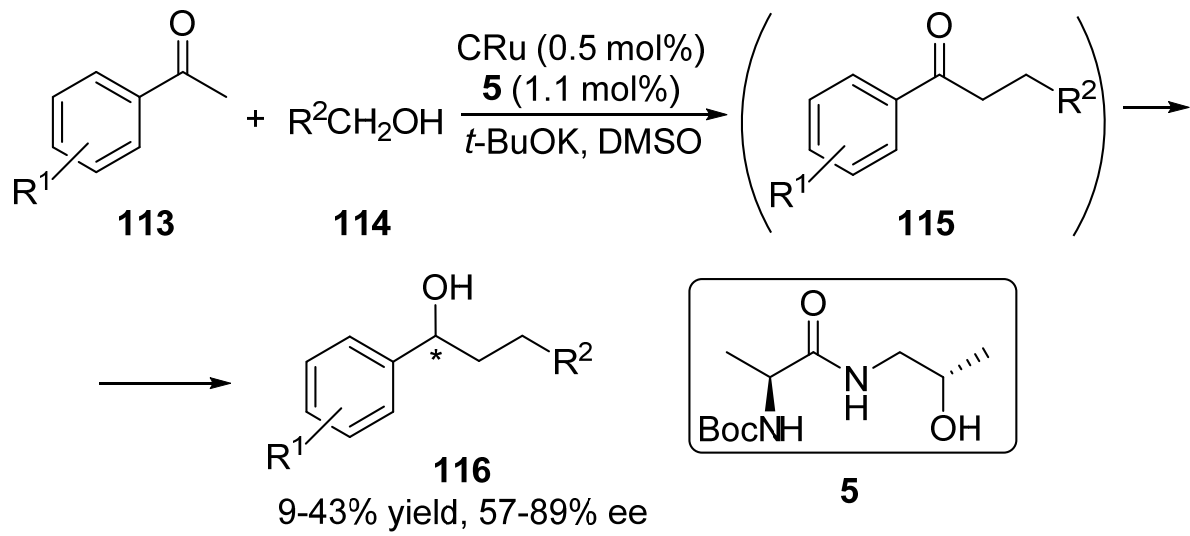

Scheme 16. Preparation of alcohols 116. ${ }^{95}$

In the copper-catalyzed cyclization of 2-alkynyl acetophenones $\mathbf{1 1 7}$ in the presence of the chiral phosphoric acid 118, an ionic copper intermediate $\mathbf{1 1 9}$ is produced, which was in situ hydrogenated by the Hantzsch ester (120) to give the corresponding isochromene derivatives 121 with excellent results concerning yields and enantioselectivities (Scheme 17). ${ }^{96}$<smiles>[R]C#Cc1ccccc1C(C)=O</smiles>

117<smiles>[R]c1cccc2c1C(CCC)C(CC)C([R])[O+]=C2C</smiles>

119

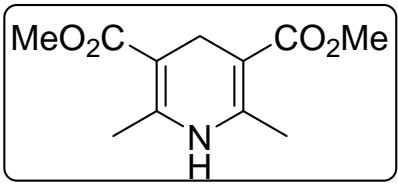

120

Scheme 17. Preparation of isochromenes $\mathbf{1 2 1} .^{96}$

\section{Special reaction conditions}

The ATH can be also performed in non-conventional reaction media or under activation using different sources of energy. For instance, ultrasound activation in the ATH of aromatic and heterocyclic ketones with $\mathrm{BRu}$ and $(1 R, 2 S)$-ephedrine under isopropanol and basic conditions got an acceleration of 5-10 times without affecting the enantioselectivity (20-98\% conv, $8-69 \%$ ee).$^{97}$ 
Ionic liquids, namely $\mathrm{N}$-methylimidazolium hexafluorophosphate [bmim] $\left.\mathrm{PF}_{6}\right]$, have been used in the ATH of several phenones with $\mathrm{CRu}$ and the chiral ligand 122 in the presence of formic acid and triethylamine as the reaction medium giving excellent conversions and enantioselectivities. ${ }^{98}$

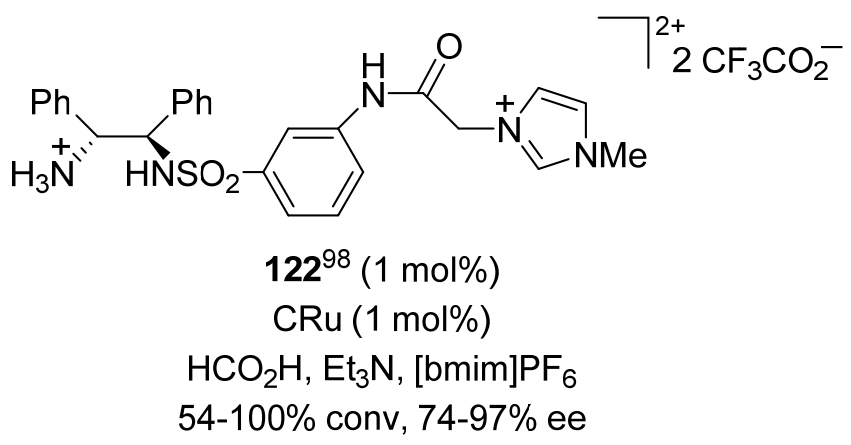

A micromesh gas/liquid reactor has been reported to be very effective for the ATH of acetophenone using an aminoindanol pentamethylindium complex as catalyst and isopropanol as the hydrogen source, this methodology being interesting for scaling-up the process. ${ }^{99}$

\section{Supported catalysts}

Some ligands, such as TsDPEN (9) which had shown to be active in ATH were affixed on different supports in order to study their behavior. Among a series of polystyrene (PS)-supported ruthenium catalysts used in the ATH of phenones with formic acid and triethylamine in dichloromethane, the TsDPEN derivative 123 was the most effective one. ${ }^{100}$

In order to work under aqueous conditions a copolymer of polystyrene containing phosphonic acid units $\mathbf{1 2 4}$ has been prepared and used in ATH of several phenones, formic acid and triethylamine in water being the reaction medium. Excellent yields and enantioselectivities were obtained in all cases. ${ }^{101}$

Microspheres made from cross-linked polystyrene bearing diaminosulfonyl functionalities and CRu 125 have been shown to be active in the ATH of acetophenone with sodium formate under aqueous conditions. Interestingly the polymer was reused until four times without losing activity concerning yields and enantioselectivities. ${ }^{102}$ 


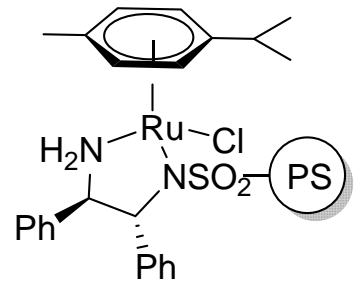

$123^{100}(0.6 \mathrm{~mol} \%)$

$\mathrm{HCO}_{2} \mathrm{H}, \mathrm{Et}_{3} \mathrm{~N}$

26-99\% conv, 86-99\% ee

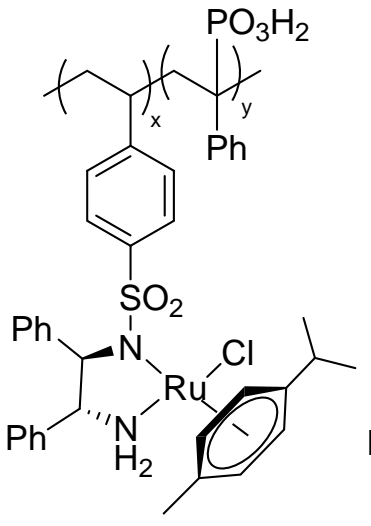

$$
\begin{gathered}
124^{101}(0.15 \mathrm{~mol} \%) \\
\mathrm{y} / \mathrm{x}=3.66-4.08 \\
\mathrm{HCO}_{2} \mathrm{H}, \mathrm{Et}_{3} \mathrm{~N}
\end{gathered}
$$

$40-99 \%$ yield, $95.1-97.9 \%$ ee

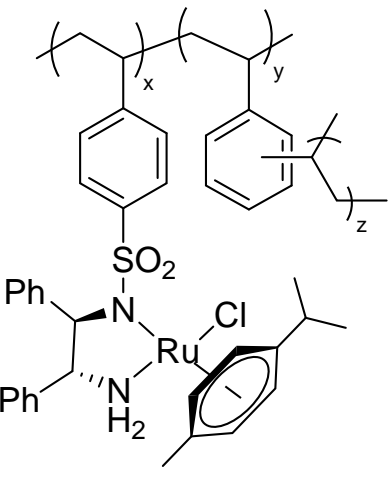

$125^{102}(0.1 \mathrm{~mol} \%)$

$\mathrm{HCO}_{2} \mathrm{Na}, \mathrm{H}_{2} \mathrm{O}$

$58->99 \%$ yield, $91-95 \%$ ee

The soluble polymer 126 containing a TsDPEN (9) unit was used in combination with $\mathrm{BRu}$ for the $\mathrm{ATH}$ of aromatic and heterocyclic ketones with formic acid and triethylamine as the reaction mixture, so variable conversions but excellent enantioselectivities were achieved. ${ }^{103}$ The three polymer-supported diamine derivatives $\mathbf{1 2 7},{ }^{104} \mathbf{1 2 8}{ }^{105}$ and $\mathbf{1 2 9}^{106}$ were effective with CRu in the ATH of aromatic, heterocyclic and ferrocenyl ketones using in all cases sodium formate under aqueous conditions. Results were generally very good in terms of yields and enantioselectivities.

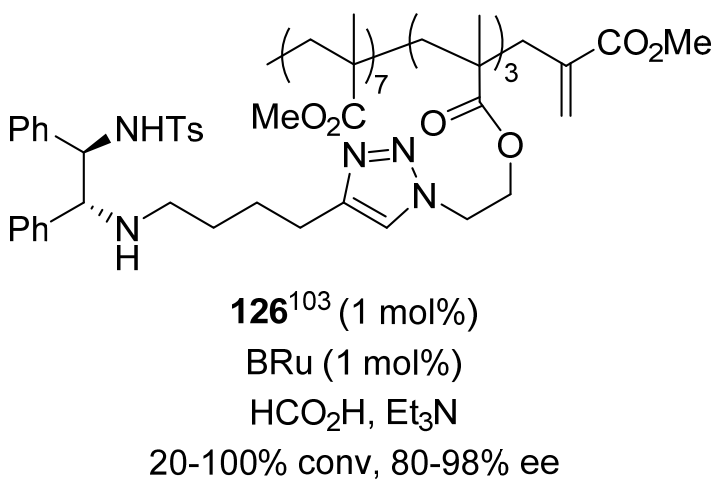




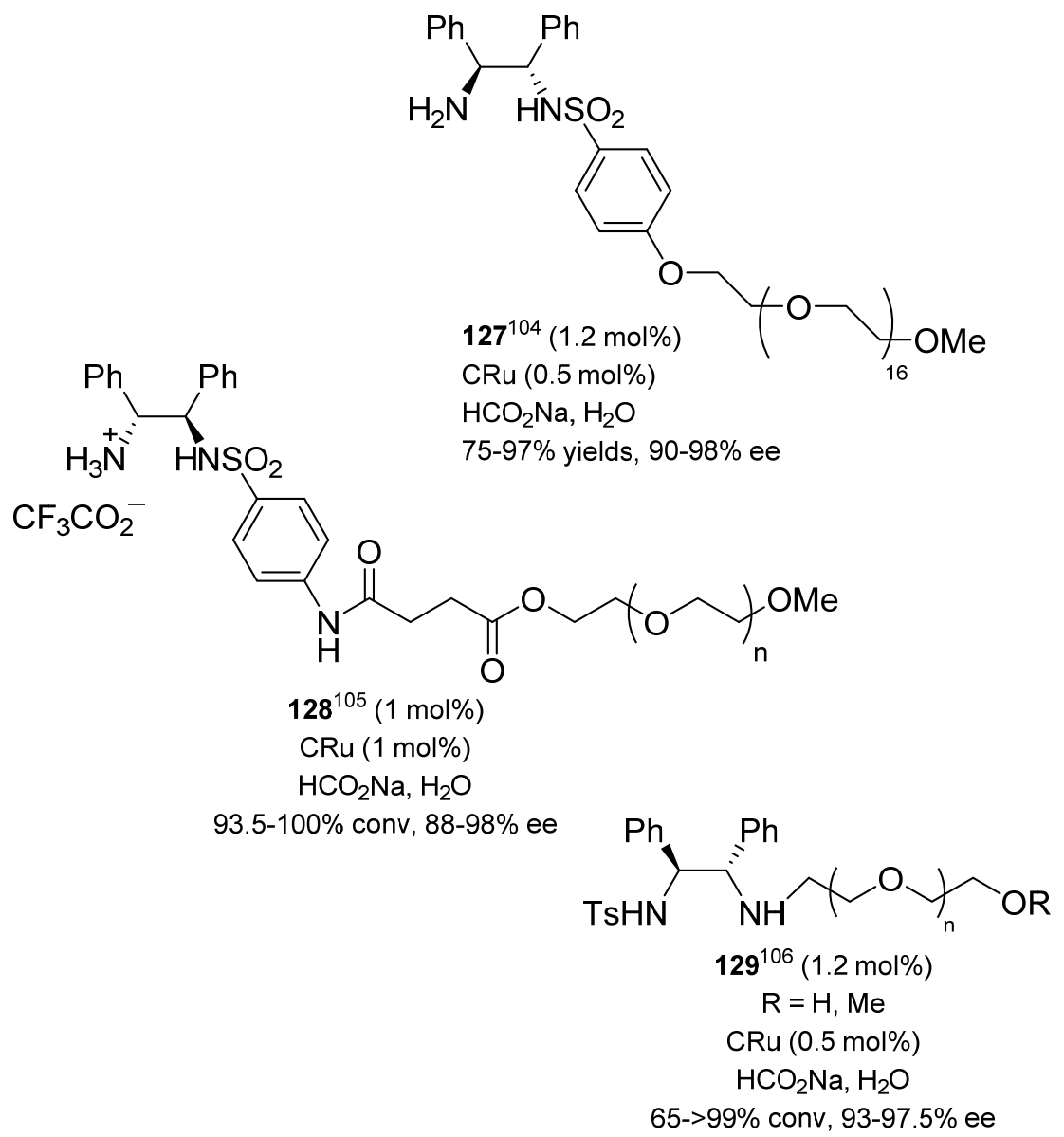

The rhodium-supported polymer 130 derived from polyethylene glycol (PEG) was efficiently used in the ATH of different phenones with sodium formate in water, giving the expected alcohols with excellent results, even after three cycles without losing activity. ${ }^{107 a} \mathrm{~A}$ chiral monosulfonyl 1,2-diamine containing a long aliphatic chain was successfully used for the rhodium-catalyzed ATH of aromatic ketones. ${ }^{107 \mathrm{~b}}$

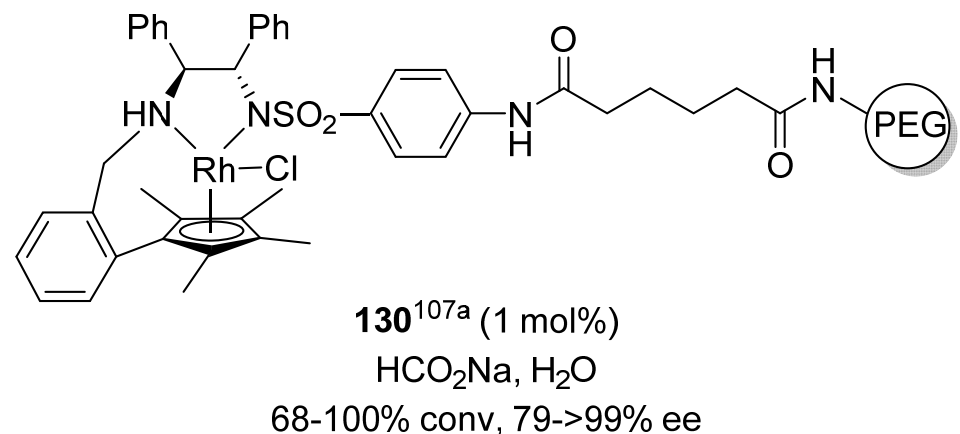

The vinyl-derived diamine 131 was copolymerized with 1,4-divinylbenzene (DVB) inside mesosilica to give a material which after treatment with the complex $\left[\mathrm{RhCl}_{2} \mathrm{Cp}^{*}\right]_{2}$ gave an active catalyst in ATH that was recycled until six times without losing any efficiency. Sodium formate in water was the reducing mixture and conversions and enantioselectivities were excellent. ${ }^{108}$ 


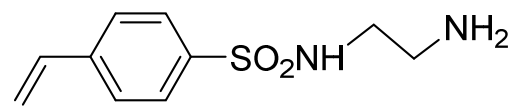

$131^{108}$

$\mathrm{HCO}_{2} \mathrm{Na}, \mathrm{H}_{2} \mathrm{O}$

94-100\% conv, $88-94 \%$ ee

One support that has been used extensively for anchoring ruthenium and rhodium organometallics is silica. Thus, the ruthenium compound $\mathbf{1 3 2}{ }^{109}$ and the rhodium derivative $133^{110}$ were very active in the ATH of phenones using aqueous sodium formate as hydrogen source. Excellent results were obtained even after ten cycles. The catalyst 132 was also immobilized into a magnetic siliceous mesocellular foam material. This heterogeneous catalyst afforded high catalytic activity and ee values in the ATH of aromatic ketones in aqueous sodium formate.
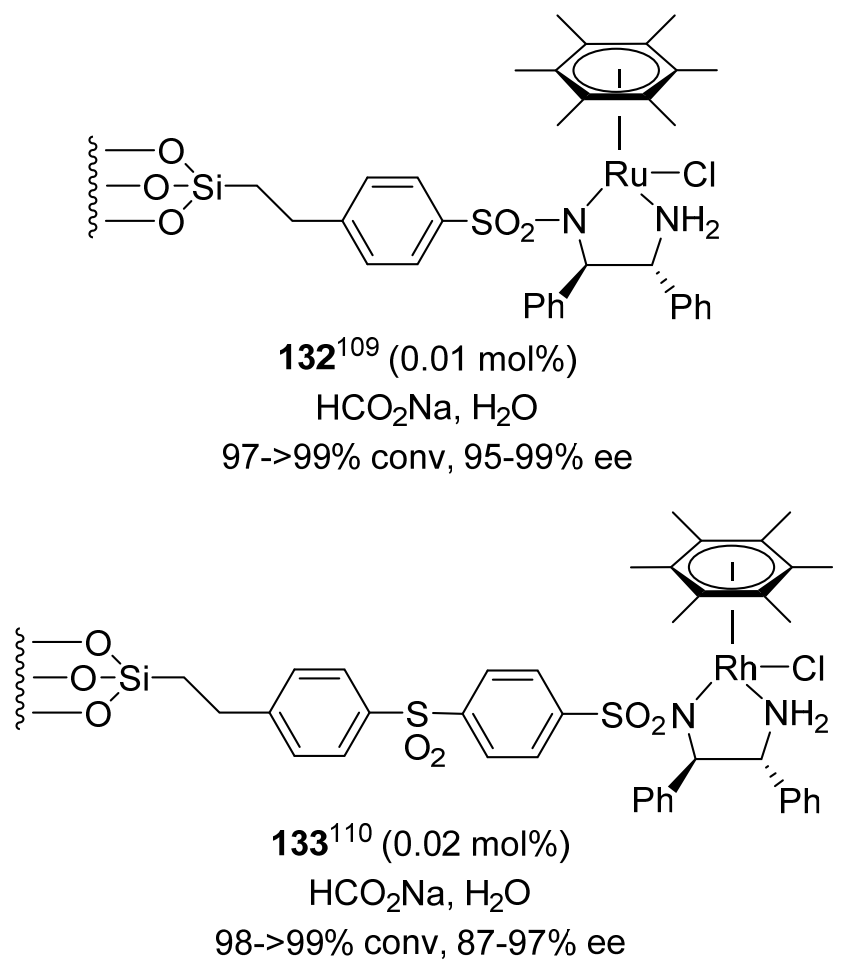

When the catalyst 95b was confined into a nanocage with an amphiphilic microenviroment the activity of this catalyst in ATH of phenones in aqueous sodium formate was enhanced ten times, mainly due to the enhanced diffusion rates of reactants during the catalytic process. ${ }^{111}$

A combination of $[\operatorname{Ir}(\mathrm{COD}) \mathrm{Cl}]_{2}$ and 9-amino epi-cinchonine anchored on an external surface passivated SBA-15 (134) was satisfactorily used in the ATH of phenones with isopropanol and potassium hydroxide as the hydrogen source. ${ }^{112}$ The same support was used to anchor ruthenium catalysts 135, which under the same reaction conditions was moderately efficient in the ATH of phenones. ${ }^{113}$ 
<smiles>N[C@H](c1cccc2ccccc12)C1CN2CCC1C2CCSCCC[Si]12CCC(CO1)O2</smiles>

$134^{112}(10 \mathrm{~mol} \%)$

$[\operatorname{lr}(\mathrm{COD}) \mathrm{Cl}]_{2}(5 \mathrm{~mol} \%)$

i- $\mathrm{PrOH}, \mathrm{KOH}$

$14->99 \%$ conv, $45-79 \%$ ee

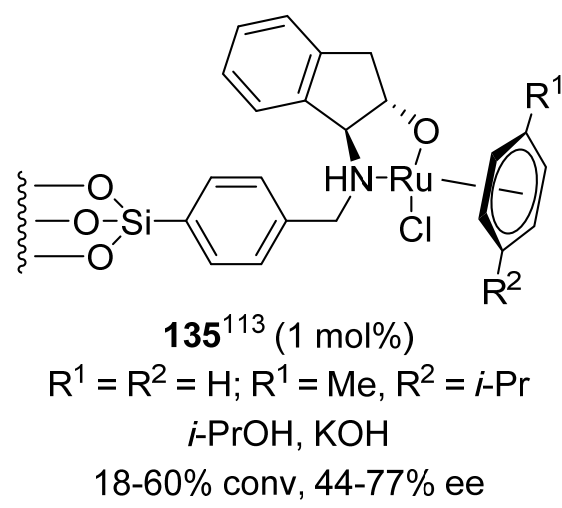

From a family of disulfonamides immobilized on commercially available functionalized silica gel, compounds 136 and $\mathbf{1 3 7}$ were the most active in the ATH of acetophenone using a rhodium compound and sodium formate in water as the reaction medium. ${ }^{114}$

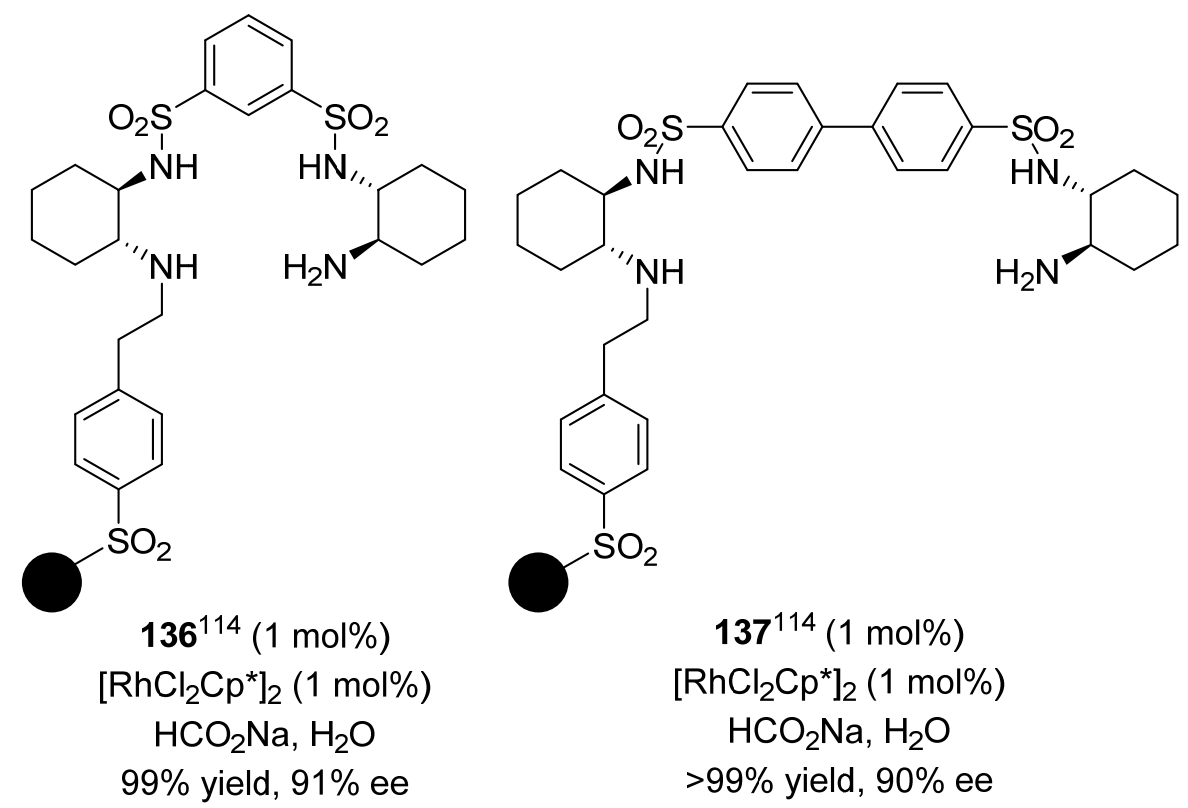

A recoverable organorhodium functionalized polyhedral oligomeric silsesquioxane $\mathbf{1 3 8}$ exhibited excellent catalytic activity in the ATH of aromatic ketones and analogues in aqueous medium with sodium formate as the hydrogen source, the reuse of the catalyst having been tested at least in twelve cycles without affecting its activity. ${ }^{115}$ 

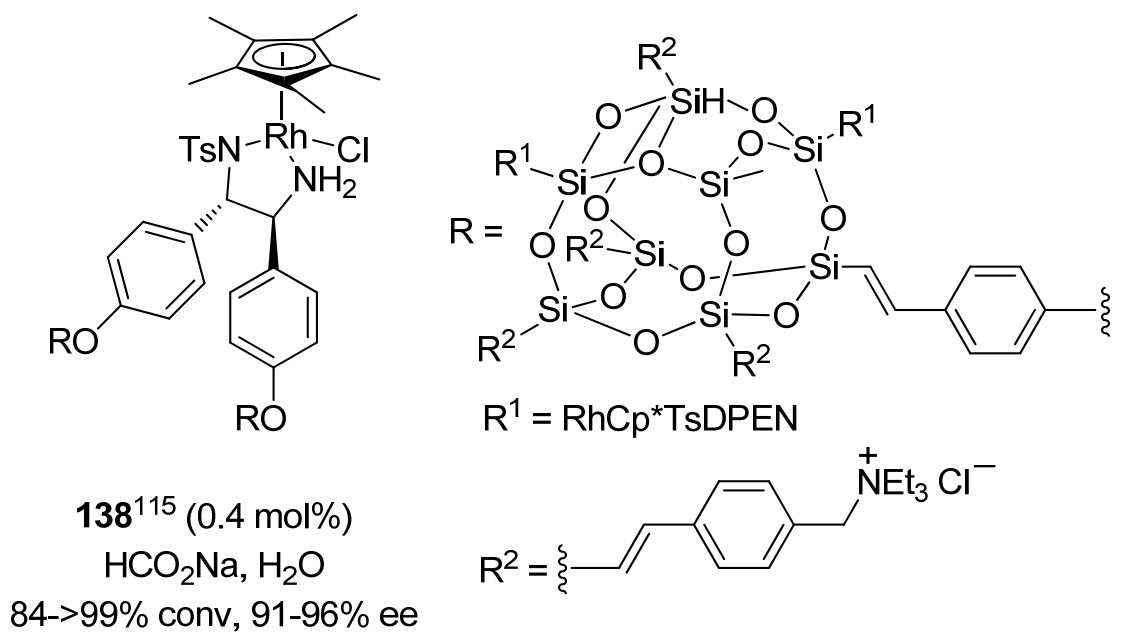

Hybrid core-shell nanospheres containing the unit $\mathbf{1 3 9}$ in the core and poly(methyl acrylate) in the shell were prepared by using a sol-gel process. This material was active in the ATH of phenones with aqueous sodium formate, and was recycled up to four times keeping the same activity. ${ }^{116}$

Magnetically recoverable silica-coated iron oxide $\left(\mathrm{SiO}_{2} @ \mathrm{Fe}_{2} \mathrm{O}_{3}\right)$ nanoparticles were an excellent platform for supporting a rhodium or iridium complex, the whole material 140 being very efficient in the ATH of aromatic ketones with aqueous sodium formate. ${ }^{117}$
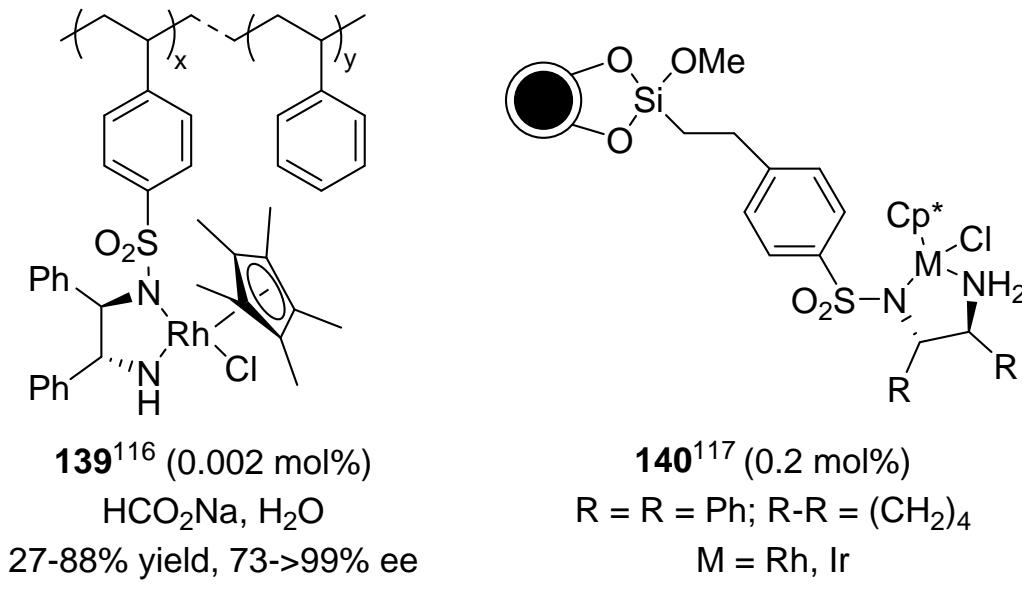

77.7->99.9. conv, 74.2-92.5\% ee

A mechanistic study on the catalytic activity of the complex $\mathbf{7 1}$ in the ATH of acetophenone with isopropanol and potassium tert-butoxide concluded that the real active species are formed by iron(0) nanoparticles, which support molecules of the chiral ligand attached to the surface of the nanoparticles. ${ }^{118}$

Denditric fluorinated ligands of the type 141 were used in combination with $\mathrm{CRu}$ for the ATH of phenones giving excellent results in terms of conversion and enantioselectivity. Depending on the dendrimer generation $(\mathrm{n}=0-2)$ the recycling of the catalyst worked positively for 5-25 cycles without decreasing in the efficiency. ${ }^{119}$ 


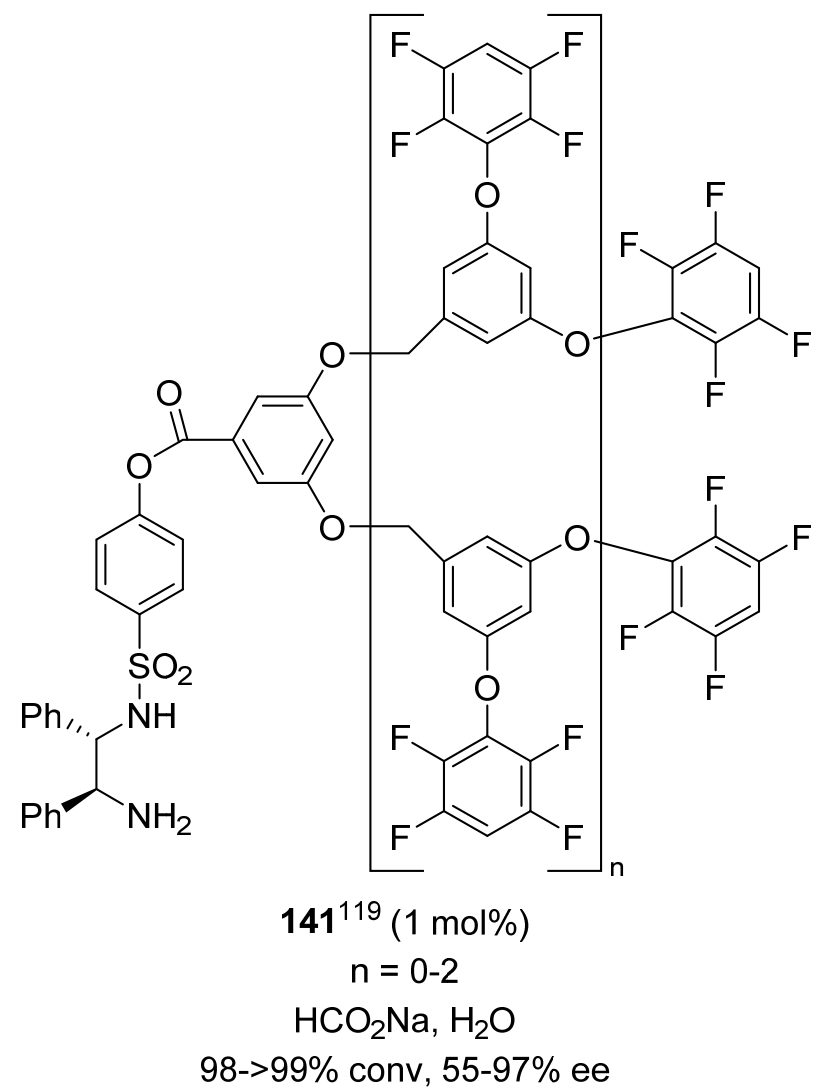

When chitosan was used for anchoring $\mathrm{CRu}$, the corresponding polymeric complex 142 was soluble in methanol, and it was active in the ATH of aromatic ketones with isopropanol as the hydrogen source under homogeneous conditions. ${ }^{120}$

Finally, a chiral rhodium catalyst was immobilized on glass (143) and used in the ATH of aromatic ketones with sodium formate in water, giving excellent conversions and enantioselectivities. ${ }^{121}$

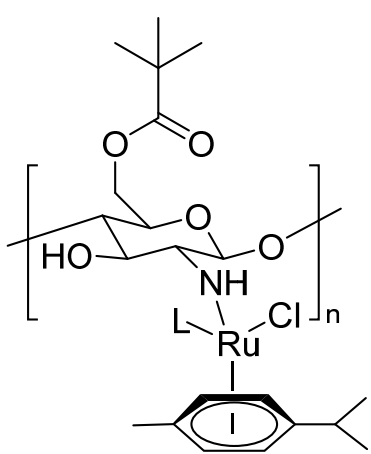

$142^{120}(0.8 \mathrm{~mol} \%)$

$\mathrm{L}=\mathrm{Cl}$, glucosamine

$i$-PrOH, $i-\mathrm{PrONa}$

$22-62 \%$ yield, $28-78 \%$ ee

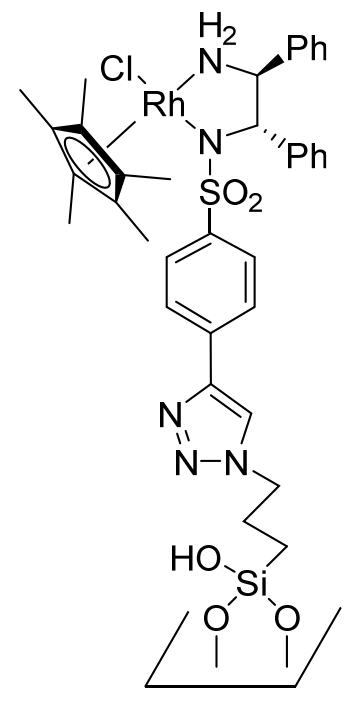

$143^{121}(0.16 \mathrm{~mol} \%)$

$\mathrm{HCO}_{2} \mathrm{Na}, \mathrm{H}_{2} \mathrm{O}$

$84-99 \%$ conv, $80-94 \%$ ee 


\section{DKR processes}

Although a kinetic resolution was applied to substituted flavones, ${ }^{122}$ since this process can give a maximum of $50 \%$ yield of each epimer, the most studied reaction of this type is the dynamic kinetic resolution (DKR), in which one only enantiomer can be achieved starting from a racemic material.

The CRu-catalyzed DKR of $\alpha$-acyl substituted tetralones 144 in the presence of TsDPEN (9) as chiral ligand, formic acid and triethylamine afforded the corresponding hydroxyketones syn-145 with very good results (Scheme 18). ${ }^{123}$

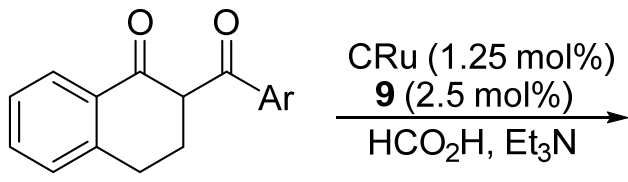

144<smiles>O=C(Br)C1CCc2ccccc2[C@H]1O</smiles>

145

$67-85 \%$ yield, $93->99 \%$ ee 92:8->99:1 dr

Scheme 18. DKR of tetralones $144 .^{123}$

$\alpha$-Keto esters 146 were transformed into the chiral substituted lactones using $\mathrm{CRu}$ and the ligand 147, and the formic acid/triethylamine combination. In this case, the in situ spontaneous cyclization of the hydroxyl esters intermediates afforded directly the final lactones 148 with very good levels of yields and enantioselectivities, the diastereoselection being $>20: 1$ in all cases (Scheme 19). ${ }^{124}$<smiles>CCOC(=O)C(=O)C(Br)C(C(=O)OCC)C(=O)OCC</smiles>

146

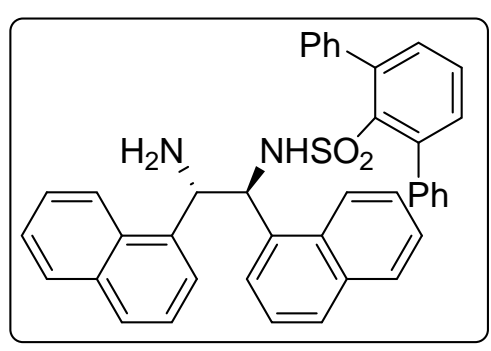

147<smiles>CCOC(=O)[C@H]1OC(=O)[C@H](C(C)=O)[C@H]1Br</smiles>

148

$82-94 \%$ yield, $78-93 \%$ ee

Scheme 19. Preparation of lactones 148 by DKR. ${ }^{124}$

$\alpha$-Alkoxy $\beta$-keto esters 149 were submitted to the DKR conditions shown above, using the catalyst 150, to yield the corresponding syn-diols 151 (Scheme 20). ${ }^{125}$ 


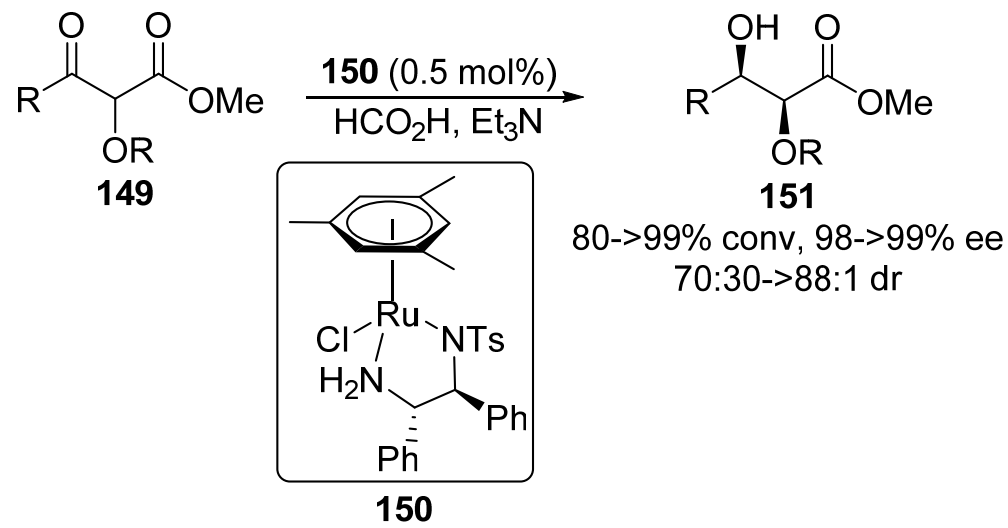

Scheme 20. DKR of $\beta$-keto esters $149 .{ }^{125}$

In the case of $\alpha$-hydroxy $\beta$-keto phosphonates 152 the application of the same methodology achieved the ATH of the keto group yielding the corresponding syn-diol derivatives 153 in general with excellent results in terms of yields, enantio- and diastereoselectivities (Scheme 21). ${ }^{126}$

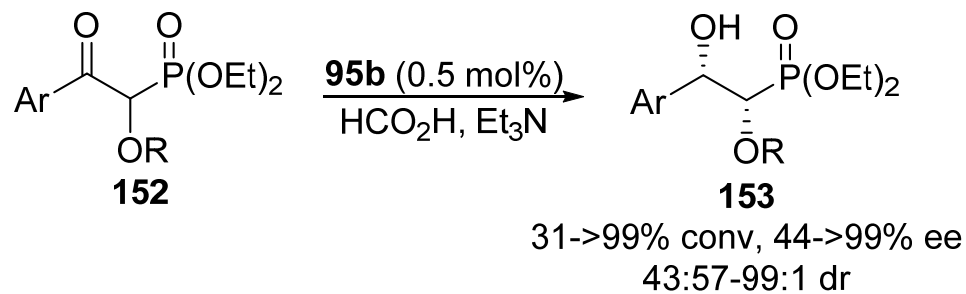

Scheme 21. Diol derivatives 153 prepared. ${ }^{126}$

Other $\beta$-keto esters bearing a protected amino group at the $\alpha$-position 154 were submitted to DKR combined with an ATH using BRu and the ligand 155 with sodium formate in aqueous conditions. The corresponding $\beta$-hydroxy $\alpha$-amino esters anti-156 were obtained with excellent results. It is remarkable that the reaction also worked for compounds having aliphatic substituents at the keto group with similar results than for aromatic substrates (Scheme 22). ${ }^{127}$<smiles>[R]C(N)C([R])C(=O)OCC</smiles>

154

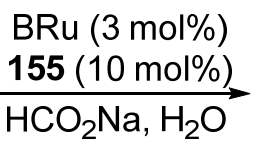<smiles>OC(NCc1ccccc1)C(Br)c1ccccc1</smiles>

155<smiles>[R]C(N)C([R])C(=O)OCC</smiles>

156

$68-85 \%, 78-96 \%$ ee

$7: 1-23: 1 \mathrm{dr}$

Scheme 22. Functionalized esters 156 prepared. ${ }^{127}$

The regioisomeric $\alpha$-hydroxy $\beta$-amino esters were obtained using $\mathrm{CRu}$ and the fluorinated ligand $\mathbf{1 5 8}$ in the presence of the formic acid/triethylamine combination, 
starting from compounds 157, so the corresponding anti-products 159 were isolated with good results (Scheme 23). ${ }^{128}$

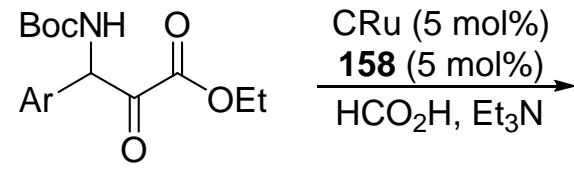

157<smiles>N[C@@H](c1ccccc1)[C@H](N)c1ccccc1</smiles><smiles>CCOC(=O)[C@H](O)[C@H]([Al])NC(=O)OC</smiles>

159 $68-96 \%$ yield, $24-98 \%$ ee $>20: 1 \mathrm{dr}$

Scheme 23. Functionalized esters 159 prepared. ${ }^{128}$

For $\beta$-keto amides 160, the complex formed by reaction of $\mathrm{CRu}$ and the ligand 158 gave excellent results in the DKR/ATH giving the corresponding syn-compounds 161 (Scheme 24). ${ }^{129}$<smiles>[R]NC(=O)C([R20])C([R])=O</smiles>

160

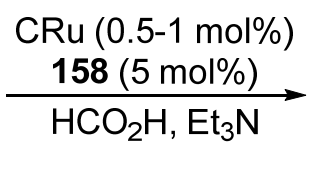<smiles>[R]NC(=O)C([R])O</smiles>

161

Scheme 24. Preparation of compounds $\mathbf{1 6 1} .^{129}$

Another type of $\beta$-keto amides are compounds 162, which by treatment with formic acid and triethylamine under catalysis by the complex 163 gave compounds 164 with excellent results (Scheme 25). ${ }^{130}$
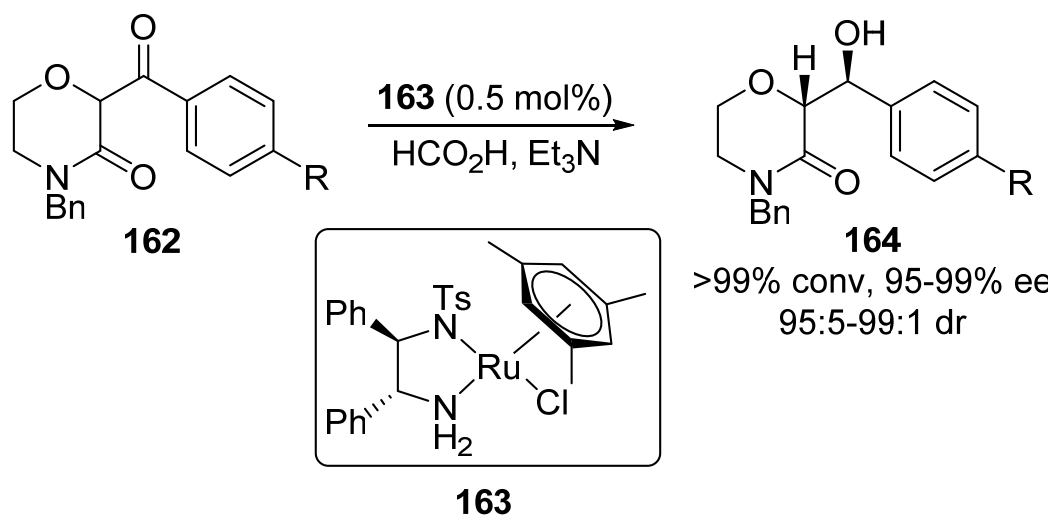

$>99 \%$ conv, $95-99 \%$ ee 95:5-99:1 dr

Scheme 25. Preparation of compounds $164 .^{130}$

The same catalyst 163 was successfully used in the transformation of $\alpha$-sulfonyl aldehydes 165 into the corresponding alcohols 166 in a process that used formic acid and triethylamine as the reducing mixture. Interestingly, the reaction worked for both aromatic and aliphatic substrates (Scheme 26). ${ }^{131}$ 


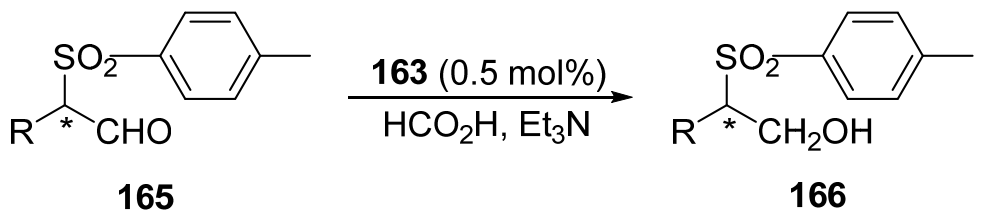

$62-92 \%$ yield, $59-90 \%$ ee

Scheme 26. Preparation of $\beta$-hydroxy sulfones $166 .^{131}$

The DKR of $\beta$-keto sulfones via an ATH reaction catalyzed by the complex 163 was very efficient with formic acid and triethylamine as the reaction medium, so the starting materials 167 gave the anti-products 168 (Scheme 27). ${ }^{132}$<smiles>[R]C(=O)C([R])S(=O)(=O)OCCOCCN</smiles>

167<smiles>[R]C(O)C([R])[Sb](=O)(=O)O</smiles>

168

$87-96 \%$ yield, $57->99 \%$ ee

51-49->99:1 dr

Scheme 27. $\beta$-Hydroxy sulfones 168 prepared. ${ }^{132}$

\section{Water as solvent}

Although water was used in many ATH reactions already cited in previous sections, especially when sodium formate was used as the hydrogen source, ${ }^{133}$ in this section reactions involving water soluble substrates and/or catalysts, or ionic ligands will be considered. $^{134}$

Modular amino alcohols 169 were used in the aqueous ATH of acetophenone with CRu as the organometallic catalyst and sodium formate as the hydrogen source. Surprisingly, a negative effect in conversion was observed with both neutral and ionic surfactants. ${ }^{13}$

$$
\begin{aligned}
& \mathrm{R}^{2}=\mathrm{H}, 4-\mathrm{Ph}, 4-\mathrm{F}_{3} \mathrm{C}, 4-\mathrm{F} \\
& \mathrm{CRu}(1 \mathrm{~mol} \%) \\
& 13-94 \% \text { conv, 53-84\% ee }
\end{aligned}
$$

Chiral water soluble ligands $\mathbf{1 7 0},{ }^{136} \mathbf{1 7 1}^{137}$ and $\mathbf{1 7 2}^{138}$ were used in the ATH of phenones with $\mathrm{CRu}$ as the organometallic catalyst, using in all cases aqueous sodium formate as the reducing component. In general, excellent conversions and enantioselectivities were obtained. 

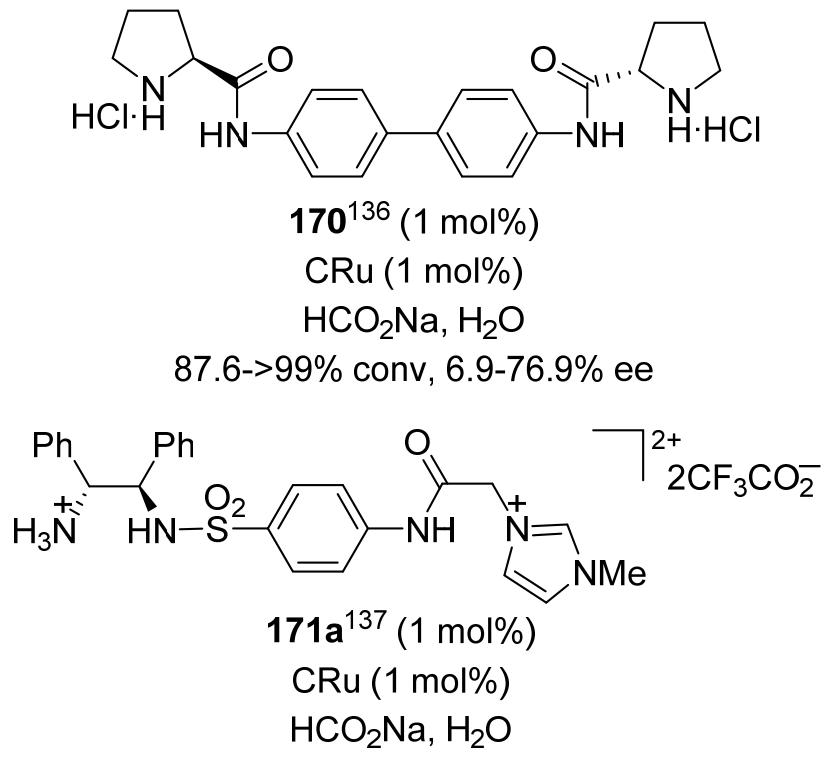

$87.8-100 \%$ conv, $90-98 \%$ ee

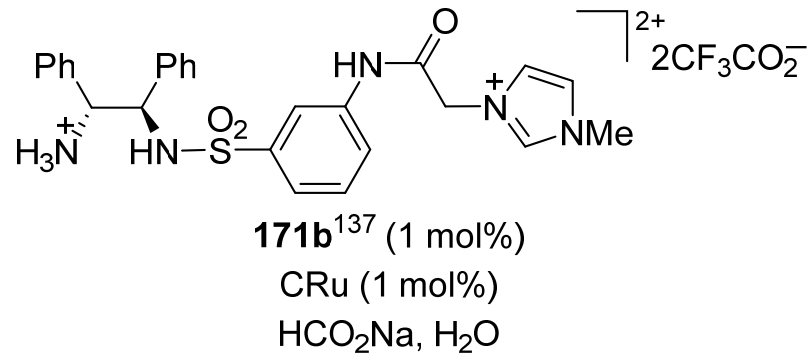

92.4-100\% conv, $94-98 \%$ ee

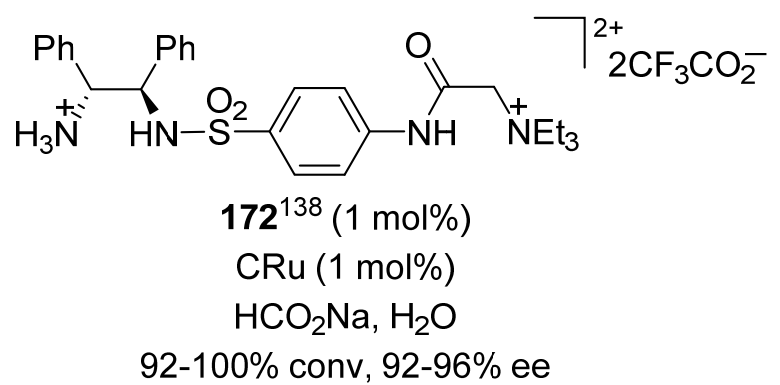

The monocationic ligand $\mathbf{1 7 3}$ was very efficient in the ATH of phenones using a rhodium catalyst and aqueous sodium formate as the reaction mixture. ${ }^{139}$ Also with the same rhodium catalyst, the water soluble triamine ligand 174 was an excellent one for the ATH of several aromatic and heterocyclic ketones in water and with sodium formate as the reductant. ${ }^{140}$ 


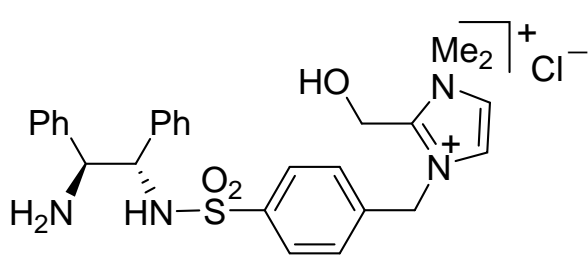

$173^{139}(0.2 \mathrm{~mol} \%)$

$\left[\mathrm{RhCl}_{2} \mathrm{Cp}^{\star}\right]_{2}(0.1 \mathrm{~mol} \%)$

$\mathrm{HCO}_{2} \mathrm{Na}, \mathrm{H}_{2} \mathrm{O}$

$52-100 \%$ conv, $44-98 \%$ ee<smiles>C[13CH2][13C](=O)[O-]</smiles>

$174^{140}(1 \mathrm{~mol} \%)$

$\left[\mathrm{RhCl}_{2} \mathrm{Cp}^{*}\right]_{2}(1 \mathrm{~mol} \%)$

$\mathrm{HCO}_{2} \mathrm{Na}, \mathrm{H}_{2} \mathrm{O}$

90-99\% conv, 73->99\% ee

The ATH of aromatic ketones was carried out satisfactorily in aqueous medium with the same rhodium catalyst and the ligand $\mathbf{1 7 5}$ with low catalyst loading and sodium formate as the hydrogen source, giving the expected alcohols in general with high yields and enantioselectivities. $^{141}$

Specially active in aqueous medium is the bifunctionalized catalyst $\mathbf{1 7 6}$ formed from flower-like mesoporous silica and the rhodium complex generated from $\left[\mathrm{RhCl}_{2} \mathrm{Cp}^{*}\right]_{2}$ and a TsDPEN fragment, and used in the ATH of different phenones with sodium formate as the reducing agent. ${ }^{142}$

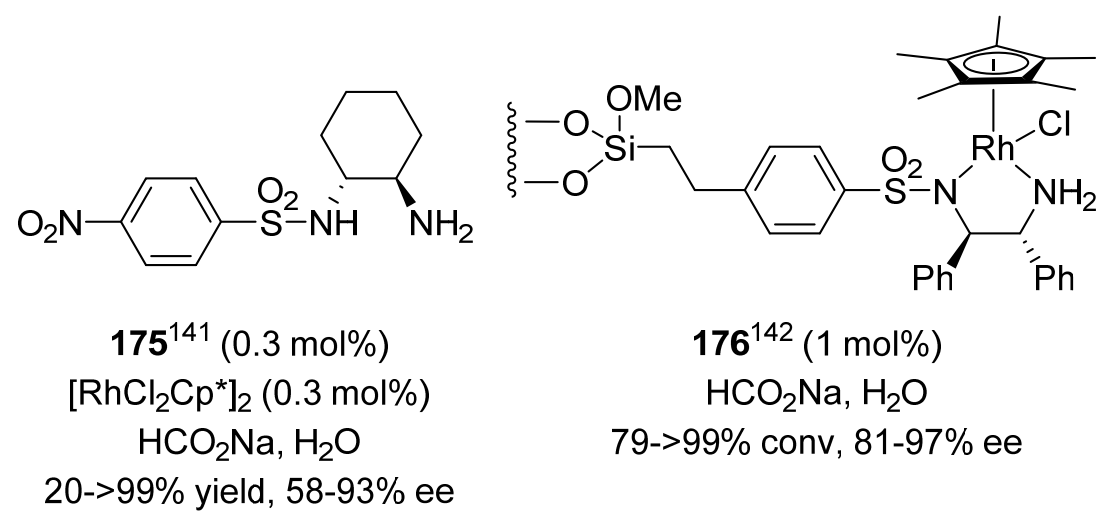

The two polymeric ionic ligands $177^{143}$ and $\mathbf{1 7 8}^{144}$ with $\mathrm{CRu}$ as metal complex were successfully used in the ATH of aromatic ketones in water and with sodium formate as the hydrogen source. 


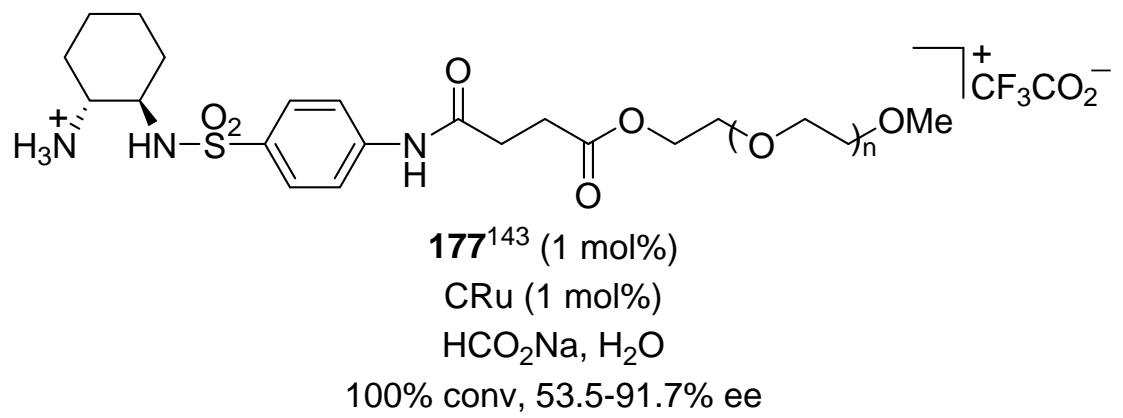

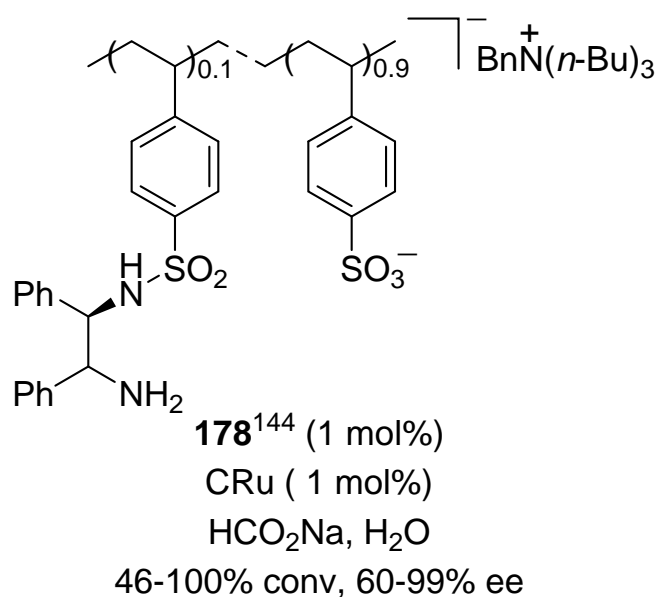

The polymeric complex 179 was very efficient in the ATH of aromatic ketones in pure water and with sodium formate. This amphiphilic block polypeptide based system operates under mild conditions giving very high conversions and enantioselectivities, as well as high level of recyclability. ${ }^{14}$

The use of surfactants for the aqueous ATH has been explored with $\alpha$-keto esters. Thus, dodecyltrimethylammonium bromide (DTAB) showed to be one of the most efficient promoters for the $\mathrm{CRu}$-catalyzed ATH of $\alpha$-keto esters in the presence of the ligand $\mathbf{1 8 0}$ and sodium formate in water. ${ }^{146}$ The surfactant acceleration can also be achieved using an anionic ligand attached to a ruthenium (181) or rhodium (182) complex and cetyltrimethylammonium bromide, so the ATH of a series of aromatic and heterocyclic ketones worked nicely with sodium formate and water. ${ }^{147}$

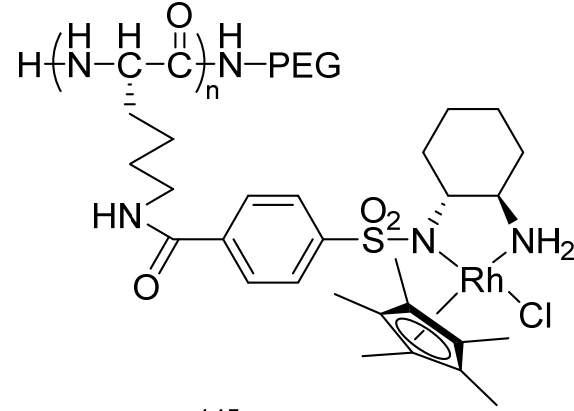

$179^{145}(1 \mathrm{~mol} \%)$

$\mathrm{HCO}_{2} \mathrm{Na}, \mathrm{H}_{2} \mathrm{O}$

74-100\% conv, $90-95 \%$ ee

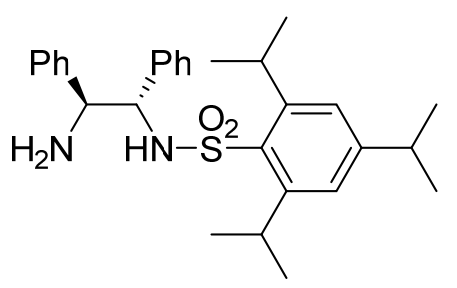

$180^{146}(1 \mathrm{~mol} \%)$

CRu (1 mol\%)

$\mathrm{HCO}_{2} \mathrm{Na}, \mathrm{H}_{2} \mathrm{O}$

50-100\% conv, 33.0-91.1\% ee 

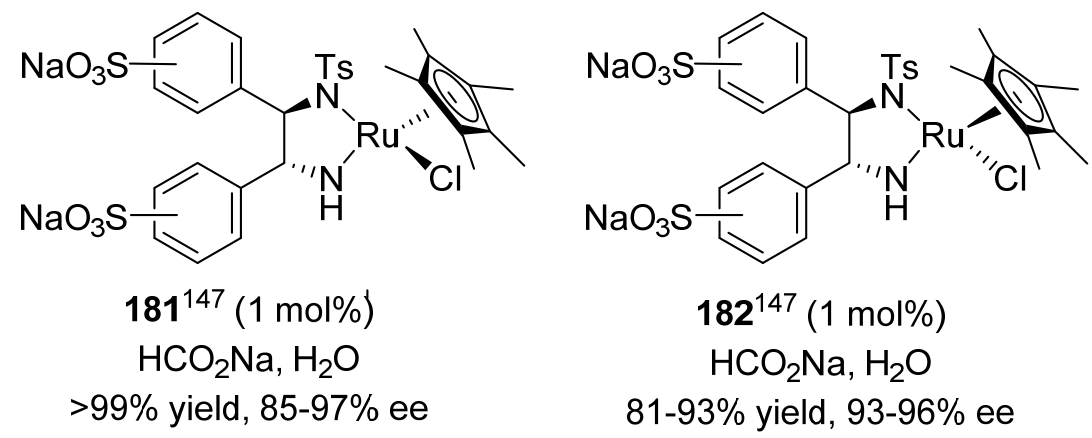

An emulsion promoted by tetra- $n$-butylammonium iodide (TBAI), working in a biphasic dichloromethane/water system, was very efficient for the ATH of phenones with the in situ generated catalyst from CRu and TsDPEN (9) giving variable yields (51-99\%) and enantioselectivities (48-98\% ee). ${ }^{148}$ Another application of the emulsion technology was efficiently used for the ATH of $\alpha$-amido $\beta$-keto esters through a DKR with BRu and $(1 S, 2 S)$-2-(benzylamino)-1,2-diphenylethanol as ligand and the formic acid/triethylamine combination in water. ${ }^{149}$ Finally, a surface molecularly imprinted ruthenium complex catalyst was used efficiently for the ATH of aromatic and heterocyclic ketones in water and using sodium formate as reducing agent, so the corresponding alcohols were isolated with $57-99 \%$ ee values. ${ }^{150}$

\section{Mechanisms and calculations}

Different kinetic results were obtained depending on the rhodium complexes used in the ATH of ketones. Whereas pseudo-first order dependence on the substrate was observed for thioamide ligands, a pseudo-zero order resulted from hydroxamic acid ones, ${ }^{151}$ and a first order dependence was determined for the rhodium anchored to a polymer. ${ }^{152}$

A series of complexes obtained from different chiral 1,2-amino alcohols and ruthenium compounds of the type $\left[\mathrm{RuCl}_{2} \text { (arene) }\right]_{2}$ was submitted to the ATH of acetophenones, and evaluated using high-throughput experiments. A genetic algorithm was applied to this library in order to adjust the parameters of the algorithm for obtaining a maximum of the best catalysts within a minimal number of generations. ${ }^{153}$

Several techniques, such as kinetic measurements, isotopic effects, IR and NMR probing, as well as DFT modeling and X-ray structure analysis, have been used to study the mechanism of the ATH of acetophenone with the ruthenium complexes $183^{154}$ and $\mathbf{1 8 4}{ }^{155}$ using sodium formate and isopropanol, respectively, under basic conditions. A series of intermediates have been isolated and a complete mechanism was proposed to explain the obtained results.

A series of ruthenium complexes were prepared in situ by reaction of $\left[\mathrm{RuCl}_{2} \text { (arene) }\right]_{2}$ and pseudo-dipeptides 185 and used for the ATH of several phenones with isopropanol and sodium isopropoxide as the reducing mixture. From the corresponding kinetic studies it was concluded that a novel bimetallic outer-sphere-type mechanism operated in this process, in which a bifunctional catalyst mediated the hydride transfer. ${ }^{156}$ 


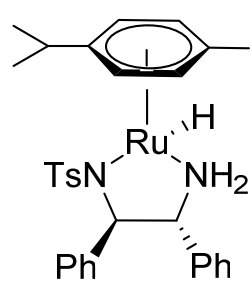

$183^{154}$

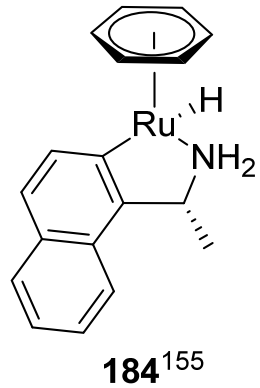<smiles>[R3]C(CO)NC(=O)C([R12])[R1]</smiles>

$185^{156}$

$\mathrm{R}^{1}=\mathrm{Me}, i-\mathrm{Pr}, \mathrm{Ph}$

$\mathrm{R}^{2}=\mathrm{Boc}, \mathrm{Cbz}, \mathrm{Alloc}, \mathrm{CF}_{3} \mathrm{CO}$

$\mathrm{R}^{3}=\mathrm{H}, \mathrm{Ph}$

Computational studies on the use of several complexes of the type 183, but including mesitylene as the arene moiety, in ATH have been performed concluding that in contrast to gas phase, the mentioned reactions proceeded via two steps in solution: (i) enantio-determining hydride transfer, and (ii) proton transfer through the contact ionpair intermediate. ${ }^{157}$ In another previous study, DFT calculations on the ATH of acetophenone with the complex 183 and the formic acid/triethylamine combination afforded transition state geometries with the hydrogen transfer taking place through the standard six-membered cyclic form. ${ }^{158}$

DFT calculations on the ATH of acetophenone with the rhodium complex 186 were performed in order to study the activity of this complex in comparison with the corresponding ruthenium derivative, concluding that the rhodium system gave better results in aqueous conditions in terms of enantioselectivity. ${ }^{159}$

The same level of theoretical calculations was applied to the ligands $\mathbf{1 8 7}$ and $\mathbf{1 8 8}$ in the ATH of acetophenone, in collaboration to $\left[\mathrm{RhCl}_{2} \mathrm{Cp}^{*}\right]_{2}$ and isopropanol/sodium isopropoxide as the reaction mixture. It was found that three factors operate influencing the stereoselectivity: (i) the energy difference between the metal-ligand binding modes, (ii) the energy difference between the intermediate hydrogenated catalyst, and (iii) the existence of a stabilizing $\mathrm{CH}-\pi$ interaction between the $\mathrm{Cp} *$ ligand of the catalyst and the phenyl moiety of the substrate. ${ }^{160}$

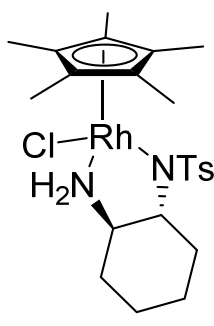

$186^{159}$<smiles>CC(C)[C@H](NC(=O)OCc1ccccc1)C(=O)NO</smiles>

$187^{160}$<smiles>CC(C)C(C)NC(=S)C(NC(=O)OC(C)(C)C)c1ccccc1</smiles>

$188^{160}$

On the basis of a kinetic study a mechanism of activation of the complex 189 (of the type 73) was proposed for the ATH of acetophenone in basic isopropanol. The intermediates were characterized by multinuclear NMR and high-resolution mass spectrometry. ${ }^{161}$ 


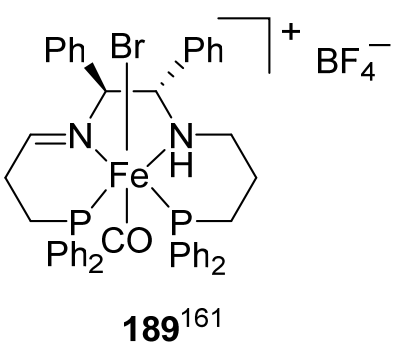

\section{Enzymatic reactions}

An efficient methodology for the ATH of ketones in aqueous isopropanol was achieved with E. coli biocatalysts expressing phenylacetaldehyde reductase from Rhodococcus sp. ST-10 and alcohol dehydrogenase from Leifsonia s.p. S749. ${ }^{162}$

The catalytic activity of artificial metalloenzymes 190 and 191 derived from bovine $\beta$ lactoglobuline for the ATH of aromatic ketones using sodium formate in water was reported. It depends not only on the metal (ruthenium or rhodium) but also on the chelating activity and the length of the lipidic chain. The rhodium cofactor derived from palmitic acid showed to be the most active in terms of enantioselectivity. ${ }^{163}$

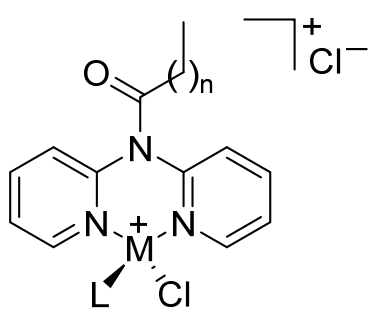

$190^{163}$

$\mathrm{M}=\mathrm{Ru}, \mathrm{Rh} ; \mathrm{n}=8-16$

$\mathrm{L}=p$-cymene (for $\mathrm{Ru}), \mathrm{Cp}$ (for $\mathrm{Rh}$ )

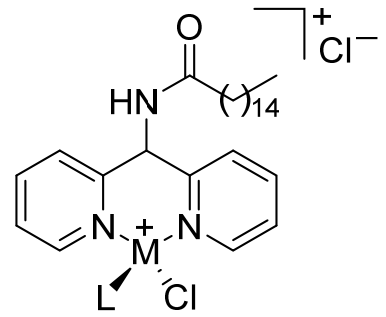

$191^{163}$

$\mathrm{M}=\mathrm{Ru}, \mathrm{Rh} ; \mathrm{n}=8-16$

$\mathrm{L}=p$-cymene (for $\mathrm{Ru}$ ), $\mathrm{Cp}$ (for $\mathrm{Rh}$ )

\section{Applications to total synthesis}

In former sections several examples of the application of ATH methodology to the synthesis of different functionalities has been described. Here we focus our attention to the application of this technology to the total synthesis of interesting organic molecules, also at the industrial scale. ${ }^{164}$

$(R)-(-)$-Tembamide (195) and (R)-(-)-aegeline (196), $\alpha$ - and $\beta$-adrenergic blockers and agonists in the treatment of cardiovascular diseases, were efficiently produced by ATH of the corresponding ketones 192 and 193, respectively, with a monosulfonamide rhodium complex resulting from the combination of $\mathrm{CRu}$ and chiral ligand 194, using isopropanol as the reducing reagent, and potassium hydroxide as the base. Reductions took place in high yields in a total enantioselective fashion (Scheme 28). ${ }^{165}$ 


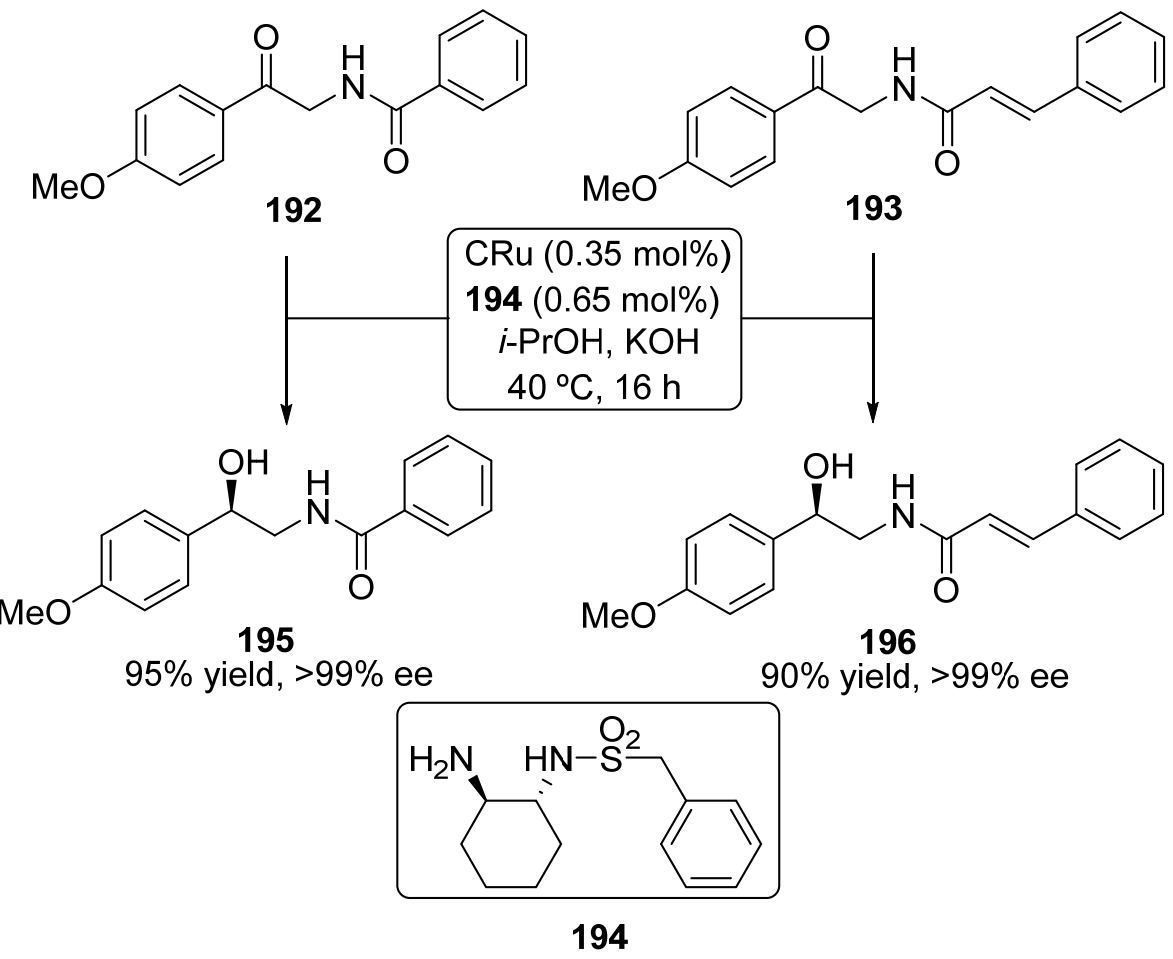

Scheme 28. Synthesis of (-)-tembamide (195) and (-)-aegeline (196). ${ }^{165}$

An ATH of the keto ester 197 was used in collaboration with chiral ruthenium catalyst 198 in basic isopropanol to install the sterocenter at the C-6 position in one step of the total synthesis of $(+)$-centrolobine (200). The corresponding hydroxyl ester 199 was obtained in excellent yield and good enantioselectivity (Scheme 29). ${ }^{166}$<smiles>CCOC(=O)CCCC(=O)c1ccc(OC)cc1</smiles>

Scheme 29. Synthesis of $(+)$-centrolobine (200). ${ }^{166}$

A similar strategy was used by the same research group in the total synthesis of diospongins B (203) and A (204) (the first one being a potent agent against osteoporosis) to generate the alcohol functionality at the $\mathrm{C}-4$ position, starting from the tetrahydropyran-4H-2-one 201. In this case, the ATH was totally stereoselective, leading to tetrahydropyran-4-ol 202 in high yield (Scheme 30). ${ }^{167}$ 


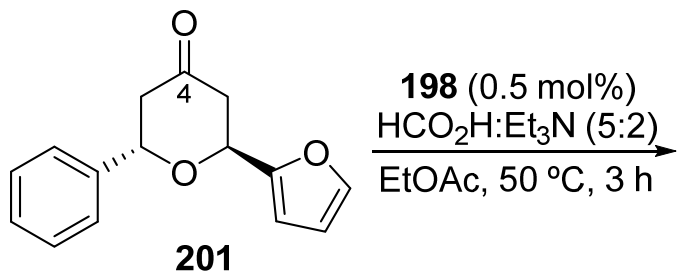
201<smiles>O=[R]OC1C[C@H](O)C[C@@H](c2ccco2)O1</smiles>

$96 \%$ yield, $>99 \%$ de<smiles>CCCCCCCC#Cc1cccc(C(=O)C[C@@H]2C[C@H](O)C[C@H](c3ccccc3)O2)c1</smiles>

204<smiles>O=C(CC1C[C@H](O)C[C@H](c2ccccc2)O1)c1ccccc1</smiles>

203

Scheme 30. Synthesis of diospongins B (203) and A (204). ${ }^{167}$

The key step in one asymmetric synthesis of antidepressant (S)-duloxetine (207) was the formation of the stereocenter bearing the alcohol functionality by ATH with $\mathrm{CRu}$ as catalyst and TsDPEN (9) as chiral ligand in the presence of formic acid and triethylamine as the hydrogen source in methanol. The process took place in high chemical yield and good enantioselectivity to transform ketone 205 into alcohol 206 (Scheme 31). ${ }^{168}$<smiles>CN(C)CCC(=O)c1cccs1</smiles>

205

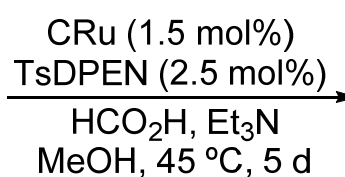

$\mathrm{MeOH}, 45^{\circ} \mathrm{C}, 5 \mathrm{~d}$<smiles>CNCCC(Oc1cccc2ccccc12)c1cccs1</smiles>

207<smiles>CN(C)CC[C@H](O)c1cccs1</smiles>

$84 \%$ yield, $94 \%$ ee

Scheme 31. Synthesis of (S)-duloxetine (207). ${ }^{168}$

A highly enantioselective synthesis of 1,3-aminoalcohols 211 and 213 was achieved also through an ATH of the ketones 208 and 209, respectively, using ruthenium and rhodium catalysts in the presence of chiral amino acid based ligands. Optimal results for alcohol 211, precursor of $(S)$-duloxetine (207), were found when CRu was combined with ligand 210. In the case of alcohol 213, which is the precursor of antidepressant $(R)$ fluoxetine (214), the highest yield and enantioselectivity were found with the combination of $\left[\mathrm{RhCp}^{*} \mathrm{Cl}_{2}\right]_{2}$ and chiral ligand 212 (Scheme 32). ${ }^{169}$ 

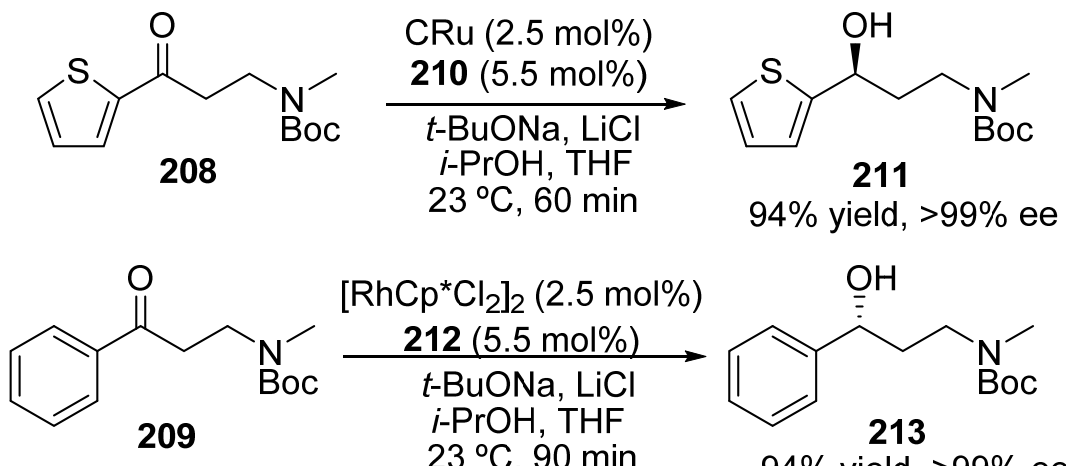

$\left[\mathrm{RhCp}^{*} \mathrm{Cl}_{2}\right]_{2}(2.5 \mathrm{~mol} \%)$<smiles>CN(C)CC[C@@H](O)c1ccccc1</smiles>
$i-\mathrm{PrOH}, \mathrm{THF}$ $23^{\circ} \mathrm{C}, 90 \mathrm{~min}$<smiles>CC(C)(C)OC(=O)NC(C(=O)NCC(O)c1ccccc1)C1CCCC1</smiles>

210<smiles>CC(O)CNC(=O)C(C)NC(=O)OCc1ccccc1</smiles>
$94 \%$ yield, $>99 \%$ ee

212<smiles>CNCC[C@H](Oc1ccc(C(F)(F)F)cc1)c1ccccc1</smiles>

Scheme 32. Synthesis of $(R)$-fluoxetine (214). ${ }^{169}$

A rhodium-catalyzed ATH of aryl bromomethyl ketone 215 with sodium formate in polyethylene glycol and water as the reaction medium, in the presence of polymersupported diamine derivative 127, allowed the enantioselective formation of bromohydrine 216, a direct precursor after four steps of the $\beta_{2}$-adrenoreceptor $(R)$ salmeterol (217) (Scheme 33). ${ }^{170}$

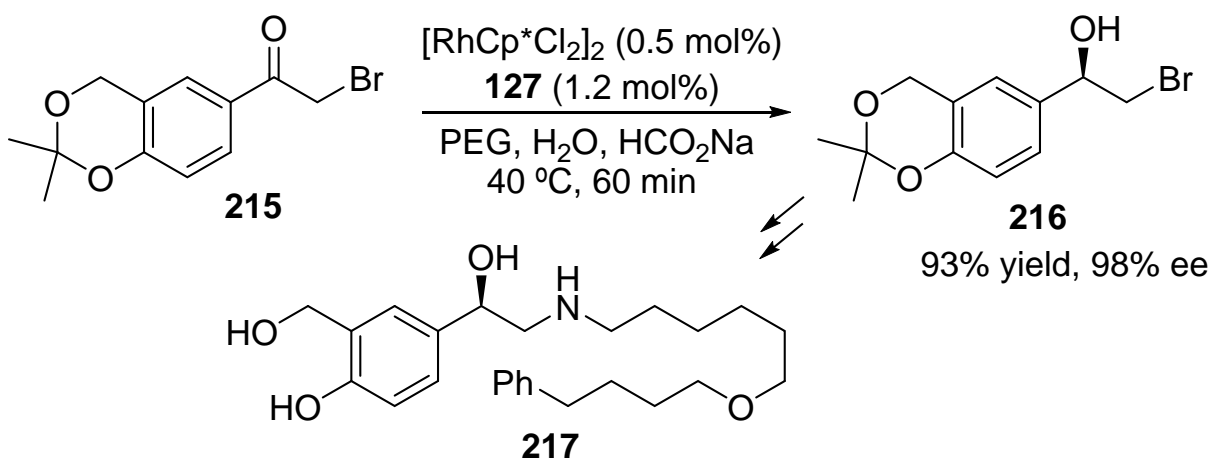

Scheme 33. Synthesis of $(R)$-salmeterol (217). ${ }^{170}$

A ruthenium catalyzed ATH with complex 198 in isopropanol was a key step in the synthesis of the potent histone deacetylase inhibitor FK228 (220). Importantly, the reduction of aliphatic ketone $\mathbf{2 1 8}$ with this combination led to propargylic alcohol $\mathbf{2 1 9}$ in good yield and $98 \%$ ee. Another key setp in the synthesis of target molecule 220 was the formation of the lactone ring under Mitsunobu reaction conditions with inversion of the configuration at the carbon atom bearing the alcohol functionality (Scheme 34). ${ }^{171}$ 


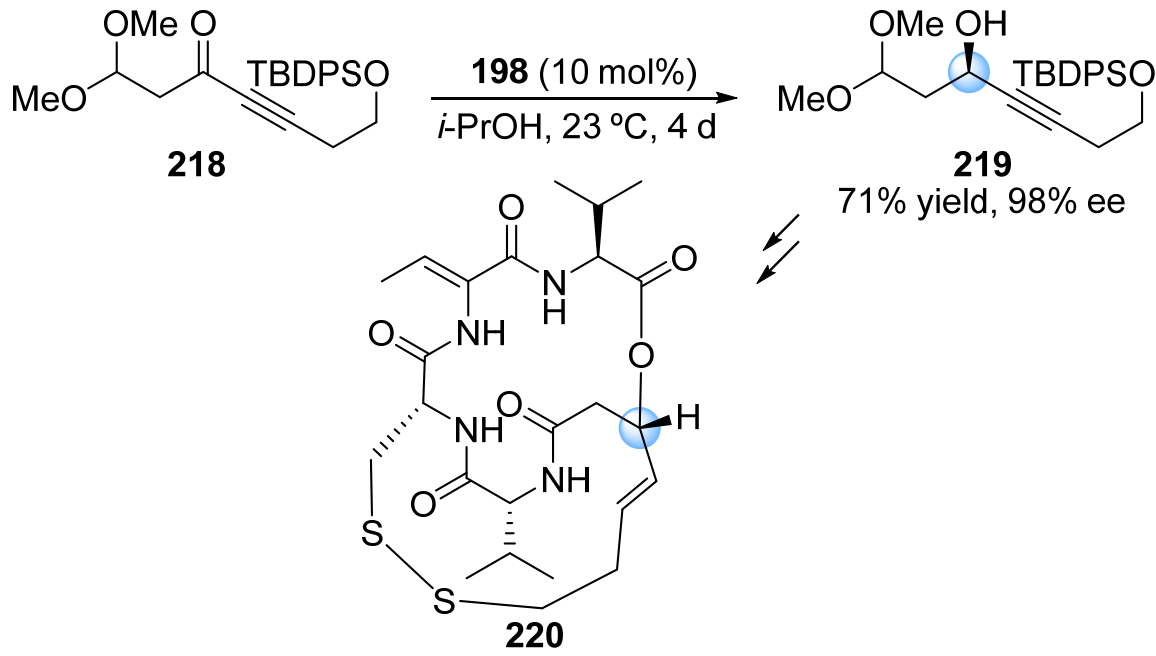

Scheme 34. Synthesis of histone deacetylase inhibitor FK228 (220). ${ }^{171}$

The only stereocentre present in the anti Alzheimer drug Ladostigol (TV3326, 223) was generated by a ruthenium-catalyzed ATH with the CRu-TsDPEN (9) combination of the ketone 221 with aqueous sodium formate. The final transformation of the generated alcohol 222 (obtained in quantitative yield as a single enantiomer) was performed by a $\mathrm{S}_{\mathrm{N}} 2$ reaction of the corresponding mesylate with propargylamine (Scheme 35 ). ${ }^{172}$

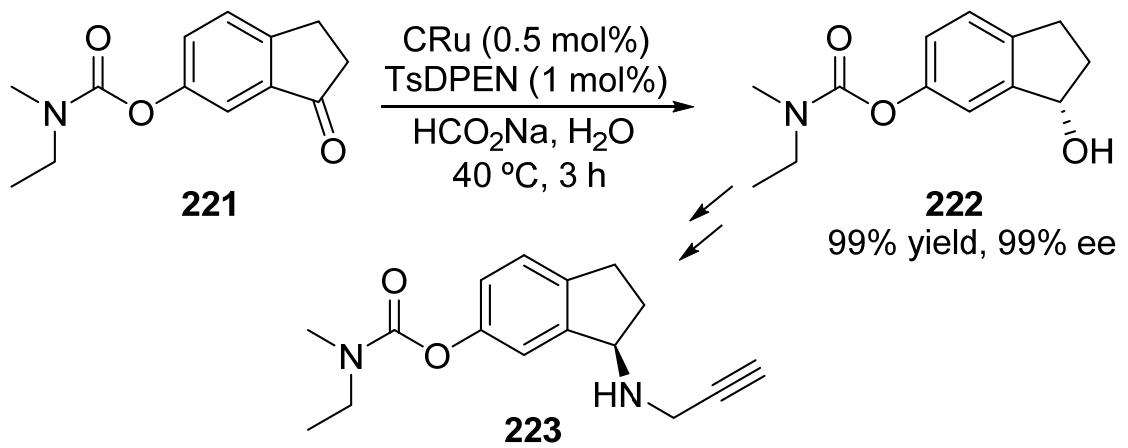

Scheme 35. Synthesis of ladostigol (TV3326, 223). ${ }^{172}$

Tenofovir (227), an antiviral and immunobiologically active compound, and its analogues were also synthesized taking advantage of the ATH to create the stereocentre in the molecule using a ruthenium catalyst and sodium formate as the hydrogen source. In this case the metallic source was the complex BRu and the chiral ligand the pyrrolidinic aminoalcohol 225. The reduction of ketone derivative 224 under the reaction conditions shown on Scheme 36 produced compound 226 in reasonable yield and good enantioselectivity. ${ }^{173}$ 


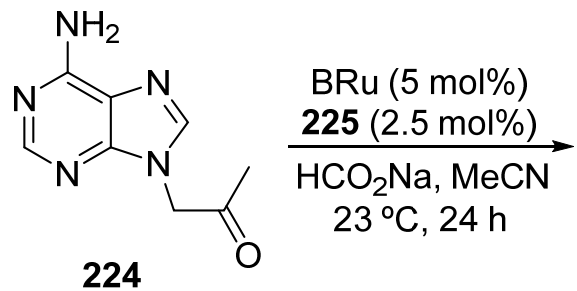<smiles>CC(O)Cn1cnc2c(N)ncnc21</smiles>

$47 \%$ yield, $93 \%$ ee<smiles>OC(c1ccccc1)(c1ccccc1)[C@H]1CC2CCC1N2</smiles>

225<smiles>[R17][X]C(Cn1cnc2c(N)ncnc21)OCP(=O)(O)O</smiles>

Scheme 36. Synthesis of tenofovir (227). ${ }^{173}$

Finally a ruthenium catalyst 198 was successfully used for the formation of the stereocentre of eslicarbazepine acetate (230) by an ATH of the ketone precursor 228 (through alcohol 229), using formic acid as a source of hydrogen. It has surprisingly been found that high conversions with good enantiomeric excess were obtained by using a weak anionic ion exchange resin in place of triethylamine or other tertiary amines as base (Scheme 37). ${ }^{174}$<smiles>NC(=O)N1c2ccccc2CC(=O)c2ccccc21</smiles>

228<smiles>CC(=O)OC1Cc2ccccc2N(C(N)=O)c2ccccc21</smiles>

230<smiles>NC(=O)N1c2ccccc2C[C@@H](O)c2ccccc21</smiles>

229

Scheme 37. Synthesis of eslicarbazepine acetate (230). ${ }^{174}$

Other useful applications of the ATH include the total synthesis of (S)-panaxjapyne A, ${ }^{175}(+)$-yashabushitriol, ${ }^{176}$ wortmannilactone $\mathrm{C},{ }^{177}(+)$-aglaiastatin and (-)-aglaroxin $\mathrm{C},{ }^{178}(-)$-goniotrionin, ${ }^{179}$ and huperzin-Q. ${ }^{180}$

\section{Conclusions}


As a general conclusion, the most commonly used organometallic complexes uses as catalysts in ATH are ruthenium derivatives, namely $\mathrm{CRu}$. Concerning chiral ligands, 1,2-diamine derivatives are the most versatile ones, among them TsDPEN being the most useful. In general, the ATH of ketones works properly only for aromatic and heterocyclic ketones, the application to aliphatic ketones being very restricted and working with low results in terms of yields and enantioselectivities. Recently, the use of supported catalysts and ligands allows the easy recycling of the catalyst and the possibility of using this technology for industrial processes. The outstanding development of the ATH in the last few years predicts promising findings in the next future in the field of synthetic organic chemistry, namely in asymmetric catalysis.

\section{Abbreviations}

Alloc: allyloxycarbonyl

ATH: asymmetric transfer hydrogenation

[bmim $^{+}: \quad N$-butyl- $N$-methylimidazolium

Bn: benzyl

Boc: tert-butoxycarbonyl

$\mathrm{BRu}: \quad\left[\mathrm{RuCl}_{2} \text { (benzene) }\right]_{2}$

Bz: benzoyl

cat: catalyst

Cbz: benzyloxycarbonyl

COD: 1,5-cyclooctadiene

COE: cyclooctene

conv: conversion

Cp*: $\quad$ pentamethylcyclopentadienyl

$\mathrm{CRu}: \quad\left[\mathrm{RuCl}_{2}(p \text {-cymene })\right]_{2}$

CTAB: cetyltrimethylammonium bromide

Cy: cyclohexyl

DFT: density functional theory

DKR: dynamic kinetic resolution

DMSO: dimethyl sulfoxide

dr: diastereomeric ratio

DTAB: dodecyltrimethylammonium bromide

DVB: 1,4-divinylbenzene

ee: enantiomeric excess

equiv: equivalent(s)

Et: ethyl

$\mathrm{HRu}: \quad\left[\mathrm{RuCl}_{2}\left(\mathrm{Me}_{6} \mathrm{C}_{6}\right)\right]_{2}$

i-Bu: isobutyl

i-Pr: $\quad$ isopropyl

L: $\quad$ ligand

Me: methyl

MRu: $\quad\left[\mathrm{RuCl}_{2} \text { (mesitylene) }\right]_{2}$

n-Pr: $\quad$ n-propyl

PEG: polyethylene glycol

Ph: phenyl

PS: $\quad$ polystyrene

SBA: Santa Barbara University at California

TBAI: tetrabutylammonium iodide 
t-Bu: $\quad$ tert-butyl

Tf: trifluoromethylsulfonyl

THF: tetrahydrofuran

Ts: $\quad 4$-methylphenylsulfonyl

TsDPEN: $N$-(p-toluenesulfonyl)-1,2-diphenylethylene diamine

\section{Acknowledgements}

We thank the continuous financial support from our Ministerio de Ciencia e Innovación (MICINN (projects CTQ2007-62771/BQU, CTQ2010-20387, CONSOLIDER INGENIO 2010-CDS2007-00006, CTQ2011-24151, CTQ2011-24165), the Ministerio de Economía y Competitividad (MINECO) (projects CTQ2013-43446-P, CTQ201451912-REDC, CTQ2014-53695-P), FEDER, the Generalitat Valenciana (PROMETEO 2009/039, PROMETEOII/2014/017), and the University of Alicante.

\section{Notes and references}

1. Modern Reduction Methods; Andersson, P. G.; Munslow, I. J., Eds.; WileyVCH: Weinheim, Germany, 2008.

2. Hydrogen Transfer Reactions; Hynes, J. T.; Klinman, J. P.; Limbach, H.-H.; Schowen, R. L., Eds.; Wiley-VCH: Weinheim, Germany, 2007; Vols. 1-4.

3. Breuer, M.; Ditrich, K.; Habicher, T.; Hauer, B.; Keßeler, M.; Stürmer, R.; Zelinski, T. Angew. Chem. Int. Ed. 2004, 43, 788-824.

4. (a) Noyori, R.; Hashiguchi, S. Acc. Chem. Res. 1997, 30, 97-102; (b) Palmer, M. J.; Wills, M. Tetrahedron: Asymmetry 1999, 10, 2045-2061; (c) Gladiali, S.; Alberico, E. Chem. Soc. Rev. 2006, 35, 226-236; (d) Samec, J. S. M.; Bäckvall, J.-E.; Andersson, P. G.; Brandt, P. Chem. Soc. Rev. 2006, 35, 237248; (e) Wang, C.; Wu, X.; Xiao, J. Chem. Asian. J. 2008, 3, 1750-1770.

5. Wills, M. In ref 1, pp 271-296.

6. Han, M.-L.; Hu, X.-P.; Huang, J.-D.; Chen, L.-G.; Zheng, Z. Tetrahedron: Asymmetry 2011, 22, 222-225.

7. Guillarme, S.; Nguyen, T. X. M.; Saluzzo, C. Tetrahedron: Asymmetry 2008, $19,1450-1454$.

8. Huynh, K.-D.; Ibrahim, H.; Toffano, M.; Vo-Thanh, G. Tetrahedron: Asymmetry 2010, 21, 1542-1548.

9. Deshpande, S. H.; Kelkar, A. A.; Gonnade, R. G.; Shingote, S. K.; Chaudhari, R. V. Catal. Lett. 2010, 138, 231-238.

10. Lundberg, H.; Adolfsson, H. Tetrahedron Lett. 2011, 52, 2754-2758.

11. Chakka, S. K.; Andersson, P. G.; Maguire, G. E. M.; Kruger, H. G.; Govender, T. Eur. J. Org. Chem. 2010, 972-980.

12. Xu, Z.; Mao, J.; Zhang, Y.; Guo, G.; Zhu, J. Catal. Commun. 2008, 9, 618623.

13. Elalami, M. S. I.; Dahdouh, A. A.; Mansour, A. I.; ElAmrani, M. A.; Suisse, I.; Mortreux, A.; Agbossou-Niedercorn, F. C. R. Chim. 2009, 12, 1253-1258.

14. Heyan, J. J. Chem. Res. 2013, 37, 761-763.

15. Carmona, D.; Viguri, F.; Lamata, M. P.; Ferrer, J.; Bardají, E.; Lahoz, F. J.; García-Orduña, P.; Oro, L. A. Dalton Trans. 2012, 41, 10298-10308.

16. (a) Fujii, A.; Hashiguchi, S.; Uematsu, N.; Ikariya, T.; Noyori, R. J. Am. Chem. Soc. 1996, 118, 2521-2522; (b) Zhou, X.; Wu, X.; Yang, B.; Xiao, J. J. Mol. Catal. A: Chem. 2012, 357, 133-140. 
17. Zhang, B.; Wang, H.; Lin, G.-Q.; Xu, M.-H. Eur. J. Org. Chem. 2011, 42054211.

18. Manville, C. V.; Docherty, G.; Padda, R.; Wills, M. Eur. J. Org. Chem. 2011, 6893-6901.

19. Liu, J.; Wu, Y.; Li, X.; Chan, A. S. C. J. Organomet. Chem. 2008, 693, $2177-$ 2180.

20. Václavíc, J.; Kačer, P.; Kuzma, M.; Červený, L. Molecules 2011, 16, 54605495.

21. Martins, J. E. D.; Contreras Redondo, M. A.; Wills, M. Tetrahedron: Asymmetry 2010, 21, 2258-2264.

22. (a) Martins, J. E. D.; Clarkson, G. J.; Wills, M. Org. Lett. 2009, 11, 847-850;

(b) Soni, R.; Collinson, J.-M.; Clarkson, G. C.; Wills, M. Org. Lett. 2011, 13, 4304-4307; (c) Soni, R.; Cheung, F. K.; Clarkson, G. C.; Martins, J. E. D.; Graham, M. A.; Wills, M. Org. Biomol. Chem. 2011, 9, 3290-3294.

23. Martins, J. E. D.; Morris, D. J.; Tripathi, B.; Wills, M. J. Organomet. Chem. 2008, 693, 3527-3532.

24. Parekh, V.; Ramsden, J. A.; Wills, M. Catal. Sci. Technol. 2012, 2, 406-414.

25. (a) Kičić, A.; Stephan, M.; Mohar, B. Org. Lett. 2013, 15, 1614-1617; (b) Kišić, A.; Stephan, M.; Mohar, B. Adv. Synth. Catal. 2014, 356, 3193-3198.

26. Clay, D. R.; McIntosh, M. C. Tetrahedron Lett. 2012, 53, 1691-1694.

27. Manville, C. V.; Docherty, G.; Padda, R.; Wills, M. Eur. J. Org. Chem. 2011, 6893-6901.

28. Denizalti, S.; Mercan, D.; Şen, B.; Gökçe, A. G.; Çetinkaya, B. J. Organomet. Chem. 2015, 779, 62-66.

29. Mao, J.; Guo, J. Chirality 2010, 22, 173-181.

30. Montalvo-González, R.; Chávez, D.; Aguirre, G.; Parra-Hake, M.; Somanathan, R. Synth. Commun. 2009, 39, 2737-2746.

31. Liu, X.; Zhang, T; Hu, Y.; Shen, L. Catal. Lett. 2014, 144, 1289-1295.

32. (a) Coll, M.; Pàmies, O.; Adolfsson, H.; Diéguez, M. ChemCatChem 2013, 5, 3821-3828; (b) Coll, M.; Pàmies, O.; Diéguez, M. Adv. Synth. Catal. 2014, 356, 2293-2302.

33. El Alami, M. S. I.; El Amrani, M. A.; Dahdouh, A.; Roussel, R.; Suisse, I.; Mortreux, A. Chirality 2012, 24, 675-682.

34. Zhou, Z.; Bian, Y. Heteroatom Chem. 2008, 19, 682-686.

35. Roszkowski, P.; Maurin, J. K.; Czarmocki, Z. Tetrahedron: Asymmetry 2013, 24, 643-650.

36. Jerphagnon, T.; Haak, R.; Berthiol, F.; Gayet, A. J. A.; Ritleng, V.; Holuigue, A.; Pannetier, N.; Pfeffer, M.; Voelklin, A.; Lefort, L.; Verzijl, G.; Tarabiono, C.; Janssen, D. B.; Minnaard, A. J.; Feringa, B. L.; de Vries, J. G. Top. Catal. 2010, 53, 1002-1008

37. Ito, M.; Shibata, Y.; Watanabe, A.; Ikariya, T. Synlett 2009, 1621-1626.

38. Sheeba, M. M.; Tamizh, M. M.; Farrugia, L. J.; Endo, A.; Karvembu, R. Organometallics 2014, 33, 540-550.

39. (a) Aydemir, M.; Durap, F.; Kayan, C.; Baysal, A.; Turgut, Y. Synlett 2012, 23, 2777-2784; (b) Durap, F.; Aydemir, M.; Elma, D.; Baysal, A.; Turgut, Y. C. R. Chim. 2013, 16, 363-371; (c) Elma, D.; Durap, F.; Aydemir, M.; Baysal, A.; Meric, N.; Ak, B.; Turgut, Y.; Gümgüm, B. J. Organomet. Chem. 2013, 729, 46-52.

40. Durap, F.; Aydemir, M.; Baysal, A.; Elma, D.; Ak, B.; Turgut, Y. Inorg. Chim. Acta 2014, 411, 77-82. 
41. (a) Aydemir, M.; Meriç, N.; Baysal, A.; Kayan, C.; Toğrul, M.; Gümgüm, B. Appl. Organomet. Chem. 2009, 24, 215-221; (b) Aydemir, M.; Meriç, N.; Durap, F.; Baysal, A.; Toğrul, M. J. Organomet. Chem. 2010, 695, 13921398; (c) Aydemir,M.; Meric, N.; Baysal, A.; Gümgüm, B.; Toğrul, M.; Togurt, Y. Tetrahedron: Asymmetry 2010, 21, 703-710.

42. Işik, U.; Aydemir, M.; Meriç, N.; Durap, F.; Kayan, C. J. Mol. Catal. A: Chem. 2013, 379, 225-233.

43. Aydemir, M.; Meric, N.; Baysal, A.; Turgut, Y.; Kayan, C.; Şeker, S.; Togrul, M. J. Organomet. Chem. 2011, 696, 1541-1546.

44. Arena, C. G.; Cuzzola, A.; Drommi, D. Polyhedron, 2012, 48, 221-226.

45. Madrigal, C. A.; García-Fernández, A.; Gimeno, J.; Lastra, E. J. Organomet. Chem. 2008, 693, 2535-2540.

46. Zeng, L.; Wu, F.; Li, Y.-Y.; Dong, Z.-R.; Gao, J.-X. J. Organomet. Chem. 2014, 762, 34-39.

47. Ye, W.; Zhao, M.; Du, W.; Jiang, Q.; Wu, K.; Wu, P.; Yu, Z. Chem. Eur. J. 2011, 17, 4737-4741.

48. Ye, W.; Zhao, M.; Yu, Z. Chem. Eur. J. 2012, 18, 10843-10846.

49. Cambeiro, X. C.; Pericàs, M. A. Adv. Synth. Catal. 2011, 353, 113-124.

50. Johnson, T. C.; Totty, W. G.; Wills, M. Org. Lett. 2012, 14, 5230-5233.

51. Peters, B. K.; Chakka, S. K.; Naicker, T.; Maguire, G. E. M.; Kruger, H. G.; Andersson, P. G.; Govender, T. Tetrahedron: Asymmetry 2010, 21, 679-687.

52. Barrón-Jaime, A.; Aguirre, G.; Parra-Hake, M.; Chávez, D.; Madrigal, D.; Sanders, B; Cooksky A. L.; Somanathan, R. J. Mex. Chem. Soc. 2011, 55, 1620.

53. (a) Cortez, N. A.; Aguirre, G.; Parra-Hake, M.; Somanathan, R. Tetrahedron: Asymmetry 2008, 19, 1304-1309. (b) Cortez, N. A.; Aguirre, G.; Parra-Hake, M.; Somonathan, R.; Arita, A. J.; Coosky, A. L.; Anaya de Parrodi, C.; Huelgas, G. Synth. Commun. 2011, 41, 73-84.

54. Montalvo-González, R.; Chávez, D.; Aguirre, G.; Parra-Hake, M.; Somanathan, R. J. Braz. Chem. Soc. 2010, 21, 431-435.

55. Matharu, D. S.; Martins, J. E. D.; Wills, M. Chem. Asian. J. 2008, 3, 13741383.

56. Echevarria, P.-G.; Férad, C.; Phansavath, P.; Ratovelomanana-Vidal, V. Catal. Commun. 2015, 62, 95-99.

57. Tang, L.; Lin, Z.; Wang, Q.; Wang, X.; Cun, L.; Yuan, W.; Zhu, J.; Deng, J. Tetrahedron Lett. 2012, 53, 3828-3830.

58. Ahlford, K.; Adolfsson, H. Catal. Commun. 2011, 12, 1118-1121.

59. Aupoix, A.; Bournaud, C.; Vo-Thanh, G. Eur. J. Org. Chem. 2011, 27722776.

60. Tinnis, F.; Adolfsson, H. Org. Biomol. Chem. 2010, 8, 4536-4539.

61. Jiang, R.; Sun, X.; He, W.; Chen, H.; Kuang, Y. Appl. Organomet. Chem. 2009, 23, 179-182.

62. Nindakova, L. O.; Shainyan, B. A.; Badyrova, N. M.; Lebed, F. M. Russ. J. Org. Chem. 2012, 48, 59-63.

63. Morris, D. M.; McGeagh, M.; De Peña, D.; Merola, J. S. Polyhedron 2014, 84, 120-135.

64. de Julian, E.; Díez, J.; Lastra, E.; Gamasa, M. P. J. Mol. Catal. A: Chem. 2014, 394, 295-302.

65. Paredes, P.; Díez, J.; Gamasa, M. P. Organometallics 2008, 27, 2597-2607.

66. Chiyojima, H.; Sakaguchi, S. Tetrahedron Lett. 2011, 52, 6788-6791. 
67. Dyson, G.; Frison, J.-C.; Whitwood, A. C.; Douthwaite, R. E. Dalton Trans. 2009, 7141-7151.

68. Diez, C.; Nagel, U. Appl. Organomet. Chem. 2010, 24, 509-516.

69. Tang, L.; Wang, Q.; Wang, J.; Lin, Z.; Wang, X.; Cun, L.; Yuan, W.; Zhu, J.; Liao, J.; Deng, J. Tetrahedron Lett. 2012, 53, 3839-3842.

70. Zhang, X.-Q.; Li, Y.-Y.; Dong, Z.-R.; Shen, W.-Y.; Cheng, Z.-B.; Gao, J.-X. J. Mol. Catal. A: Chem. 2009, 397, 149-153.

71. Yu, S. L.; Li, Y. Y.; Dong, Z. R.; Zhang, J. N.; Li, Q.; Gao, J. X. Chin. Chem. Lett. 2011, 22, 1269-1272.

72. Meyer, N.; Lough, A. J.; Morris, R. H. Chem. Eur. J. 2009, 15, 5605-5610.

73. (a) Lagaditis, P. O.; Lough, A. J.; Morris, R. H. J. Am. Chem. Soc. 2011, 133, 9662-9665; (b) Sues, P. E.; Lough, A. J.; Morris, R. H. Organometallics 2011, 30, 4418-4431; (c) Sues, P. E.; Demmans, K. Z.; Morris, R. H. Dalton Trans. 2014, 43, 7650-7667.

74. (a) Zuo, W.; Tauer, S.; Prokopchuk, D. E.; Morris, R. H. Organometallics 2014, 33, 5791-5801; (b) Zuo, W.; Lough, A. J.; Li, Y . F.; Morris, R. H. Science 2013, 342, 1080-1083; (c) Mikhailine, A.; Lough, A. J.; Morris, R. H. J. Am. Chem. Soc. 2009, 131, 1394-1395.

75. (a) Naik, A.; Maji, T.; Reiser, O. Chem. Commun. 2010, 46, 4475-4477. For cyclopentadienyl iron complexes, see: (b) Berkessel, A.; Reichau, S.; von der Höh, A.; Leconte, N.; Neudörfl, J.-M. Organometallics 2011, 30, 3880-3887; (c) Hopewell, J.; Martins, J. E. D.; Johnson, T. V.; Godfrey, J.; Wills, M. Org. Biomol. Chem. 2012, 10, 134-145; (d) Gajewski, P.; Renom-Carrasco, M.; Vailati Facchini, S.; Pignataro, L.; Lefort, L.; de Vries, J. G.; Ferraccioli, R.; Forni, A.; Piarulli, U.; Gennari, C. Eur. J. Org. Chem. 2015, 1887-1893.

76. Vega, E.; Lastra, E.; Gamasa, M. P. Inorg. Chem. 2013, 52, 6193-6198.

77. Carmona, D.; Lahoz, F. J.; García-Orduna, P.; Oro, L. A. Organometallics 2012, 31, 3333-3345. For a recent account, see: Coverdale, J. P. C.; SanchezCano, C.; Clarkson, G. J.; Soni, R.; Wills, M. Chem. Eur. J. 2015, 21, 80438046.

78. Baratta, W.; Ballico, M.; Del Zotto, A.; Siega, K.; Magnolia, S.; Rigo, P. Chem. Eur. J. 2008, 14, 2557-2563. See also: Chelucci, G.; Baldino, S.; Baratta, W. Acc. Chem. Res. 2015, 48, 363-379, and references cited therein.

79. Dong, Z. R.; Li, Y. Y.; Yu, S. L.; Sun, G. S.; Gao, J. X. Chin. Chem. Lett. 2012, 23, 533-536.

80. Mejía, E.; Aardoom, R.; Togni, A. Eur. J. Inorg. Chem. 2012, 5021-5032.

81. Michalek, F.; Lagunas, A.; Jimeno, C.; Pericàs, M. A. J. Mater. Chem. 2008, 18, 4692-4697.

82. Xu, Z.; Yin, W.; Wu, N.; Shi, J.; Liu, T.; Wan, Y.; Wu, H. Lett. Org. Chem. 2011, 8, 737-742.

83. Xu, Z.; Zhu, S.; Liu, Y.; He, L.; Geng, Z.; Zhang, Y. Synthesis 2010, 811-817.

84. Fuglseth, E.; Sundby, E.; Hoff, B. H. J. Fluorine Chem. 2009, 130, 600-603.

85. Zerla, D.; Facchetti, G.; Fuse, M.; Pellizzoni, M.; Castellano, C.; Cesarotti, E.; Gandolfi, R.; Rimoldi, I. Tetrahedron: Asymmetry 2014, 25, 1031-1037.

86. Vazquez-Villa, H.; Reber, S.; Ariger, M. A.; Carreira, E. M. Angew. Chem. Int. Ed. 2011, 50, 8979-8981.

87. Perryman, M. S.; Harris, M. E.; Foster, J. L.; Joshi, A.; Clarkson, G. J.; Fox, D. J. Chem. Commun. 2013, 49, 10022-10024.

88. Zhang, H.; Feng, D.; Sheng, H.; Ma, X.; Wan, J.; Tang, Q. RSC Adv. 2014, 4, 6417-6423. 
89. Fang, Z.; Wills, M. J. Org. Chem. 2013, 78, 8594-8605. See also: Druais, V.; Meyer, C.; Cossy, J. Org. Lett. 2012, 14, 516-519.

90. Zhang, J.; Blazecka, P. G.; Bruendl, M. M.; Huang, Y. J. Org. Chem. 2009, 74, 1411-1414.

91. Geng, Z.; Wu, Y.; Miao, S.; Shen, Z.; Zhang, Y. Tetrahedron Lett. 2011, 52, 907-909.

92. Zhang, D.; Cheng, T.; Zhao, Q.; Xu, J.; Liu, G. Org. Lett. 2014, 16, 57645767.

93. Kumaraswamy, G.; Ramakrishna, G.; Raju, R.; Padmaja, M. Tetrahedron 2010, 66, 9814-9818.

94. (a) Guillena, G.; Ramón, D. J.; Yus, M. Angew. Chem. Int. Ed. 2007, 46, 2358-2364; (b) Hamid, M. H. S. A.; Slatford, P. A.; Williams, J. M. J. Adv. Synth. Catal. 2007, 349, 1555-1575.

95. Kovalenko, O. O.; Lundberg, H.; Hubner, D.; Adolfsson, H. Eur. J. Org. Chem. 2014, 6639-6642.

96. Saito, K.; Kajiwara, Y.; Akiyama, T. Angew. Chem. Int. Ed. 2013, 52, 1328413288.

97. Shingote, S. K.; Kelkar, A. A.; Borole, Y. L.; Joshi, P. D.; Chaudhari, R. V. Ultrason. Sonochem. 2008, 15, 289-293.

98. Zhou, Z.; Sun, Y.; Zhang, A. Cent. Eur. J. Chem. 2011, 9, 175-179.

99. (a) Sun, X.; Gavriilidis, A. Org. Proc. Res. Devel. 2008, 12, 1218-1222; (b) Sun, X.; Gavriilidis, A. Chem. Eng. Technol. 2009, 32, 1318-1325; (c) Zanfir, M.; Sun, X.; Gavriilidis, A. Ind. Eng. Chem. Res. 2008, 47, 8995-9005.

100. Marcos, R.; Jimeno, C.; Pericàs, M. A. Adv. Synth. Catal., 2011, 353, 13451352.

101. (a) Xu, X.; Wang, R.; Wan, J.; Ma, X.; Peng, J. RSC Adv. 2013, 3, 6747-6751; (b) Wang, R.; Wan, J.; Ma, X.; Xu, X.; Liu, L. Dalton Trans. 2013, 42, 65136522.

102. Sun, Q.; Jin, Y.; Zhu, L.; Wang, L.; Meng, X; Xiao, F.-S. Nano Today 2013, 8, 342-350.

103. Zammit, C. M.; Wils, M. Tetrahedron: Asymmetry 2013, 24, 844-852.

104. (a) Liu, J.; Zhou, Y.; Wu, Y.; Li, X.; Chan, A. S. C. Tetrahedron: Asymmetry 2008, 19, 832-837; (b) Wu, Y.; Lu, C.; Shan, W.; Li, X. Tetrahedron: Asymmetry 2009, 20, 584-587.

105. Zhou, Z.; Sun, Y. Reac. Kinet. Mech. Cat. 2010, 99, 391-396.

106. Shan, W.; Meng, F.; Wu, Y.; Mao, F.; Li, X. J. Organomet. Chem. 2011, 696, 1687-1690.

107. (a) Dimroth, J.; Keilitz, J.; Schedler, U.; Schomäker, R.; Haag, R. Adv. Synth. Catal. 2010, 352, 2497-2506; (b) Ahlford, K.; Lind, J.; Mäler, L.; Adolfsson, H. Green Chem. 2008, 10, 832-835.

108. Zhang, X.; Zhao, Y.; Peng, J.; Yang, Q. Green Chem. 2015, 17, 1899-1906.

109. (a) Xu, X.; Cheng, T.; Long, J.; Liu, K.; Qian, Q.; Gao, F.; Liu, G.; Li, H. Adv. Synth. Catal. 2012, 354, 3250-3258; (b) Liu, R.; Cheng, T.; Kong, L.; Chen, C.; Liu, G.; Li, H. J. Catal. 2013, 307, 55-61; (c) Zhang, D.; Xu, J.; Zhao, Q.; Cheng, T.; Liu, G. ChemCatChem 2014, 6, 2998-3003.

110. (a) Zhang, H.; Jin, R.; Yao, H.; Tang, S.; Zhuang, J.; Liu, G.; Li, H. Chem. Commun. 2012, 48, 7874-7876; (b) Cheng, T.; Long, J.; Liang, X.; Liu, R.; Liu, G. Mater. Res. Bull. 2014, 53, 1-6.

111. Bai, S.; Yang, H.; Wang, P.; Gao, J.; Li, B.; Yang, Q.; Li, C. Chem. Commun. 2010, 46, 8145-8147. 
112. (a) Shen, Y.; Chen, Q.; Lou, L.-L.; Yu, K.; Ding, F.; Liu, S. Catal. Lett. 2010, 137, 104-109; (b) Lou, L.-L.; Du, H.; Shen, Y.; Yu, K.; Yu, W.; Chen, Q.; Liu, S. Microporous Mesoporous Mater. 2014, 187, 94-99.

113. Parambadath, S.; Sing, A. P. Catal. Today 2009, 141, 161-167.

114. Cortez, N. A.; Aguirre, G.; Parra-Hake, M.; Somanathan, R. Tetrahedron Lett. 2009, 50, 2228-2231.

115. Tang, S.; Jin, R.; Zhang, H.; Yao, H.; Zhuang, J.; Liu, G.; Li, H. Chem. Commun. 2012, 48, 6286-6288.

116. Wei, J.; Zhang, X.; Zhang, X.; Zhao, Y.; Li, R.; Yang, Q. ChemCatChem 2014, 6, 1368-1374.

117. (a) Sun, Y.; Liu, G.; Gu, H.; Huang, T.; Zhang, Y.; Li, H. Chem. Commun. 2011, 47, 2583-2585; (b) Liu, G.; Gu, H.; Sun, Y.; Long, J.; Xu, Y.; Li, X. Adv. Synth. Catal. 2011, 353, 1317-1324; (c) Gao, X.; Liu, R.; Zhang, D.; Wu, M.; Cheng, T.; Liu, G. Chem. Eur. J. 2014, 20, 1515-1519.

118. Sonnenberg, J. F.; Coombs, N.; Dube P. A.; Morris, R. H. J. Am. Chem. Soc. 2012, 134, 5893-5899.

119. (a) Wang, W.; Wang, Q. Chem. Commun. 2010, 46, 4616-4618; (b) Wang, W.-W.; Li, Z.-M.; Su, L.; Wang, Q.-R.; Wu, Y. L. J. Mol. Catal. A: Chem. 2014, 387, 92-102.

120. Babin, M.; Clément, R.; Gagnon, J.; Fontaine, F.-G. New J. Chem. 2012, 36, 1548-1551.

121. Cheng, T.-Y.; Zhuang, J.-L.; Yao, H.; Zhang, H.-S.; Liu, G.-H. Chin. Chem. Lett. 2014, 25, 613-616.

122. Lemke, M.-K.; Schwab, P.; Fischer, P.; Tischer, S.; Witt, M.; Noehringer, L.; Rogachev, V.; Jäger, A.; Kataeva, O.; Fröhlich, R.; Metz, P. Angew. Chem. Int. Ed. 2013, 52, 11651-11655.

123. Yun, W.; Zhicong, G.; Jinjin, B.; Yawen, Z. Chin. J. Chem. 2011, 29, 14671472.

124. Steward, K. M.; Gentry, E. C.; Johnson, J. S. J. Am. Chem. Soc. 2012, 134, 7329-7332.

125. Cartigny, D.; Püntener, K.; Ayad, T.; Scalone, M.; Ratovelomanana-Vidal, V. Org. Lett. 2010, 12, 3788-3791.

126. Son, S.-M.; Lee, H.-K. J. Org. Chem. 2014, 79, 2666-2681.

127. Seashore-Ludlow, B.; Saint-Dizier, F.; Somfai, P. Org. Lett. 2012, 14, 63346337.

128. Villacrez, M.; Somfai, P. Tetrahedron Lett. 2013, 54, 5266-5268.

129. Limanto, J.; Krska, S. W.; Dorner, B. T.; Vazquez, E.; Yoshikawa, N.; Tan, L. Org. Lett. 2010, 12, 512-515.

130. Son, S.-M.; Lee, H. K. J. Org. Chem. 2013, 78, 8396-8404.

131. Wu, G.; Zhu, J.; Ding, Z.; Shen, Z.; Zhang, Y. Tetrahedron Lett. 2009, 50, 427-429.

132. Ding, Z.; Yang, J.; Wang, T.; Shen, Z.; Zhang, Y. Chem. Commun. 2009, 571573. For a recent account on a dynamic kinetic asymmetric amination of alcohols, see: Rong, Z.-Q.; Zhang, Y.; Chua, R. H. B.; Pan, H.-J.; Zhao, Y. J. Am. Chem. Soc. 2015, 137, 4944-4947.

133. Wu, X.; Li, X.; Zanotti-Gerosa, A.; Pettman, A.; Liu, J.; Mills, A. J.; Xiao, J. Chem. Eur. J. 2008, 14, 2209-2222.

134. Wu, X.; Wang, C.; Xiao, J. Platinum Metals Res., 2010, 54, 3-19.

135. Alza, E.; Bastero, A.; Jansat, S.; Pericás, M. A. Tetrahedron: Asymmetry 2008, 19, 374-378. 
136. Zhou, Z.; Wu, L. Catal. Commun. 2008, 9, 2539-2542.

137. Zhou, Z.; Sun, Y. Catal. Commun. 2009, 10, 1685-1688.

138. Zhou, Z.; Ma, Q.; Sun, Y.; Zhang, A.; Li, L. Heteroatom Chem. 2010, 21 , 505-514.

139. Kang, G.; Lin, S.; Shiwakoti, A.; Ni, B. Catal. Commun. 2014, 57, 111-114.

140. Tang, Y.; Li, X.; Lian, C.; Zhu, J.; Deng, J. Tetrahedron: Asymmetry 2011, 22, 1530-1535. See also: Lin, Z.; Li, J.; Huang, Q.; Huang, Q.; Wang, Q.; Tang, L.; Gong, D.; Yang, J.; Zhu, J.; Deng, J. J. Org. Chem. 2015, 80, 44194429.

141. Barrón-Jaime, A.; Narvaez-Garayzar, O. F.; González, J.; Ibarra-Galván, V.; Aguirre, G.; Parra-Hake, M.; Chávez, D.; Somanathan, R. Chirality 2011, 23, 178-184.

142. Gao, F.; Jin, R.; Zhang, D.; Liang, Q.; Ye, Q.; Liu, G. Green Chem. 2013, 15 , 2208-2214.

143. Zhou, Z.; Ma, Q. Appl. Organometal. Chem. 2011, 25, 233-237.

144. Arakawa, Y.; Chiba, A.; Haraguchi, N.; Itsuno, S. Adv. Synth. Catal. 2008, 350, 2295-2304.

145. Elias, S.; Goren, K.; Vigalok, A. Synlett 2012, 23, 2619-2622.

146. Yin, L.; Jia, X.; Li, X.; Chan, A. S. C. Tetrahedron: Asymmetry 2009, 20, 2033-2037.

147. Li, J.; Li, X.; Ma, Y; Wu, J.; Wang, F.; Xiang, J.; Zhu, J.; Wang, Q.; Deng, J. RSC Adv. 2013, 3, 1825-1834.

148. Wang, W.; Li, Z.; Mu, W.; Su, L.; Wang, Q. Catal. Commun. 2010, 11, 480483.

149. Seashore-Ludlow, B.; Villo, P.; Somfai, P. Chem. Eur. J. 2012, 18, 72197223.

150. Weng, Z.; Muratsugu, S.; Ishiguru, N.; Ohkoshi, S.-i.; Tada, T. Dalton Trans. 2011, 40, 2338-2347.

151. Ahlford, K.; Ekström, J.; Zaitsev, A. B.; Ryberg, P.; Erikson, L.; Adolfsson, H. Chem. Eur. J. 2009, 15, 11197-11209.

152. Dimroth, J.; Schedler, U.; Keilitz, J.; Haag, R.; Shomäcker, R. Adv. Synth. Catal. 2011, 353, 1335-1344.

153. Vriamont, N.; Govaerts, B.; Grenouillet, P.; de Bellefont, C.; Riant, O. Chem. Eur. J. 2009, 15, 6267-6278.

154. Wu, X.; Liu, J.; Di Tommaso, D.; Iggo, J. A.; Catlow, C. R. A.; Bacsa, J.; Xiao, J. Chem. Eur. J. 2008, 14, 7699-7715.

155. Pannetier, N.; Sortais, J.-B.; Dieng, P. S.; Barloy, L.; Sirlin, C.; Pfeffer, M. Organometallics 2008, 27, 5852-5859.

156. Wettergren, J.; Buitrago, E.; Ryberg, P.; Adolfsson, H. Chem. Eur. J. 2009, 15, 5709-5718.

157. Dub, P. A.; Ikariya, T. J. Am. Chem. Soc. 2013, 135, 2604-2619.

158. Václavíc, J.; Kuzma, M.; Přech, J.; Kačer, P. Organometallics 2011, 30, 48224829.

159. Madrigal, D.; Cooksy, A. L.; Somanathan, R. Comp. Theor. Chem. 2012, 999, 105-108.

160. Nordin, M.; Liao, R.-Z.; Ahlford, K.; Adolfsson, H; Himo, F. ChemCatChem 2012, 4, 1095-1104.

161. Mikhailine, A. A.; Maishan, M. I.; Lough, A. J.; Morris, R. H. J. Am. Chem. Soc. 2012, 134, 12266-12280. 
162. Itoh, N.; Isotami, K.; Nakamura, M.; Inoue, K.; Isogai, Y.; Makino, Y. Appl. Microbiol. Biotechnol. 2012, 93, 1075-1085.

163. Chevalley, A.; Cherrier, M. V.; Fontecilla-Camps, J. C.; Ghasemi, M.; Salmain, M. Dalton Trans. 2014, 43, 5482-5489. See also: Heinisch, T.; Langowska, K.; Tanner, P.; Reymond, J. L.; Meier, W.; Palivan, C.; Ward, T. R. ChemCatChem 2013, 5, 720-723, and references cited therein.

164. Cotarca, L.; Verzini, M.; Volpicelli, R. Chem. Today 2014, 32, 36-41.

165. Cortez, N. A.; Aguirre, G.; Parra-Hake, M.; Somanathan, R. Tetrahedron: Asymmetry 2013, 24, 1297-1302.

166. Kumaraswamy, G.; Rambadu, D. Tetrahedron: Asymmetry 2013, 24, 196-201.

167. Kumaraswamy, G.; Ramakrishna, G.; Naresh, P.; Jagadeesh, B.; Sridhar, B. J. Org. Chem. 2009, 74, 8468-8471.

168. He, S. Z.; Li, X. M.; Dai, J.; Yan, M. Chin. Chem. Lett. 2008, 19, $23-25$.

169. Buitrago, E.; Lundberg, H.; Andersson, H.; Ryberg, P.; Adolfsson, H. ChemCatChem 2012, 4, 2082-2089.

170. Liu, J.; Zhou, D.; Jia, X; Huang, L.; Li, X.; Chan, A. S. C. Tetrahedron: Asymmetry 2008, 19, 1824-1828.

171. Greahock, T. J.; Johns, D. M.; Noguchi, Y.; Williams, R. M. Org. Lett. 2008, 10, 613-616.

172. Luo, Z.; Qin, F.; Yan, S.; Li, X. Tetrahedron: Asymmetry 2012, 23, 333-338.

173. Zhang, Q.; Ma, B.-W.; Wang, Q.-Q.; Wang, X.-X.; Hu, X.; Xie, M.-S.; Qu, G.-R.; Guo, H.-M. Org. Lett. 2014, 16, 2014-2017.

174. Wisdom, R.; Jung, J.; Meudt, A. EP2 383261 A1, 2011.

175. Fang, Z.; Wills, M. Org. Lett. 2014, 16, 374-377.

176. Fang, Z.; Clarkson, G. J.; Wills, M. Tetrahedron Lett. 2013, 54, 6834-6837.

177. Brandt, D.; Dittoo, A.; Bellosta, V.; Cossy, J. Org. Lett. 2015, 17, 816-819.

178. Stone, S. D.; Lajkiewicz, N. J.; Whitesell, L.; Hilmy, A.; Porco, J. A., Jr. J. Am. Chem. Soc. 2015, 137, 525-530.

179. Dias, L. C.; Ferreira, M. A. B. J. Org. Chem. 2012, 77, 4046-4062.

180. Nakayama, A.; Kogure, N.; Kitajima, M.; Takayama, H. Angew. Chem. Int. Ed. 2011, 50, 8025-8028. 
GRAPHICAL ABSTRACT

Catalytic asymmetric transfer hydrogenation of ketones:

\section{Recent advances}

Francisco Foubelo, Carmen Nájera and Miguel Yus*

Departamento de Química Orgánica, Facultad de Ciencias, and Centro de Innovación en Química Avanzada (ORFEO-CINQA), Universidad de Alicante, Apdo. 99, E-03080 Alicante, Spain

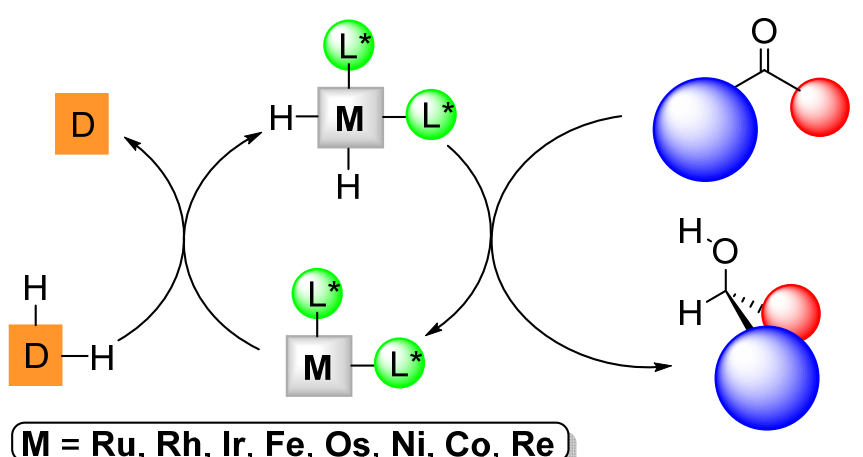

$M=R u, R h, I r, F e$, Os, Ni, Co, Re 


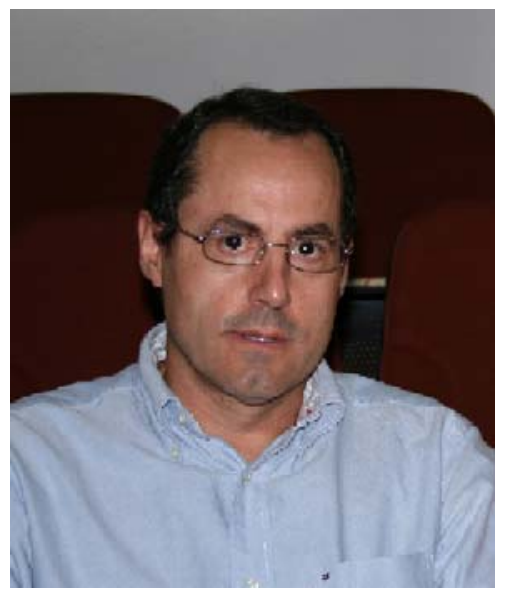

Francisco Foubelo studied chemistry at the University of Oviedo from which he received B.S. (1984), M.S. (1986), and Ph.D. (1989) degrees. After that, he spent a postdoctoral stay (1989-1991) as a Fulbright fellow at Princeton University. Then, he moved to the University of Alicante where he became Associate Professor in 1995 and Full Professor in 2002. His research interests are focused on heterofunctionalisation of alkenes and the development of new synthetic methods for asymmetric synthesis related to chiral sulfinimines.

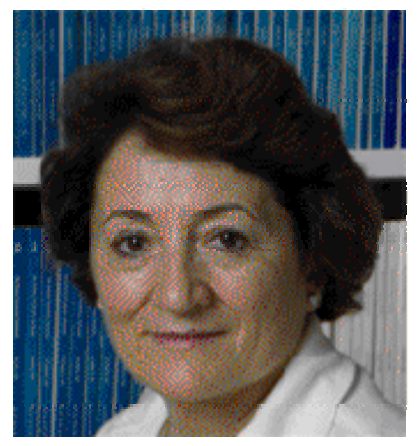

Carmen Nájera was born in Nájera (La Rioja) and was graduated from the University of Zaragoza in 1973, obtaining her doctorate in chemistry from the University of Oviedo in 1979. She spent postdoctoral stays at the ETH (Zurich), the Dyson Perrins Laboratory (Oxford), Harvard University, and Uppsala University. She became Associate Professor in 1985 at the University of Oviedo and Full Professor in 1993 at the University of Alicante. She is coauthor of more than 300 papers and book chapters and has supervised more than $40 \mathrm{PhD}$ students. She has been awarded with the 2006 Organic Chemistry Prize from the Spanish Royal Chemical Society of Chemistry, the 2006 Rosalind Franklin International Lectureship from the English Royal Society, the SCF 2010 French-Spanish Prize from the Société Chimique de France and the IUPAC 2015 Distinguished Woman in Chemistry or Chemical Engineering Award. In 2012 she was named full Member of the Royal Spanish Academy of Sciences, and was appointed as Active Member of the European Academy of Sciences and Arts. 


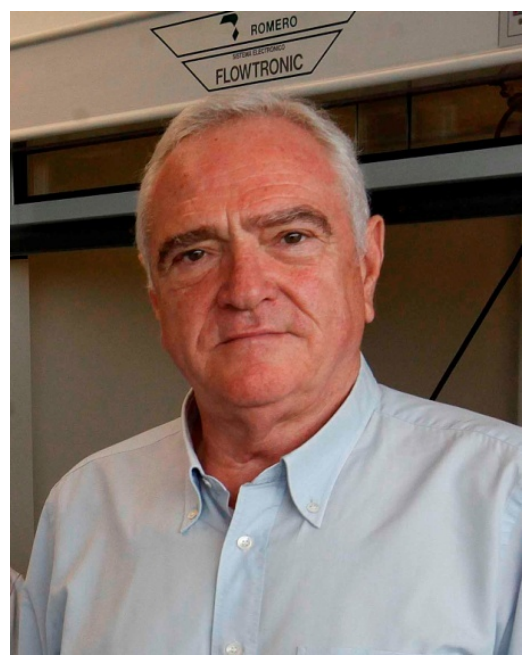

Miguel Yus was born in Saragossa in 1947 and received his BSc (1969), MSc (1971) and $\mathrm{PhD}$ (1973) from the University of Saragossa. After spending two years as a postdoctoral fellow at the Max Plack Institut in Mülheim he became Associate Professor (1977) and Professor (1987) at the University of Oviedo. In 1988 he moved to his current position at the University of Alicante. He has been invited professor at ETHZürich, Oxford, Harvard, Uppsala, Tucson, Okayama, Paris, Strasbourg, Bologna, Sassari, Tokyo and Kyoto. Dr. Yus has authored more than 500 papers and five patents, has delivered around 200 lectures abroad and has supervised more than $60 \mathrm{PhD}$ students. Among others he has receive the Spanish-French Prize (1999), twice the Japan Society for the Promotion of Science Prize (2000, 2007), the Stiefvater Memorial Lectureship Award (2001), the Conference Lourenco-Madinaveitia (1912), the Serratosa Lecctureship (2010) and the Medalla Felix Serratosa (2012), being Academician of the European Academy of Sciences and Arts (2012). He has been in the Advisory Bord of about 20 international journals and founded ten years ago the company MEDALCHEMY for the commercialization of fine chemicals. 
